\title{
Development and Implications of a Predictive Cost Methodology for Modular Pumped Storage Hydropower (m-PSH) Projects in the United States
}

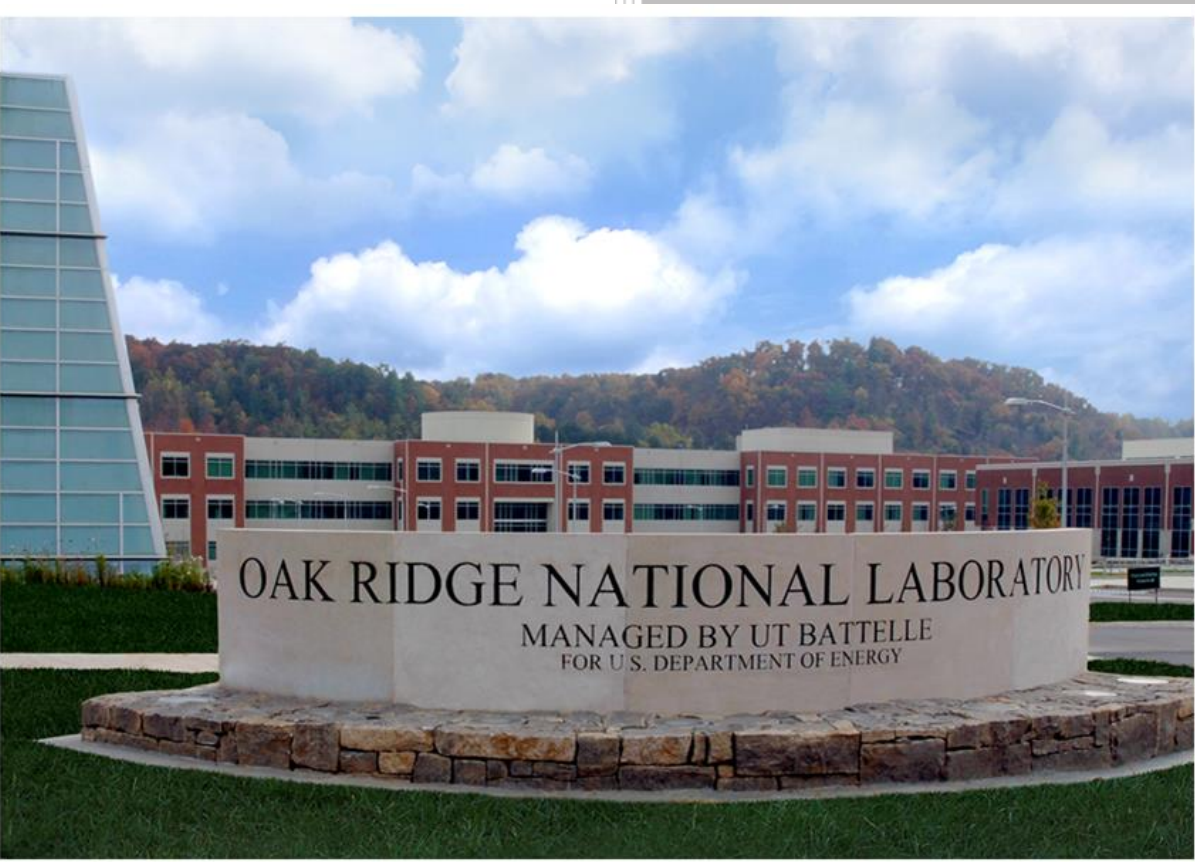

Adam Witt

Dol Raj Chalise

Boualem Hadjerioua Michael Manwaring Norm Bishop

September 2016 


\section{DOCUMENT AVAILABILITY}

Reports produced after January 1, 1996, are generally available free via US Department of Energy (DOE) SciTech Connect.

Website http://www.osti.gov/scitech/

Reports produced before January 1, 1996, may be purchased by members of the public from the following source:

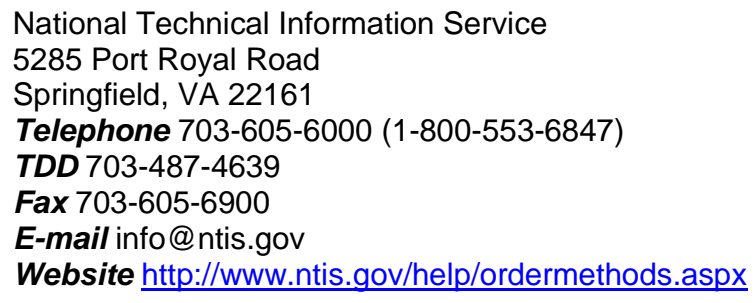

Reports are available to DOE employees, DOE contractors, Energy Technology Data Exchange representatives, and International Nuclear Information System representatives from the following source:

Office of Scientific and Technical Information

PO Box 62

Oak Ridge, TN 37831

Telephone 865-576-8401

Fax 865-576-5728

E-mail reports@osti.gov

Website http://www.osti.gov/contact.html

This report was prepared as an account of work sponsored by an agency of the United States Government. Neither the United States Government nor any agency thereof, nor any of their employees, makes any warranty, express or implied, or assumes any legal liability or responsibility for the accuracy, completeness, or usefulness of any information, apparatus, product, or process disclosed, or represents that its use would not infringe privately owned rights. Reference herein to any specific commercial product, process, or service by trade name, trademark, manufacturer, or otherwise, does not necessarily constitute or imply its endorsement, recommendation, or favoring by the United States Government or any agency thereof. The views and opinions of authors expressed herein do not necessarily state or reflect those of the United States Government or any agency thereof. 
ORNL/TM-2016/590

\section{Environmental Sciences Division}

\section{Development and Implications of a Predictive Cost Methodology for Modular Pumped Storage Hydropower (m-PSH) Projects in the United States}

Adam Witt, Oak Ridge National Laboratory

Dol Raj Chalise, Oak Ridge National Laboratory

Boualem Hadjerioua, Oak Ridge National Laboratory

Michael Manwaring, MWH

Norm Bishop, Knight Piésold

Date Published: September 2016

Prepared by

OAK RIDGE NATIONAL LABORATORY

Oak Ridge, Tennessee 37831-6283

managed by

UT-BATTELLE, LLC

for the

US DEPARTMENT OF ENERGY

under contract DE-AC05-00OR22725 


\section{TABLE OF CONTENTS}

ACKNOWLEDGEMENTS . iii

EXECUTIVE SUMMARY iv

LIST OF FIGURES $\mathrm{v}$

LIST OF TABLES. viii

ABBREVIATIONS ix

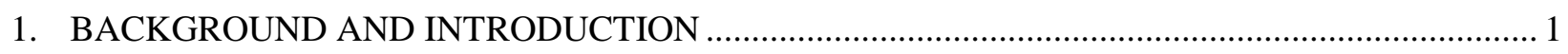

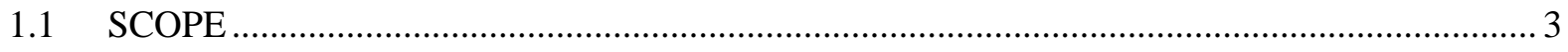

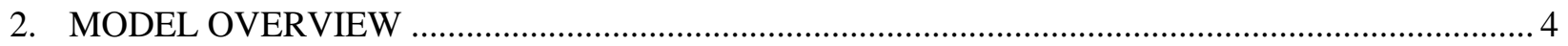

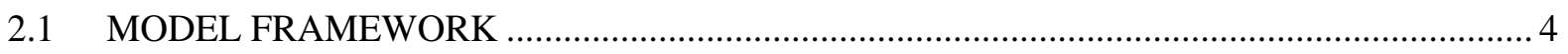

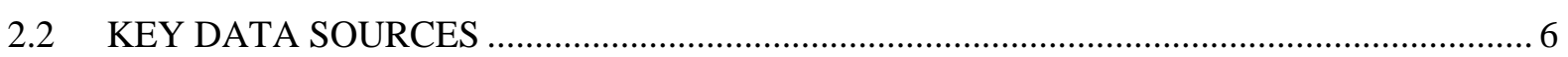

2.3 IMPORTANT MODEL ASSUMPTIONS AND LIMITATIONS .......................................... 6

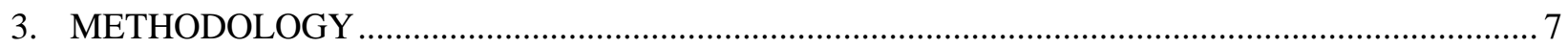

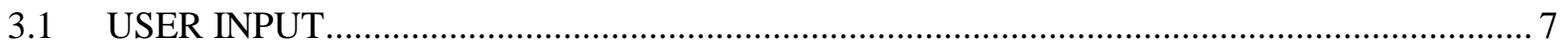

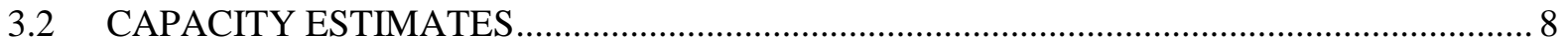

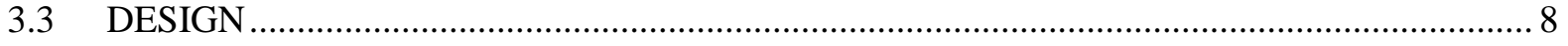

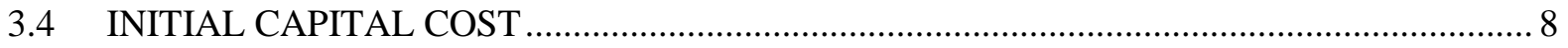

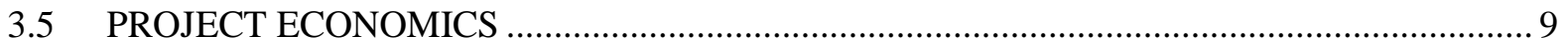

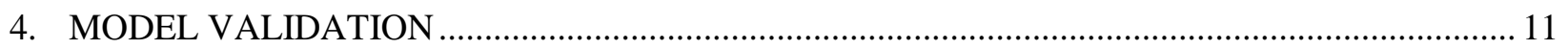

4.1 EXISTING STUDIES AND COST ESTIMATES …..................................................... 11

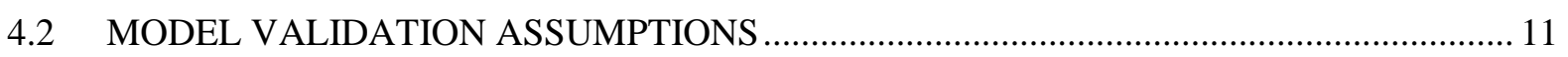

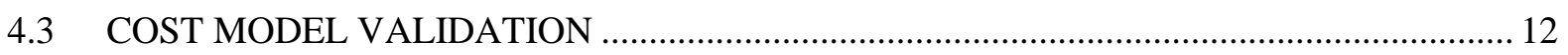

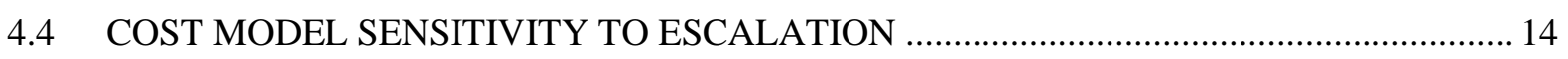

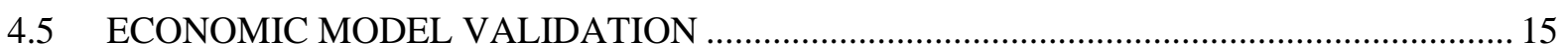

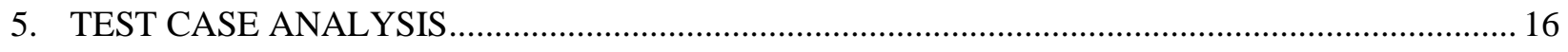

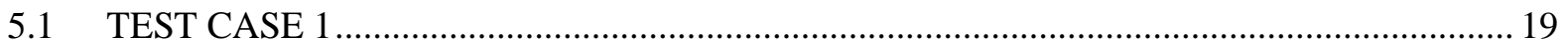

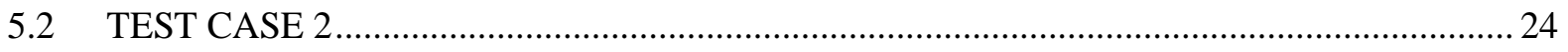

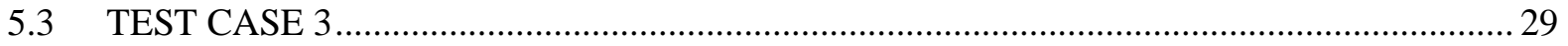

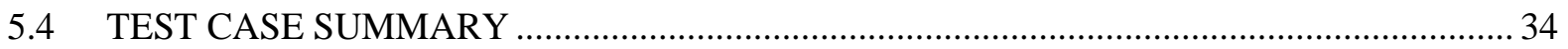

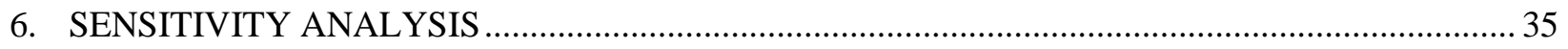

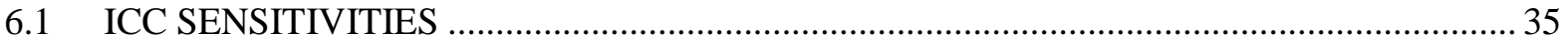

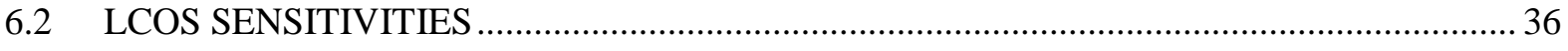

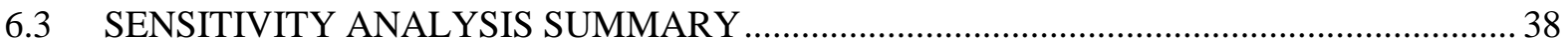




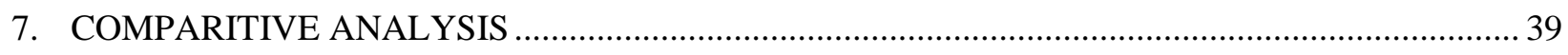

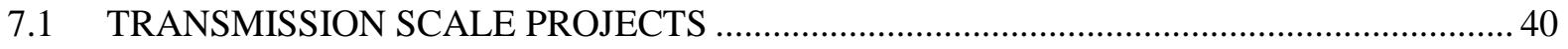

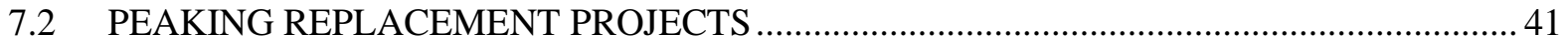

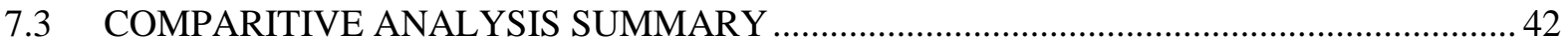

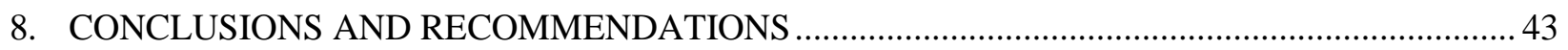

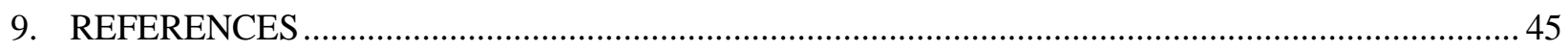

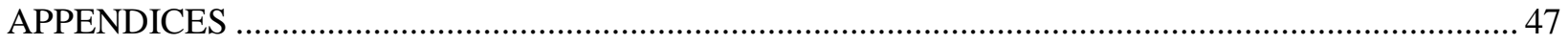

Appendix A. DESIGN AND COST METHODOLOGIES …................................................. 48

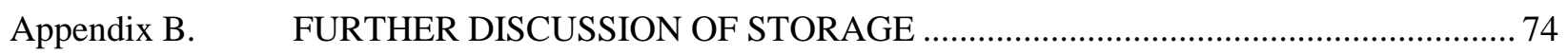

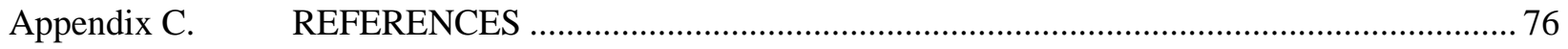




\section{ACKNOWLEDGEMENTS}

The authors would like to acknowledge and express their appreciation to all the following individuals and programs for their review, comments, and support of this report.

\section{DOE Water Power Program}

- Daniel Rabon, Water Power Program Manager

- Tim Welch, Hydropower Program Manager

Oak Ridge National Lab

- Miles Mobley

\section{New Mexico Institute of Mining and Technology}

- Rebecca Brink 


\section{EXECUTIVE SUMMARY}

The slow pace of Pumped Storage Hydropower development in the US over the past twenty years has led to widespread interest in the feasibility and viability of alternative PSH designs, development schemes, and technologies. Since 2011, Oak Ridge National Lab has been exploring the economic viability of modular Pumped Storage Hydropower (m-PSH) development through targeted case studies, revenue simulations, and analysis of innovative configurations and designs. This paper outlines the development and supporting analysis of a scalable, comprehensive cost modeling tool designed to simulate the initial capital costs for a variety of potential m-PSH projects and deployment scenarios. The tool is used to explore and determine innovative strategies that can improve the economic viability of m-PSH in US markets.

The major finding of this work is that development of m-PSH scale projects is technically feasible with existing technologies and construction techniques, but the cost to build the project is the largest deterrent to m-PSH deployment. Based on numerous simulations and test case analyses, improvements in the cost of storage provide the critical path towards achieving m-PSH economic feasibility. Test cases developed to analyze the cost implications of varying levels of existing storage works showed when two new reservoirs are required, a project is generally uneconomic unless it can be developed at a high head greater than $500 \mathrm{ft}$. If instead the excavation burden is only $20 \%$ of a completely new reservoir, a much greater range of $\mathrm{m}-\mathrm{PSH}$ projects are brought into the realm of economic feasibility. The reduced excavation burden not only reduces the physical volume of earth that requires movement, it also reduces the construction time and overall costs associated with preparing the reservoir for long-term storage. This idea is not novel - most conventional PSH projects within the existing US fleet take advantage of existing infrastructure and storage works. However, the changing paradigm of smaller scale m-PSH projects coupled with the pressing need for innovation and cost reductions in electrical energy storage demands a fresh look at what kinds of locations can readily support m-PSH projects. The results presented herein can be put into a more tangible context if better insight is gained into the types of m-PSH resources that are widely and readily available in the US.

Following improvements in the cost of storage, either through cost reductions in the civil works associated with storage construction or through strategic siting, innovative technical research and development should be focused on reducing the largest cost drivers of m-PSH development. At lower relative heads, the cost of electromechanical equipment is substantial, and could be improved through new designs and manufacturing strategies for modular reversible pump-turbines. At higher relative heads, both electromechanical equipment and water conveyance costs become large project cost categories. New penstock materials, joining techniques, and construction strategies that utilize a combination of conventional and alternative materials have the potential to reduce overall project costs. These cost reductions become more pronounced with increases in head and penstock length.

A comparative analysis of simulated m-PSH costs to alternative electrical energy storage technologies of various scale and maturities showed that m-PSH facilities exhibit an installed cost and a levelized cost of storage range that is on par or better than many battery alternatives at many scales, even if both reservoirs need to be excavated and constructed. The added benefits of long useful life, proven technology, high roundtrip efficiency, known technology scalability, and low performance degradation over time further make m-PSH a compelling alternative. An important finding of this analysis is the need for a common basis for economic and financial comparisons across electrical energy storage technologies. Existing comparisons can be improved and made more reliable by offering explicit detail on how lifecycle costs and cost assumptions are developed for mature, recently deployed, new, and future energy storage technologies. 


\section{LIST OF FIGURES}

Figure 1. Global energy storage projects as of March, 2016. Scatter points represent individual plants, line plot represents cumulative number of plants over time. Data obtained from (U.S. Department of Energy \& Sandia National Laboratories, 2015).....

Figure 2. Capital cost estimates of global energy storage projects as of March, 2016. Data obtained from (U.S. Department of Energy \& Sandia National Laboratories, 2015) .............................. 2

Figure 3. Capital cost and system power ratings of various energy storage technologies, highlighting the potential for m-PSH innovation (Welch, 2016, as adapted from the State Utility Forecasting Group)

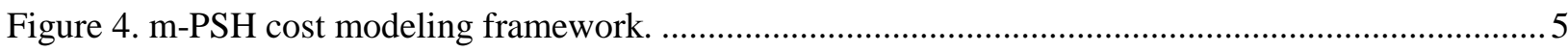

Figure 5. Methodology to compute m-PSH initial capital cost........................................................... 9

Figure 6. Frequency distribution of variables used for model validation. .............................................. 12

Figure 7. Cost model validation against existing projects and projects under study. All costs are in $\$ 2015$.

Figure 8. ICC prediction in $\$ / \mathrm{kWh}$ of simulated projects with installed capacity $<500 \mathrm{MW}$ and storage time of $<10$ hours compared to estimates for various transmission scale energy storage technologies. All costs are in $\$ 2015$.

Figure 9. Simulated project cost category (right) validated against conventional PSH cost categories (left). Average distribution is shown in each pie, with the min and max observed values shown in parenthesis.

Figure 10. LCOS prediction of simulated projects with installed capacity < $500 \mathrm{MW}$ compared to industry estimated of LCOS for various transmission scale energy storage technologies (Lazard, 2015).

Figure 11. Simulated ICC of m-PSH projects with installed capacity of < $100 \mathrm{MW}$ : assuming construction of a new upper and lower reservoir (top left) and assuming an upper reservoir is a refurbishment of existing storage infrastructure, and the lower reservoir is largely in place (top right). Corresponding line plots at various storage volumes and head are shown below the contour plots.

Figure 12. Costs of developing an m-PSH reservoir under different scenarios.

Figure 13. Representation of simulated m-PSH projects with 8 hours of storage (left) and 4 hours of storage (right). Note the difference in installed capacity associated with design head and storage volume of each project design.

Figure 14. Cost estimates for Test Case 1 with 8 hours of storage (left) and 4 hours of storage (right)...19

Figure 15. Cost category estimates for test points in Test Case 1 with 8 hours of storage (top) and 4 hours of storage (bottom). Civil works, electro-mechanical equipment, and electrical equipment categories include contingencies.

Figure 16. ICC estimates for Test Case 1 in $\$ / \mathrm{kW}$ for 8 (top) and 4 (bottom) hours of storage. Gray line indicates the ICC estimate of conventional PSH projects (EPRI, 2010)..

Figure 17. ICC estimates for Test Case 1 in $\$ / \mathrm{kWh}$ for 8 (top) and 4 (bottom) hours of storage. Gray line indicates the ICC estimate of conventional PSH projects (EPRI, 2010)..........................22

Figure 18. LCOS estimates in \$/MWh for Test Case 1 with 8 (top) and 4 (bottom) hours of storage......23

Figure 19. ICC estimates for Test Case 2 with 8 hours of storage (left) and 4 hours of storage (right)....24 
Figure 20. Cost category estimates for test points in Test Case 2 with 8 hours of storage (top) and 4 hours of storage (bottom). Civil works, electro-mechanical equipment, and electrical equipment categories include contingencies.

Figure 21. ICC estimates for Test Case 2 in $\$ / \mathrm{kW}$ for 8 (top) and 4 (bottom) hours of storage. Gray line indicates the ICC estimate of conventional PSH projects (EPRI, 2010). .26

Figure 22. ICC estimates for Test Case 2 in $\$ / \mathrm{kWh}$ for 8 (top) and 4 (bottom) hours of storage. Gray line indicates the ICC estimate of conventional PSH projects (EPRI, 2010).

Figure 23. LCOS estimates in \$/MWh for Test Case 2 with 8 (top) and 4 (bottom) hours of storage...... 28

Figure 24. Cost estimates for Test Case 3 with 8 hours of storage (left) and 4 hours of storage (right). ..29

Figure 25. Cost category estimates for test points in Test Case 3 with 8 hours of storage (top) and 4 hours of storage (bottom). Civil works, electro-mechanical equipment, and electrical equipment categories include contingencies.

Figure 26. ICC estimates for Test Case 3 in $\$ / \mathrm{kW}$ for 8 (top) and 4 (bottom) hours of storage. Gray line indicates the ICC estimate of conventional PSH projects (EPRI, 2010)..

Figure 27. ICC estimates for Test Case 3 in $\$ / \mathrm{kWh}$ for 8 (top) and 4 (bottom) hours of storage. Gray line indicates the ICC estimate of conventional PSH projects (EPRI, 2010).......................... 32

Figure 28. LCOS estimates in \$/MWh for Test Case 3 with 8 (top) and 4 (bottom) hours of storage......33

Figure 29. Cost sensitivities for Test Case 2 test points \#1 (top) and \#5 (bottom). Each bar represents a variation in ICC based on the perturbation of the individual category of the y-axis within the limits identified in the figure text.

Figure 30. LCOS sensitivities for Test Case 2 test points \#1 (top) and \#5 (bottom). Each bar represents a variation in LCOS based on the perturbation from the default value identified on the y-axis. Financing impact on ICC is taken as the undiscounted portion of ICC.

Figure 31. ICC estimates in $\$ / \mathrm{kWh}$ for Test Case 1 (no existing storage works), Test Case 2 (50\% existing storage works), and Test Case 3 (80\% existing storage works) with $90 \mathrm{MW}-100$ MW of generating capacity and 8 hours of storage (green) compared to estimates of comparable EES technologies (blue). * indicates limited commercial applications available at this scale, $* *$ indicates early demonstration at this scale based on estimates from EPRI (2010).

Figure 32. LCOS comparison for m-PSH projects in all test cases with $90 \mathrm{MW}-100 \mathrm{MW}$ of generating capacity and 8 hours of storage (green) compared to analyst estimates of comparable EES technologies (blue) (estimates obtained from Lazard, 2015). * indicates limited commercial applications available at this scale, $* *$ indicates early demonstration at this scale based on estimates from EPRI (2010).

Figure 33. ICC estimates in $\$ / \mathrm{kWh}$ for m-PSH projects in all test cases with $20 \mathrm{MW}-30 \mathrm{MW}$ of generating capacity and 4 hours of storage (green) compared to analyst estimates of comparable EES technologies (blue) (data obtained from Lazard, 2015). * indicates limited commercial applications available at this scale, $* *$ indicates early demonstration at this scale based on estimates from EPRI (2010).

Figure 34. LCOS comparison for m-PSH projects in all test cases with $20 \mathrm{MW}-30 \mathrm{MW}$ of generating capacity and 4 hours of storage (green) compared to analyst estimates of comparable EES technologies (blue) (estimates obtained from Lazard, 2015). * indicates limited commercial applications available at this scale, $* *$ indicates early demonstration at this scale based on estimates from EPRI (2010). 
Figure 35. m-PSH reservoir system.

Figure 36. Relationships between site preparation and storage design parameters. Storage volume (yaxis) increases with increase in design specification (x-axis).............................................51

Figure 37. Typical plan of a vertical unit Francis powerhouse (USBR, 1980) .......................................56

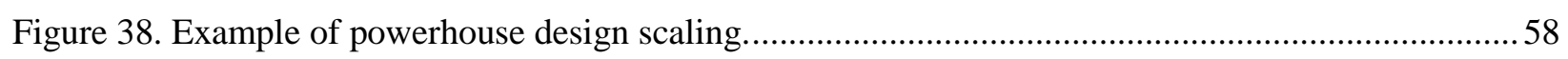

Figure 39. Cost indices comparison (modified from O'Connor et al., 2015a). .......................................61

Figure 40. Example of water conveyance cost scaling. ID refers to inner diameter................................66

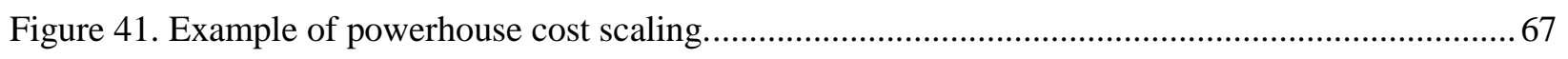

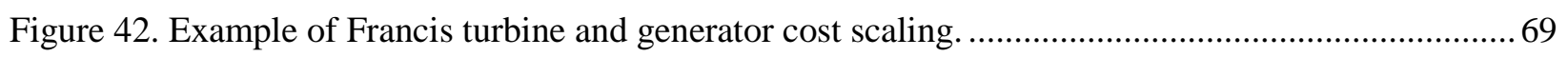

Figure 43. Example of transformer, switchyard, and substation cost scaling......................................... 70

Figure 44. Material cost comparison of alternative water storage types. Net head of $350 \mathrm{ft}$, turbine efficiency of $90 \%$, and 10 hours of storage are assumed to provide an estimate of storage capacity in $\mathrm{kWh}$. 


\section{LIST OF TABLES}

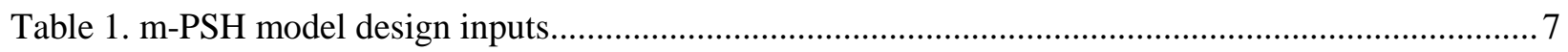

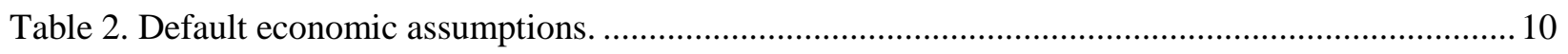

Table 3. Estimated 2015 installed costs of conventional PSH plants in the US. ..................................... 11

Table 4. Definition of cost categories for comparison in Figure 9. ..................................................... 14

Table 5. Cost escalation index comparison for various years. Minimum values are highlighted in

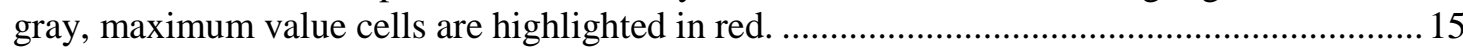

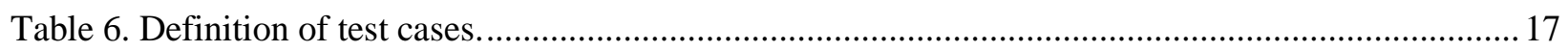

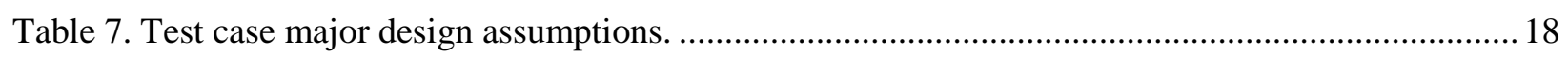

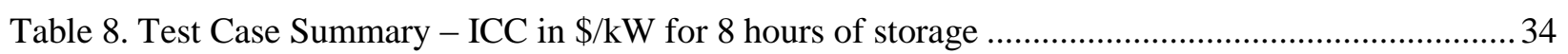

Table 9. Test Case Summary - ICC in \$/kW 4 hours of storage ........................................................... 34

Table 10. Model variables and corresponding ranges for ICC sensitivity analysis .................................35

Table 11. Model variables and corresponding ranges for LCOS sensitivity analysis...............................36

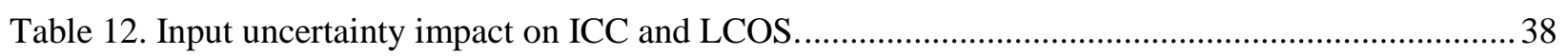

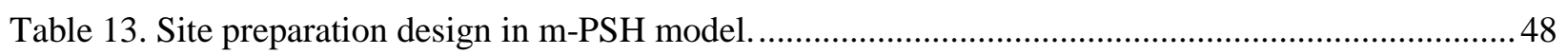

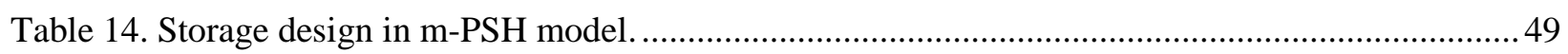

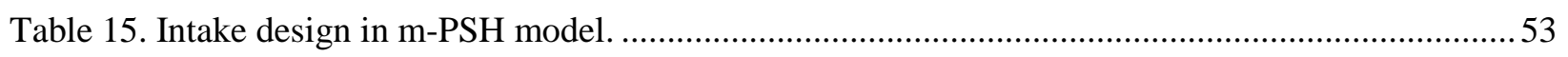

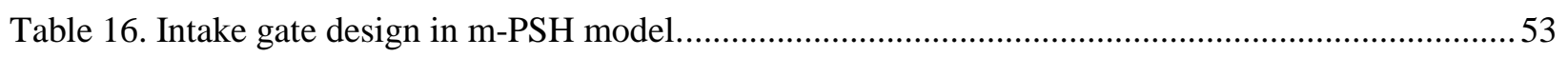

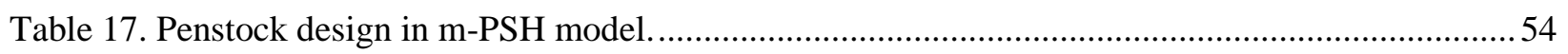

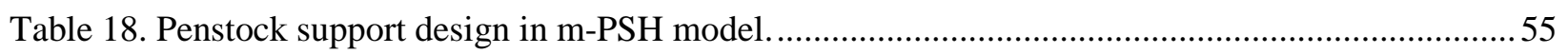

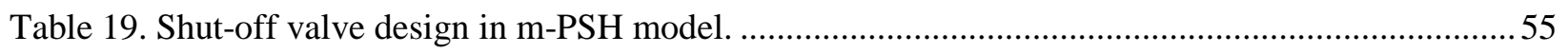

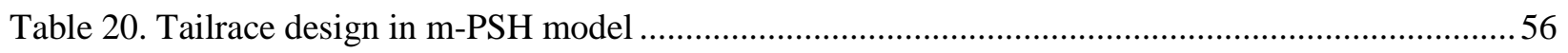

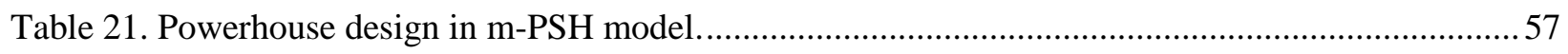

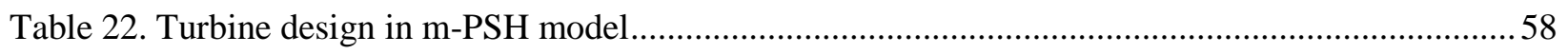

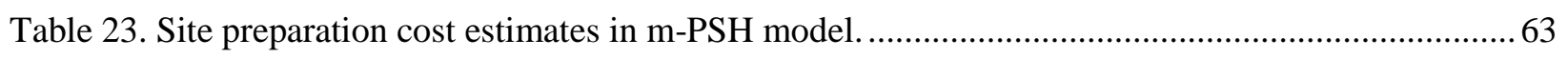

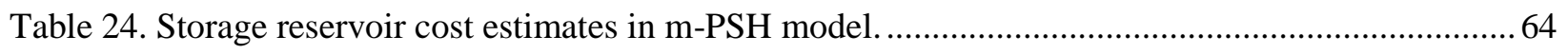

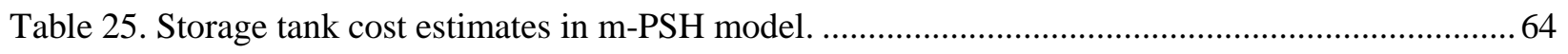

Table 26. Water conveyance system cost estimates in m-PSH model.................................................... 65

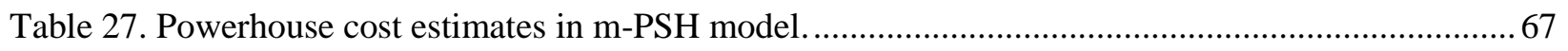

Table 28. Electro-mechanical equipment cost estimates in m-PSH model.............................................. 68

Table 29. Electrical infrastructure cost estimates in m-PSH model...................................................... 70

Table 30. Environmental mitigation cost estimates in m-PSH model. ................................................. 71

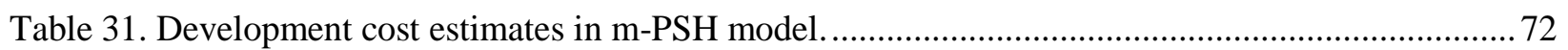

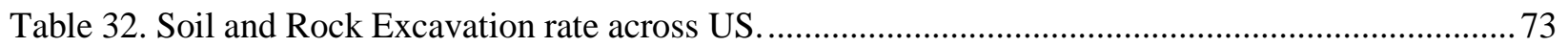

Table 33. Comparison of tank and reservoir storage options for m-PSH facilities. ................................. 74 


Institute
ory Commission
Hydropower
ower
Reclamation
of Capital

$\begin{array}{ll}\text { CPI } & \text { Consumer Price Index } \\ \text { DOE } & \text { Department of Energy }\end{array}$

ECM Engineering and Construction Management

EES

EM

Electrical Energy Storage

ENR

Environmental Mitigation

Engineering News Record

EPRI

Electric Power Research Institute

FERC

ICC

Federal Energy Regulatory Commission

LCOS

Initial Capital Cost

m-PSH

O\&M

Levelized Cost of Storage

ORNL

Modular Pumped Storage Hydropower

PSH

RTE

Operations and Maintenance

Oak Ridge National Lab

USACE

USBR

Pumped Storage Hydropower

Roundtrip Efficiency

WACC

United States Bureau of Reclamation

Weighted Average Cost of Capital 
[This page left intentionally blank] 


\section{BACKGROUND AND INTRODUCTION}

Pumped storage hydropower (PSH) provides nearly all utility-scale energy storage in the world (U.S. Department of Energy \& Sandia National Laboratories, 2015). The process of pumping water from a low elevation into a reservoir at a higher elevation and releasing that water through hydroelectric turbines back into a lower reservoir is an efficient and reliable means to store electrical energy. In the U.S. and globally, nearly all PSH facilities have capacity in excess of $100 \mathrm{MW}$ with greater than 4 hours of storage, reflecting both the economies of scale in construction and equipment procurement available to large projects, and the market advantage of marginal energy storage (Deane et al., 2010; Uria-Martinez et al., 2015). The pace of PSH development in the U.S. slowed to a standstill over the past 25 years, largely the result of economic uncertainties in a deregulated electricity market, protracted siting and environmental constraints, and a continuous decline in natural gas prices (Yang \& Jackson, 2011). A shifting energy landscape, driven by the growth of intermittent renewable energy generating capacity, the rise of state mandated renewable portfolio standards, and the emergence of wholesale electricity markets, is redefining the role of energy storage. Many opportunities are arising for smaller, efficient, deployable distributed energy storage systems to competitively enter the electricity market (IHS, 2015).

An interesting perspective on energy storage is gained by viewing the historical timeline of energy storage projects throughout the world (Figure 1). PSH plants were the predominant energy storage projects being installed for nearly 80 years, from their introduction in the early 1900s through the turn of the century. Capacities in the range of $400 \mathrm{MW}$ to $1,000 \mathrm{MW}$ were most common, with few dedicated ${ }^{1}$ PSH projects under $100 \mathrm{MW}$. In the past 20 years, the pace of PSH construction has slowed significantly while the number of electro-chemical (i.e., battery) storage projects has significantly increased, primarily as a result of advanced in technology, along with favorable state policies and federal incentives favoring small scale energy storage projects. While PSH projects still provide the vast majority of global energy storage capacity, cumulative large-scale PSH plant growth is being rapidly outpaced by smaller-scale battery projects with installed capacities generally less than $10 \mathrm{MW}$ per project.
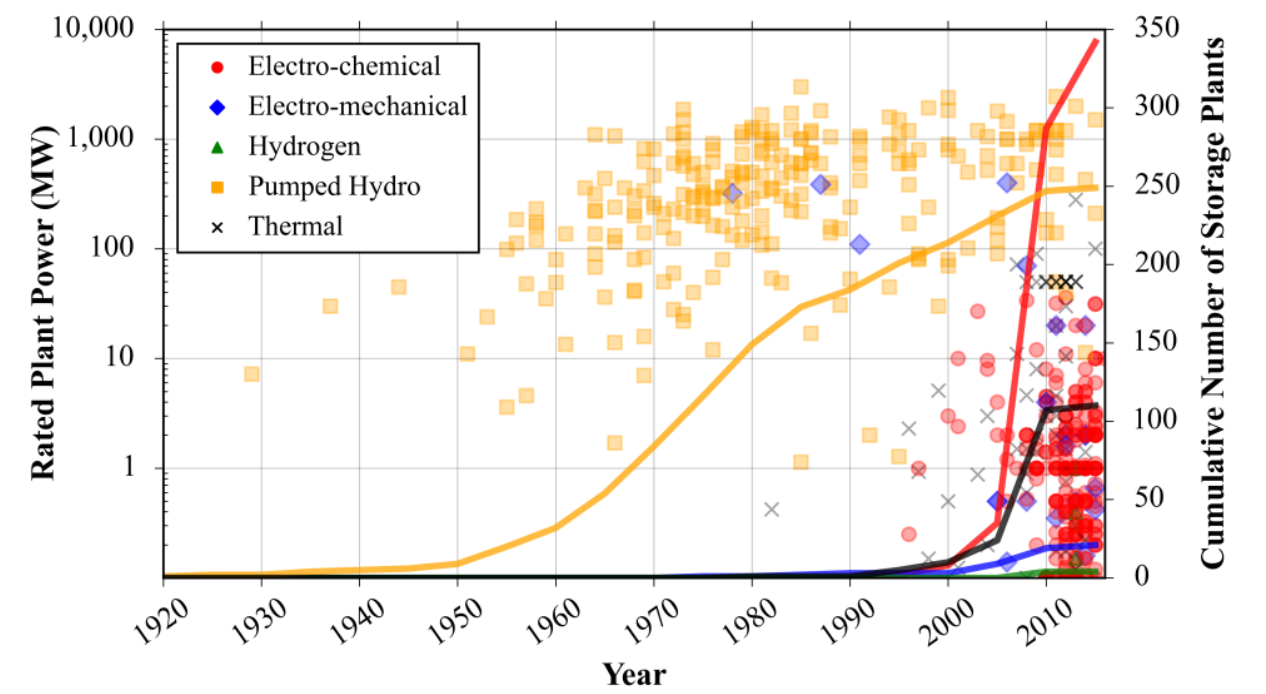

Figure 1. Global energy storage projects as of March, 2016. Scatter points represent individual plants, line plot represents cumulative number of plants over time. Data obtained from (U.S. Department of Energy \& Sandia National Laboratories, 2015)

1 Conventional hydropower projects with reversible turbines can offer pumped storage capabilities. While this type of development is common in the US, and these units are included in Figure 1, they are not discussed in this report. 
As a mature and proven technology, existing large-scale PSH plants are efficient and highly cost competitive as an energy storage mechanism. Historically, PSH has been the cheapest form of energy storage on a $\$ / \mathrm{kW}$ installed basis by roughly an order of magnitude (Figure 2). A clear trend of increasing PSH installed costs $(\$ / \mathrm{kW})$ over time is evident, reflecting both an increase in labor and construction costs, a decreased in average projects size, the added costs and challenges of developing less topographically favorable sites, and increased environmental protection and mitigation requirements. Understanding the complex economics of energy storage is a challenge due to the variety of energy storage installation types, capacities, lifetimes, and technical characteristics, and thus it is easiest to compare various energy storage alternatives based on a levelized cost of energy storage (LCOS), where LCOS is measured on a $\$ / M W h$ basis. PSH is nearly always the least cost storage technology alternative on a LCOS basis. For example, the unsubsidized LCOS of transmission scale PSH plants is estimated between \$188/MWh and \$275/MWh, while lithium-ion electro-chemical storage technologies with similar capacities and storage dynamics have an estimated LCOS 2-3 times greater, between \$347/MWh and \$739/MWh (Lazard, 2015).

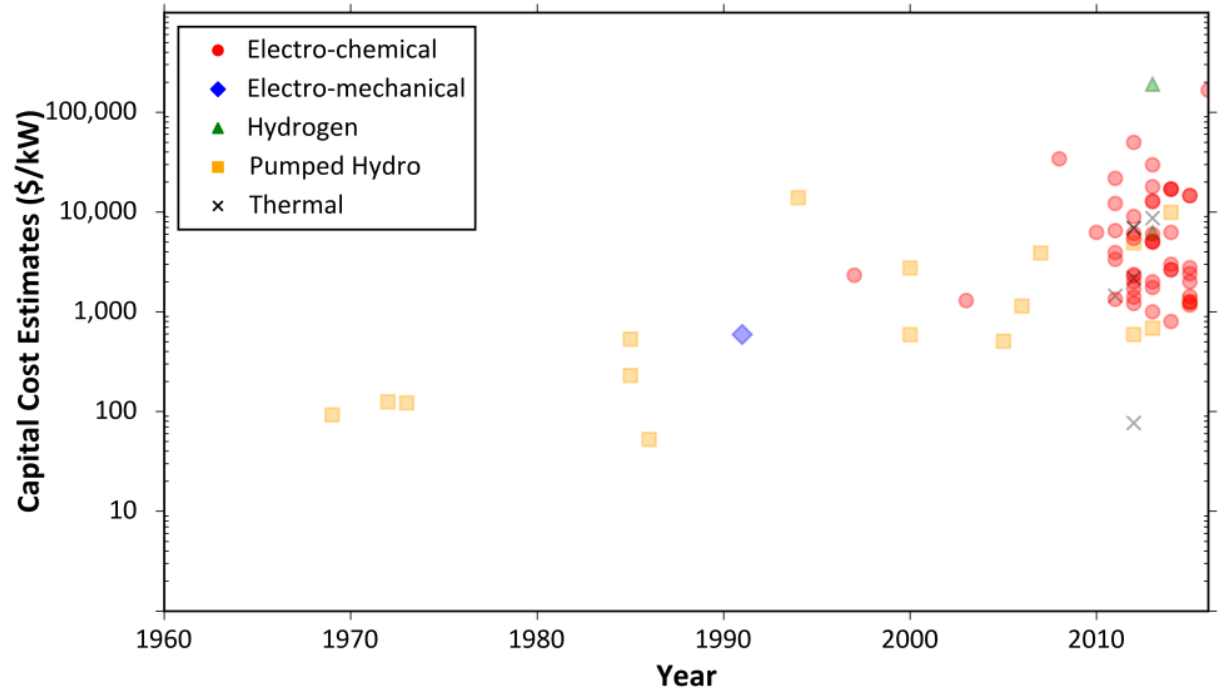

Figure 2. Capital cost estimates of global energy storage projects as of March, 2016. Data obtained from (U.S. Department of Energy \& Sandia National Laboratories, 2015).

The recent increase in electro-chemical storage technology installations is often attributed to scale and deployability. Batteries generally have a smaller physical footprint than PSH, they do not require a large elevation difference or a substantial volume of water, they can be installed at any grid location, they are commissioned and constructed in a relatively short period of time, and they can scale up in power capacity efficiently and effectively through the addition of battery cells. However, batteries fall well short of the scalability of PSH in terms of both power and energy. For example, the largest battery storage facility in the US in 2015 was rated at $31.5 \mathrm{MW}$ of power with $12.2 \mathrm{MWh}$ of storage, giving roughly 39 minutes per discharge cycle. Numerous small plants on the scale of $10 \mathrm{MW}$ or less generally have storage capacities on the order of 30 minutes to 2 hours. PSH plants, on the other hand, contain single pumping and generating units on a scale of several MW to several hundred MW, with storage capacities of hours to days. PSH is in fact quite scalable from a technology standpoint using existing technologies and construction methods. While over $70 \%$ of plants in the existing US PSH fleet have installed capacities of greater than $100 \mathrm{MW}$, at least six plants have units with a rated capacity of less than $20 \mathrm{MW}$, the smallest being 4.2 MW (U.S. Department of Energy \& Sandia National Laboratories, 2015). Under the existing PSH paradigm of custom site layouts and unit design, smaller, m-PSH scale plants would be more expensive to build on a per-kilowatt basis. However, the standardization and 
modularization of small PSH units could enable significant cost reductions by streamlining and standardizing design processes, manufacturing capabilities, and installation procedures. Most large-scale pumped storage projects require significant transmission additions and upgrades, which are often beneficial to the transmission system, and the requisite costs are most often solely the responsibility of the PSH facility, leading to high added cost and increased regulatory timelines for the developer. The modular approach being considered could have standard interconnection details and utilize existing transmission and distribution, requiring only minor upgrades and associated costs. Environmental footprints and impacts would be proportionally much smaller, which could lead to greater social acceptance and quicker development timelines. If m-PSH plants can be built more quickly, efficiently, and cost-effectively, they would provide an extremely competitive alternative to batteries (Figure 3).

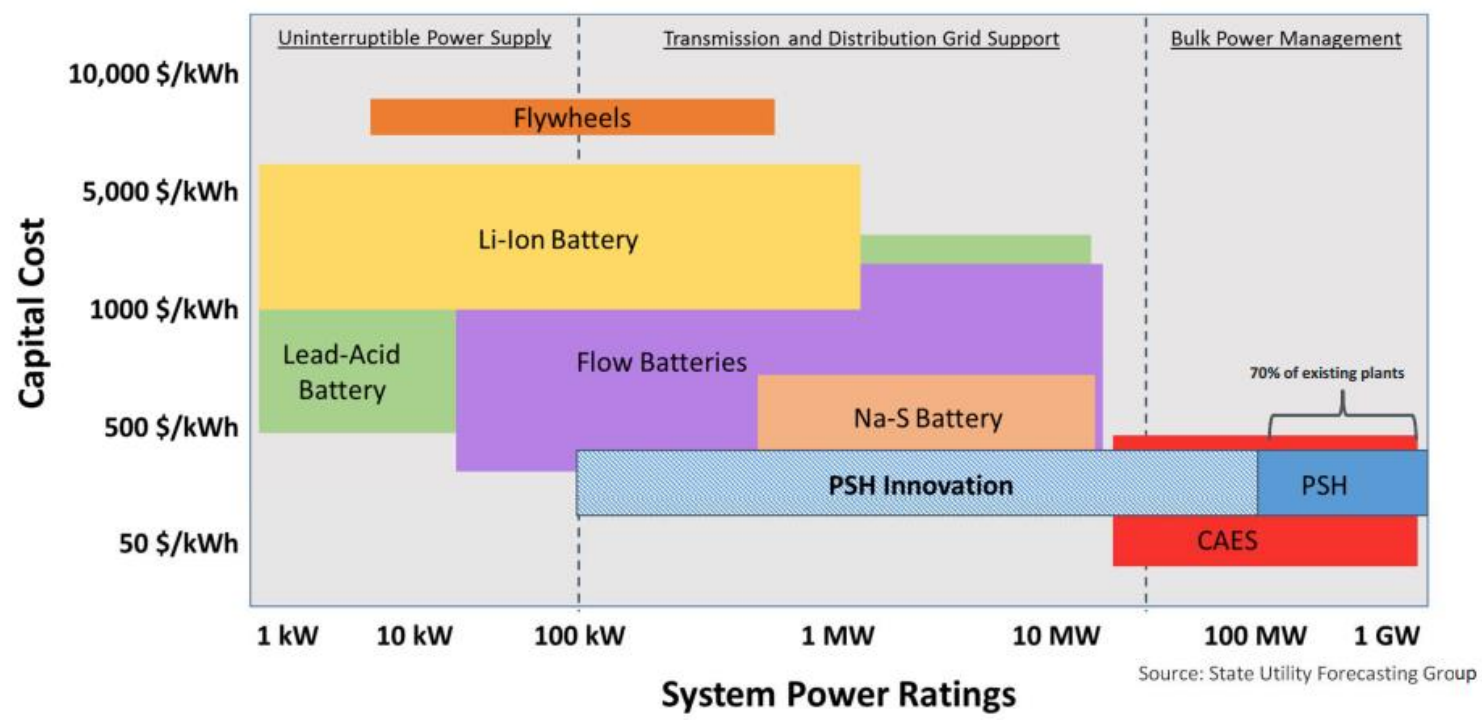

Figure 3. Capital cost and system power ratings of various energy storage technologies, highlighting the potential for m-PSH innovation (Welch, 2016, as adapted from the State Utility Forecasting Group).

Development of modular pumped storage hydropower is a major focus for the U.S. Department of Energy (DOE). To investigate the feasibility of developing m-PSH facilities, DOE's Wind and Water Power Technologies Office has tasked Oak Ridge National Laboratory (ORNL) with assessing the cost and performance trade-offs of modularizing PSH plants and the potential for cost-reduction pathways. In this report, a cost model is developed to estimate the initial capital cost of m-PSH projects. The model is developed with user inputs that allow for cost estimates at a maximum number of potential locations. This report builds upon previous model development and case studies regarding the economic feasibility of specific m-PSH deployment scenarios (Hadjerioua et al., 2011; Hadjerioua et al., 2014; Witt et al., 2015).

\subsection{SCOPE}

The scope of this study is to develop a decision making screening level tool to predict the capital costs of small scale, modular pumped storage hydropower projects. The tool is intended to support a broader DOE effort to encourage alternative pumped storage designs that can lower capital costs and reduce deployment timelines. Cost results from this analysis are validated against available data for large scale projects, specific test cases are analyzed to provide context on possible deployment scenarios, and project economics are assessed and compared with existing electric energy storage technologies. 


\section{MODEL OVERVIEW}

The m-PSH model is built using a bottom-up cost estimating approach that identifies seven major categories $^{2}$ of a project, briefly introduced and defined below:

1. Civil works - activities and costs associated with site preparation and access, and with building an upper reservoir, a lower reservoir, a water conveyance, and a powerhouse;

2. Electro-mechanical - activities and costs associated with pump-motors, turbine-generators, ancillary electrical systems, and ancillary mechanical systems;

3. Electrical - activities and costs associated with transmission lines, transformers, a switchyard, and a substation;

4. Engineering Construction Management (ECM) - activities and costs associated with managing the quality and schedule of project construction;

5. Environmental and regulatory compliance - activities and costs associated with mitigating environmental impacts and environmental regulations, including permitting, licensing, and compliance requirements;

6. Development - activities and costs associated with site acquisition, engineering, water rights, engineering feasibility, transmission planning, and development of financial models;

7. Contingencies - the cost of uncertainty associated with the unknown conditions or equipment that may arise during construction;

Within each category, the model is designed to compute elements of design and cost. Design elements refer to the design, scaling, and sizing of equipment and infrastructure. Cost elements refer to the cost of project equipment, infrastructure, components, or other development activities.

A bottom-up cost estimating approach is employed to enable a robust but flexible decision making tool for transparent investigation of cost reduction strategies. The model strives to offer generic design options that can accommodate a variety of potential m-PSH deployment scenarios. By linking dynamic design options to scalable parametric and volumetric costing methods, a powerful tool has been created for wide-area analysis of potential site configurations and project installed capacities. To date, most PSH cost modeling is based on proprietary information that does not provide a sufficient level of detail for scaling purposes (Knight Piésold Consulting, 2010; MWH, 2009), reviews of the Federal Energy Regulatory Commission (FERC) preliminary permit information, which provides planning stage bulk cost estimates but not high level category costs (O'Connor et al., 2015a), or parametric scaling of projectlevel costs based on the original total installed cost of the project (Electric Power Research Institute, 2011). The present model is distinguished by an increased level of cost and design detail available to the end user, scalability to a broad spectrum of project installed capacities, head, and storage volume, and flexibility to address alternative deployment options.

\subsection{MODEL FRAMEWORK}

A conceptual schematic of the cost estimating model framework is shown in Figure 4. The framework consists of seven basic steps:

1. Input Site Characteristics - The model requires a minimum of three (storage volume, storage time, and design head) user input parameters, from which design variables are computed based on additional default parameters;

2. Develop Reference Design - the reference design step takes input parameters and computes a basic project design using design equations and engineering judgement. Several design

2 These seven categories were adapted from Federal Energy Regulatory Commission (FERC) Form 1 guidelines, accessed through http://www.ferc.gov/docs-filing/forms/form-1/form-1.pdf 
parameters can be specified by the user, such as penstock diameter, penstock length to hydraulic head ratio, dead storage volume, site access road length, and turbine type and arrangement;

3. Estimate Project Category Cost - based on the reference design, a cost estimate for each of the seven major cost categories is developed, including contingencies for undefined, uncertain, and risk items;

4. Output Project Initial Capital Cost - the sum of all project categories is determined and output as project initial capital cost;

5. Economic Evaluation - using the project initial capital cost and basic economic and operational assumptions, the levelized cost of storage is determined;

a. Alternative design strategies - alternative project design strategies are implemented, based largely on the status of upper and lower reservoirs (Greenfield or some storage works already exists);

6. Sensitivity analysis - the sensitivity of cost assumptions are assessed based on likely variables to be encountered during m-PSH deployment, such as changes in generating unit efficiency, civil works contingencies, or penstock length to height ratio;

7. Comparative analysis - the initial capital cost and levelized cost of storage under several potential deployment scenarios are compared to alternative electrical energy storage technologies;

8. Define and Disseminate Strategies - the scenarios under which economic criteria are met are documented and discussed.

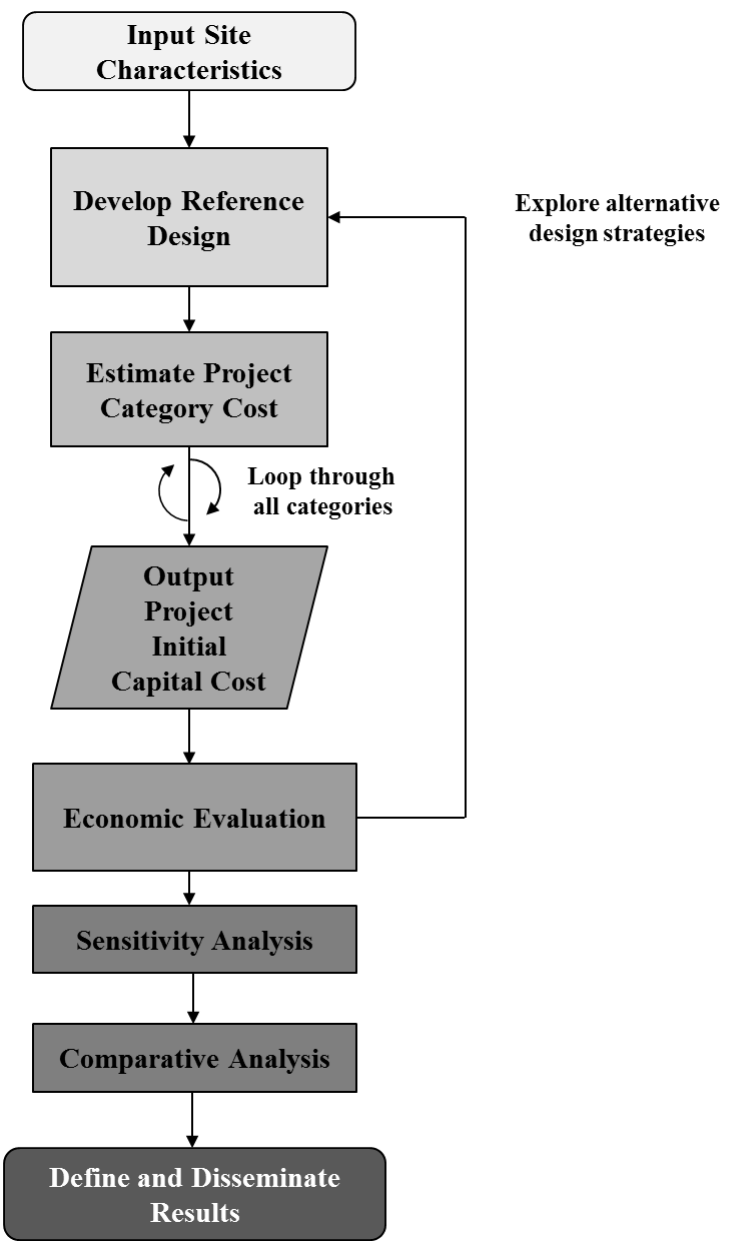

Figure 4. m-PSH cost modeling framework. 


\subsection{KEY DATA SOURCES}

The key data sources used to develop m-PSH model include:

- ORNL Hydropower Cost Model reports (O'Connor et al., 2015a,b; and O'Connor et al., 2016);

- Integrated Hydropower Cost Model (Chalise et al., 2016);

- US Bureau of Reclamation (USBR), US Army Corps of Engineers (USACE) and DOE historical design reports and project data (USACE 1979; USBR, 1980; DOE, 2002; USACE 2013);

- European Small Hydropower Design Guidelines (ESHA, 2004);

- RETScreen Small Hydropower Software (NRC, 2004);

Additional project data, design and cost information was collected from various hydropower stakeholder and reliable online resources, including recent FERC PSH application cost estimates ${ }^{3}$. Section 3 also provides data source information that is used to develop the m-PSH model.

\subsection{IMPORTANT MODEL ASSUMPTIONS AND LIMITATIONS}

To develop a wide-area m-PSH cost analysis tool, numerous design, cost, and economic assumptions are required. Major assumptions made in model development include:

- Conventional PSH projects entail custom designed facilities, where storage capacity, generation capacity, siting, penstock size, length, material, and location, and many other technical decisions are converged upon after detailed engineering, cost, and benefit tradeoff studies. This model attempts to systematically arrive at the best possible design from the lowest number of user inputs, and thus numerous design decisions are assumed and hard coded into the model. Results should be viewed in this light;

- The model assumes a production scale project. It is acknowledged that the first few m-PSH projects may have higher installed costs, contingencies, engineering construction management costs, and development timelines, but as the m-PSH concept becomes standardized and more widely adapted, these costs are assumed to decline;

- A closed-loop projects with two distinct reservoirs. Open-loop projects and pump-back schemes that use reversible pump-turbines in conventional hydropower plants are not considered;

- Some costs and contingencies reflect a production scale project. It is acknowledged that the first $\mathrm{m}$-PSH project may have higher contingencies, management costs, and development timelines.

- Surface penstock and powerhouse.

Where applicable, the sensitivity of project costs to major assumptions have been tested and quantified.

While the model is developed to apply to a vast array of m-PSH project types, there are several limitations to its applicability:

- This model is intended as an analysis tool, used to gather insight into general development cost trends, not to assess the specifics of a unique project;

- Some design and cost equations have limitations on their applicable range ${ }^{4}$; applying such equations beyond their application ranges adds uncertainty in the model results;

- Site physical, geological, and environmental conditions strongly influence the feasibility of a conventional PSH project; in practice, Monte Carlo simulations are often used as a bottoms up estimate to determine risk uncertainty and contingency for vagaries of ground and civil/geotechnical aspects, and to assess reservoir feasibility. These considerations are not explicitly accounted for in project design;

- The model carries large ranges of uncertainty that are difficult to quantify for every case.

3 http://elibrary.ferc.gov/

4 The application range of each equation is provided in Appendix A whenever applicable. 


\section{METHODOLOGY}

\subsection{USER INPUT}

In order to use the m-PSH model, a minimum of 3 (gross storage volume, storage time, and design head) and a maximum of 32 user input design parameters are required (Table 1). Out of these 32 user inputs, 19 inputs can be selected from a list. The remaining 10 items are model default values, which can be replaced by the user.

Table 1. m-PSH model design inputs.

\begin{tabular}{|c|c|c|c|c|}
\hline Items & Symbol & Units & Value $^{\dagger}$ & Note \\
\hline \multicolumn{5}{|c|}{ CIVIL WORKS } \\
\hline \multicolumn{5}{|l|}{ Storage Information } \\
\hline Gross Storage Volume & & $\mathrm{ft}^{3}$ & & Can also provide in acre-ft \\
\hline Dead Storage & $P_{d s}$ & $\%$ & & Default $=2 \%$ \\
\hline Storage Time & $\mathrm{T}$ & hrs & & \\
\hline Design Head & $\mathrm{H}$ & $\mathrm{ft}$ & & \\
\hline \multicolumn{5}{|l|}{ Upper Storage } \\
\hline Status & & & & New, Existing, Refurbishment \\
\hline Type & & & & Geomembrane lined reservoir, Tank \\
\hline Tank Type & & & & Bolted Steel, Welded Steel, Concrete \\
\hline Total Storage Depth & $\mathrm{D}_{\mathrm{s}}$ & $\mathrm{ft}$ & & Default $=50 \mathrm{ft}$ \\
\hline \multicolumn{5}{|l|}{ Lower Storage } \\
\hline Status & & & & New, Existing, Refurbishment \\
\hline Type & & & & Geomembrane lined reservoir, Tank \\
\hline Tank Type & & & & Bolted Steel, Welded Steel, Concrete \\
\hline Total Storage Depth & & & & Default $=50 \mathrm{ft}$ \\
\hline \multicolumn{5}{|l|}{ Water Conveyance System $^{+\dagger}$} \\
\hline Intake Status & & & & New, Existing, Refurbishment \\
\hline Intake Gate Type & $\mathrm{T}_{\mathrm{ig}}$ & & & Slide, Radial \\
\hline Penstock Status & & & & New, Existing, Refurbishment \\
\hline Penstock Maximum Velocity & $\mathrm{V}_{\operatorname{maxp}}$ & $\mathrm{ft} / \mathrm{s}$ & & Default $=10 \mathrm{ft} / \mathrm{s}$ \\
\hline Penstock Maximum Diameter & $\mathrm{d}_{\operatorname{maxp}}$ & $\mathrm{ft}$ & & Default = $12 \mathrm{ft}$ \\
\hline Penstock Length: Head & & & & Default $=4$ \\
\hline Upper Penstock Length & & $\mathrm{ft}$ & & \\
\hline Upper Penstock Material & & & & Steel (spiral weld), HDPE \\
\hline Lower Penstock Length & & $\mathrm{ft}$ & & \\
\hline Lower Penstock Material & & & & Steel (spiral weld), HDPE \\
\hline Tailrace Status & & & & New, Existing, Refurbishment \\
\hline Tailrace Length & $\mathrm{L}_{\mathrm{t}}$ & $\mathrm{ft}$ & & Model will compute if no length is provided \\
\hline \multicolumn{5}{|l|}{ Powerhouse } \\
\hline Powerhouse Status & & & & New, Existing, Refurbishment \\
\hline \multicolumn{5}{|l|}{ Site Preparation } \\
\hline Site Access Road Length & & & & Default $=0.5$ mile \\
\hline Terrain Complexity & & & & Low, Medium, High \\
\hline \multicolumn{5}{|c|}{ ELECTROMECHANICAL } \\
\hline \multicolumn{5}{|l|}{ Equipment } \\
\hline $\begin{array}{c}\text { Pump Turbine Arrangement } \\
\text { Turbine Type }\end{array}$ & & & & $\begin{array}{l}\text { Reversible (Default), Standard } \\
\text { Vertical Francis (Default), Pelton }\end{array}$ \\
\hline Generating Unit Efficiency & & & & Default $=90 \%$ \\
\hline Roundtrip Efficiency & & & & Default $=82 \%$ \\
\hline \multicolumn{5}{|c|}{ ELECTRICAL } \\
\hline \multicolumn{5}{|l|}{ Electrical Infrastructure } \\
\hline Transmission Status & & & & Default $=2$ miles \\
\hline
\end{tabular}




\begin{tabular}{|c|c|c|c|}
\hline Items & Symbol & Value $^{\dagger}$ & Note \\
\hline $\begin{array}{l}\text { Transmission Line Length } \\
\text { Transmission Line Voltage }\end{array}$ & & & Default $=15 \mathrm{kV}$ \\
\hline \multicolumn{4}{|c|}{ ENVIRONMENTAL COMPLIANCE } \\
\hline \multicolumn{4}{|l|}{ Compliance } \\
\hline Mitigation Type & & & 5 different environmental mitigation types \\
\hline
\end{tabular}

\subsection{CAPACITY ESTIMATES}

The project generating capacity is estimated as,

$$
P=\frac{Q H \eta}{11814}
$$

where $P$ is power delivered from turbine/generator in $\mathrm{MW}, H$ is design head acting on the turbine blade in $\mathrm{ft}$, and $\eta$ efficiency of the turbine/generator unit. $Q$ is the design flow in cfs, calculated as,

$$
Q=\frac{V_{S}}{3600 T}
$$

where $V_{s}$ is the upper storage volume for power generation in $\mathrm{ft}^{3} / \mathrm{s}, T$ is the storage time in hrs. Energy storage capacity is estimated as,

$$
E=P T
$$

where $E$ represents energy in MWh.

\subsection{DESIGN}

The m-PSH model concept design incorporates component-level design of civil works, electromechanical works and electrical infrastructure. Other project features such as engineering and construction management (ECM) and environmental mitigation (EM) are not explicitly designed in the model. The design of each model components is provided in Appendix A.1.

\subsection{INITIAL CAPITAL COST}

A detailed description of the costing approach of each model component and a comparison of historical cost indices are provided in Appendix A.2. The tool uses approximate unit based and parametric costing methods to simulate the costs of the seven total project categories: civil works, electromechanical (EM) equipment, electrical equipment, contingencies, Engineering Construction Management (ECM), environmental and regulatory compliance, and development (Figure 5). The ECM and EM equipment, having no explicit concept design, are assumed to scale with project size and such, cost implications are captured accordingly in the costing process. The project development cost includes licensing and initial engineering costs. As there is no explicit licensing cost methodology available for pumped storage projects, the m-PSH model's licensing cost is computed using INL (2003) non-powered dam licensing cost methodology, with additional validation using the current FERC licensing environment. 


\section{Civil Works}

\section{Electro-mechanical Equipment}

\section{Electrical Infrastructure}

4. Contingencies $(20 \%$ of $1,15 \%$ of 2 and 3$)$

\section{Engineering Construction Management $(15 \%$ of $1+2+3+4)$}

\section{Environmental Mitigation}

\section{Development}

\section{Initial Capital Cost $($ ICC $)=1+2+3+4+5+6+7$}

Figure 5. Methodology to compute m-PSH initial capital cost.

The m-PSH model assumes a $20 \%$ contingency ${ }^{5}$ for civil works and $15 \%$ contingency for electromechanical equipment as a default values, based on USBR (2011). It is acknowledged that there is substantial cost uncertainty in many cost categories, including contingencies, and that parametric and unit based cost estimates may vary substantially from final project costs. There are limitations to the applicability of these equations and contingencies, and where possible, sensitivity analyses have been conducted to provide a sense of model uncertainty to input parameters. It is also acknowledged that many cost estimates in this report are escalated from estimates made years ago, as these are considered reliable sources based on extensive reconnaissance evaluations of numerous installed projects. Where appropriate, spot checks on escalated cost estimates were carried out based on more recent data. See Section 4.4., Section 6, and Appendix A.2. for more discussion on sensitivity and uncertainty.

The USBR historical cost indices, Engineering News Record (ENR) cost indices, and Consumer Price Index (CPI) are used to escalate cost to $2015 \$$. The initial capital cost (ICC) of the project is taken as the sum of cost categories and contingencies

\subsection{PROJECT ECONOMICS}

Initial capital cost (ICC) and levelized cost of storage (LCOS) are used to enable a levelized comparison across $\mathrm{m}$-PSH projects of various power and storage capacities. The ICC will be presented in $\$ / \mathrm{kW}$ of generating capacity and $\$ / \mathrm{kWh}$ of energy storage capacity, and represents the overnight cost to develop and construct a project. The LCOS represents the net present value of the unit cost of storage over the lifetime of the project, assuming a single capital structure, cost of capital, and operational and cost assumptions. LCOS is computed as the sum of ICC (in \$) and discounted annual expenses minus the residual value divided by the energy output over the lifetime of the project, computed as

5 Contingency is added to the original estimated cost to cover any unforeseen expenses as well as to cover specific expenses the model does not capture that may occur during project construction. 


$$
L C O S=\frac{I C C+\sum_{i=1}^{n} \frac{O \& M_{i, a}+R_{i, a}+F_{i, a}}{(1+r)^{i}}-\frac{V_{r e s}}{(1+r)^{n+1}}}{\sum_{i=1}^{n} E_{i, a} \frac{(1-d)^{i}}{(1+r)^{i}}}
$$

where $O \& M_{i, a}=$ annual operation and maintenance expenses in year $i, R_{i, a}=$ annual replacement expenses in year $i, F_{i, a}=$ annual fuel expenses in year $i, V_{\text {res }}=$ the residual value of the project in year $n, E_{i, a}=$ annual energy output in year $i, d=$ annual degradation due to age and wear, and $r=$ the real discount rate. All future costs are adjusted for inflation. Unless otherwise specified, LCOS is computed using the assumptions outlined in Table 2. Several of these assumptions are chosen to enable a direct comparison of LCOS with other electrical energy storage (EES) technologies that have $100 \mathrm{MW}$ of installed capacity and 8 hours of storage (Lazard, 2015). The sensitivity of these assumptions and their impact on LCOS is discussed in Section 6.2.

Table 2. Default economic assumptions.

\begin{tabular}{lcc}
\hline Category & Variable & Value \\
\hline Discount rate (WACC) & $r$ & $10 \%$ \\
\hline Inflation rate & $n$ & $2 \%$ \\
\hline Project Life & $d$ & 40 years \\
\hline Annual degradation & $c y c l e s$ & $0.25 \%$ \\
\hline Days of full discharge per year & $\eta_{r t e}$ & 300 \\
\hline Roundtrip efficiency & $E_{i, a}$ & $82 \%$ \\
\hline Annual generation (MWh) & $P_{i, a}$ & $P^{*} T^{*} c y c l e s$ \\
\hline Annual pumping (MWh) & $T_{p}$ & $E_{i, a} / \eta_{r t e}$ \\
\hline Pumping tariff & & $\$ 50 / \mathrm{MWh}$ \\
\hline Annual pumping tariff escalation & $F_{i, a}$ & $0.25 \%$ \\
\hline Annual fuel cost & & $P_{i, a} T_{p}$ \\
\hline Annual O\&M (fixed) & $R_{i}$ & $\$ 12 / \mathrm{MWh}$ \\
\hline Replacement cost at 20 years & $V_{r e s}$ & $20 \%$ of EM Cost \\
\hline Residual value & & $20 \%$ of ICC \\
\hline
\end{tabular}




\section{MODEL VALIDATION}

The model is validated against a variety of installed projects and projects under study to evaluate how well the overall relationship between project costs and installed capacity (MW) is captured. Validation is carried out for a wide range of head and storage options at a substantial range of power capacities to ensure large scale trends and economies of scale are accurately modeled. A detailed validation for small scale projects is not possible as there are no dedicated m-PSH scale projects from which a comparative cost analysis can be made. However, curves were obtained that extend large scale project costs to small scales, and these are provided as a best estimate for cost model validation. Cost model outputs will be referred to as simulated projects in this section.

\subsection{EXISTING STUDIES AND COST ESTIMATES}

Three existing data sources are used to validate project costs. The first is an estimate of installed costs of six existing and operational conventional (i.e., not pump-back) PSH projects in the US with installed capacities between 280 MW and 628 MW (Electric Power Research Institute, 2011). The 2011 reported costs were escalated using a factor of 1.128 based on the USBR Composite index.

Table 3. Estimated 2015 installed costs of conventional PSH plants in the US.

\begin{tabular}{lccc}
\hline $\begin{array}{l}\text { Project } \\
\text { Name }\end{array}$ & $\begin{array}{c}\text { Capacity } \\
(\mathbf{M W})\end{array}$ & $\begin{array}{c}\text { Estimated Cost } \\
\mathbf{( 1 9 8 8} \mathbf{\$} / \mathbf{k W})\end{array}$ & $\begin{array}{c}\text { Estimated Cost } \\
\mathbf{( 2 0 1 5} \mathbf{\$} / \mathbf{k W})\end{array}$ \\
\hline Tom Sauk & 350 & 462 & 1,354 \\
\hline Cabin Creek & 280 & 404 & 1,184 \\
\hline Yards Creek & 330 & 332 & 973 \\
\hline Seneca & 380 & 505 & 1,480 \\
\hline Fairfield & 512 & 586 & 1,718 \\
\hline Bear Swamp & 540 & 507 & 1,486 \\
\hline Jocassee & 628 & 422 & 1,237 \\
\hline
\end{tabular}

Additional estimates from EPRI put the cost of PSH projects with $280 \mathrm{MW}$ to $530 \mathrm{MW}$ of capacity at $\$ 2,500$ to $\$ 4,300 / \mathrm{kW}$ (Electric Power Research Institute, 2010). The second is a screening level assessment report carried out in British Columbia to quantify the projected costs of projects between 500 MW and 1,000 MW (Knight Piésold Consulting, 2010). The third is a family of cost curves developed by MWH based on 60 preliminary level estimates for PSH projects conducted between 2005 and 2009 (MWH, 2009).

\subsection{MODEL VALIDATION ASSUMPTIONS}

To validate the cost model, several assumptions are required that align m-PSH concept design inputs with the characteristics of the projects to which they are compared. Major assumptions include:

- Two reservoirs, each with a live storage depth of approximately $50 \mathrm{ft}$ and dead storage of $2 \%$ of total storage volume;

- The majority of conventional US sites were constructed on a site with some existing infrastructure, including roads, transmission, and/or usable reservoirs (i.e. a quarry, mine, or natural reservoir). For validation purposes it is assumed that one reservoir already exists (only $20 \%$ of the excavation burden with respect to overall storage volume is required) and one reservoir has some existing storage infrastructure in place (only $50 \%$ of the excavation burden with respect to overall storage volume is required);

- All generating units are assumed to be reversible Francis turbines with a peak generating efficiency of $90 \%$; 
- Surface penstock and powerhouse;

- Many studies exclude the cost of transmission lines from the initial capital cost. Other projects may require extensive transmission at significant cost. A transmission line length of 2 miles at $230 \mathrm{kV}$ is chosen as a default value;

- Terrain with medium complexity is assumed;

- Civil works contingency of $20 \%$ and electro-mechanical and electrical infrastructure contingencies of $15 \%$;

- Fish and wildlife environmental mitigation is required;

- A random Gaussian distribution of four variables is chosen to mimic the characteristics representative of installed projects and those studied at a feasibility level (see Figure 6 for an example distribution):

$\circ$ head varying between $100 \mathrm{ft}$ and $1,000 \mathrm{ft}$;

0 storage volume varying between $10,000,000 \mathrm{ft}^{3}$ and $1,200,000,000 \mathrm{ft}^{3}(230-27,548$

acre-ft);

$\circ \quad$ storage time varying between 8 and 16 hours;

$\circ$ Penstock length to height ratio $(\mathrm{L}: \mathrm{H})$ varying between 3 and 10.

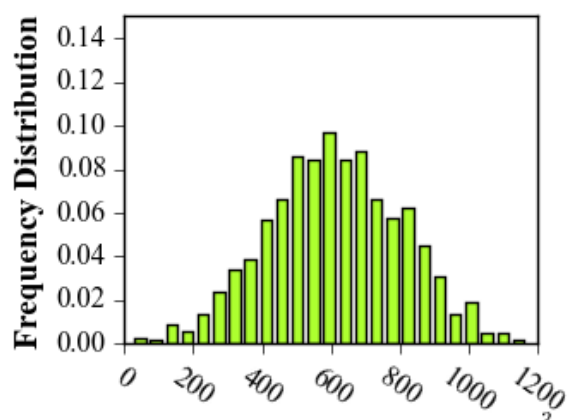

Live Storage Volume (million $\mathrm{ft}^{3}$ )

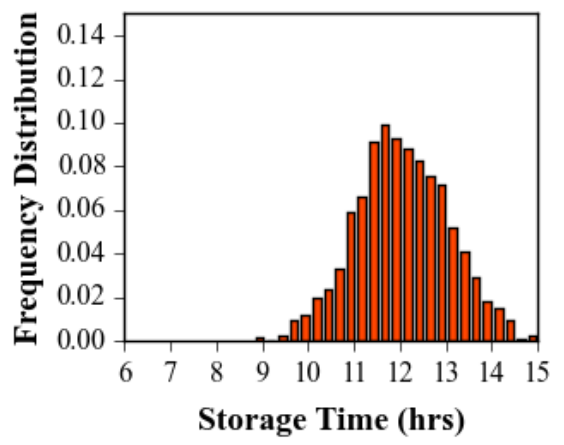

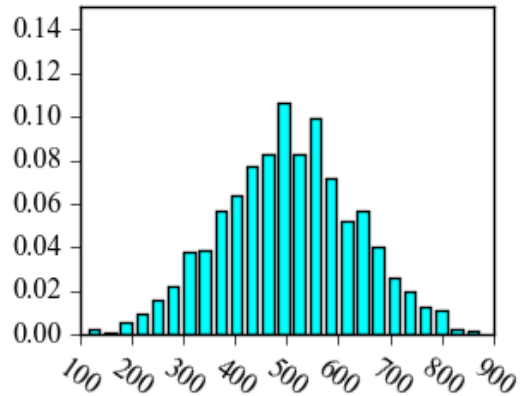

Design Head (ft)

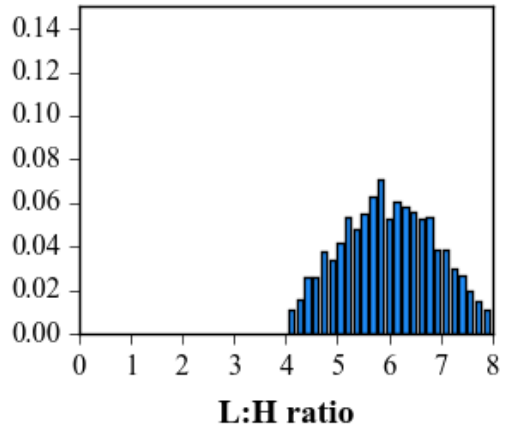

Figure 6. Frequency distribution of variables used for model validation.

\subsection{COST MODEL VALIDATION}

To capture a wide range of cost model outputs, a Monte Carlo type simulation of 1,000 projects with characteristics outlined in Section 4.2 is carried out. Simulation results are shown compared with existing projects and those under study in Figure 7. The main trend captured very well is the economies of scale in development, namely an increase in ICC as project capacity is decreased, and a decrease in ICC as capacity is increased. It is critical that any cost model accurately reflect these cost dynamics. For a given project capacity, a lower ICC is indicative of a higher relative design head and a lower relative storage volume. As head is decreased and storage volume is increased, at the same capacity, a rise in ICC is 
observed. The spread between low and high costs becomes increasingly more apparent as project capacity is decreased, indicating low capacity simulated projects are most economically viable at higher relative design head. It is interesting to note that installed project costs are significantly lower than those under study. This accurately reflects the low ICC of the existing PSH fleet, and the challenges in the current PSH development market.

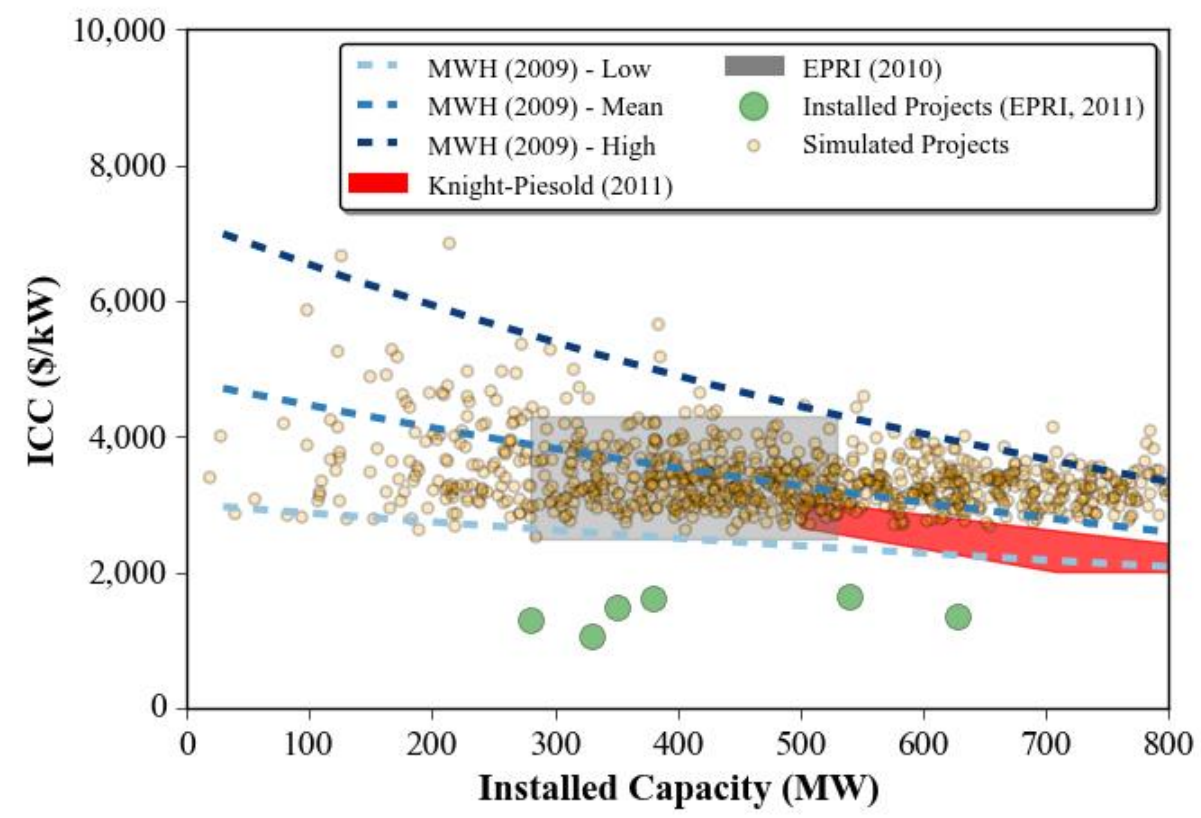

Figure 7. Cost model validation against existing projects and projects under study. All costs are in \$2015.

The range of ICC in $\$ / \mathrm{kWh}$ for simulated projects is compared with estimates for conventional PSH in Figure 8. A wide spread of ICC is predicted by the model, a result of the greater range of installed capacities and storage times simulated compared to the Lazard (2015) model, which only assumed projects with 100MW of capacity and 8 hours of storage, and compared to EPRI (2011), which assumed projects with $280 \mathrm{MW}$ to $530 \mathrm{MW}$ in installed capacity and 6 to 10 hours of storage. The EPRI estimates likely provide the best comparison, as it is unclear what siting and civil costs are included in the Lazard (2015) estimate.

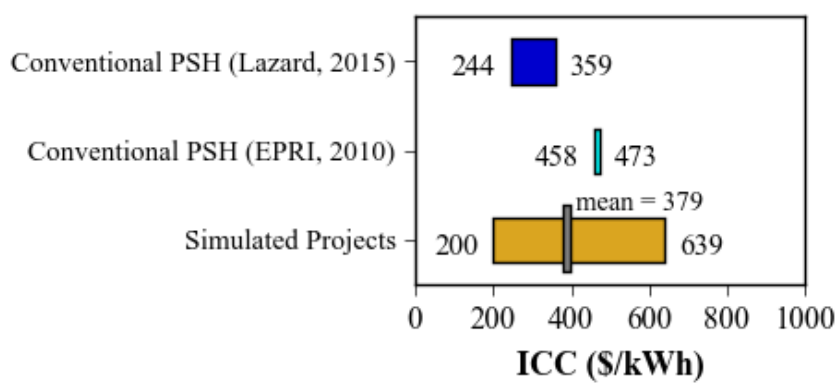

Figure 8. ICC prediction in $\$ / \mathbf{k W h}$ of simulated projects with installed capacity $<500 \mathrm{MW}$ and storage time of $<10$ hours compared to estimates for various transmission scale energy storage technologies. All costs are in \$2015.

Average simulated project cost distribution among four major categories is shown in Figure 9, with cost categories defined in Table 4. The electro-mechanical and electrical equipment categories are combined 
and contingencies are backed out of civil works and electro-mechanical and electrical equipment categories to match the cost estimation categories of Knight Piésold (2010). There is overall good agreement between the major cost categories, with excellent agreement in the ranges and average civil works costs and soft costs percentages. The largest discrepancy is the difference between contingencies and electro-mechanical and electrical equipment, though the potential range of the latter overlaps with that of Knight Piésold (2011). Overall, the range of cost distributions predicted by the model are consistent with those predicted by engineering consultant with expertise in PSH development.

Average PSH Cost Distribution (Knight Piesold, 2011)

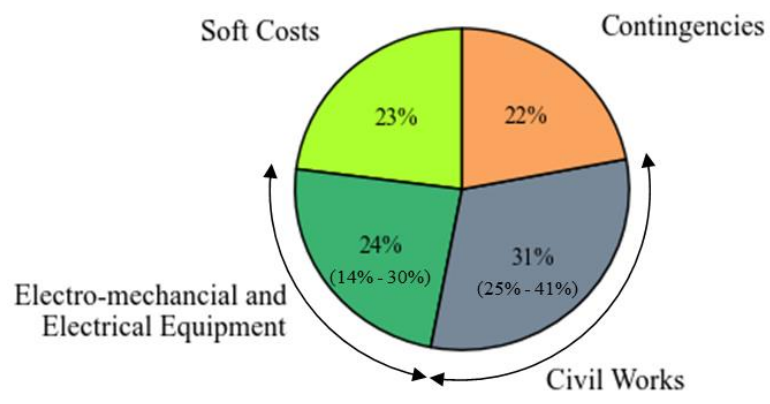

Simulated Project Average Cost Distribution

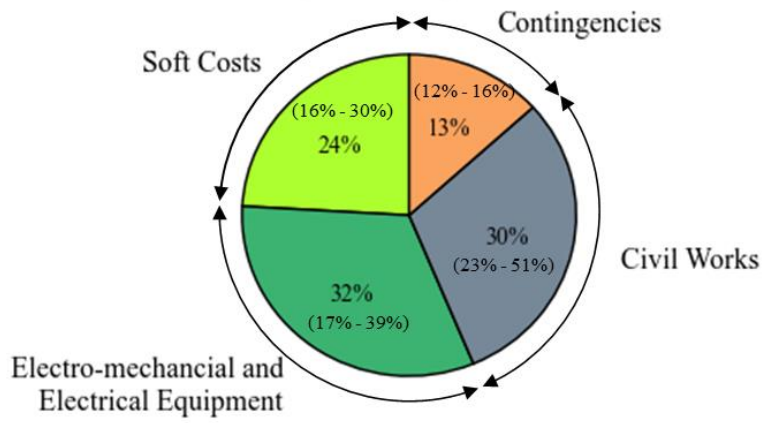

Figure 9. Simulated project cost category (right) validated against conventional PSH cost categories (left). Average distribution is shown in each pie, with the min and max observed values shown in parenthesis.

Table 4. Definition of cost categories for comparison in Figure 9.

\begin{tabular}{|c|c|c|}
\hline Category Name & Knight Piésold (2011) & Cost Model Simulation \\
\hline Contingencies & Contingency & Contingency \\
\hline Civil Works & Construction costs & Civil works \\
\hline $\begin{array}{l}\text { Electro-mechanical and } \\
\text { Electrical Equipment }\end{array}$ & $\begin{array}{l}\text { Generating equipment and } \\
\text { switchyard }\end{array}$ & $\begin{array}{c}\text { Electro-mechanical equipment, } \\
\text { electrical equipment }\end{array}$ \\
\hline Soft Costs & $\begin{array}{l}\text { Owner's costs, Mobilization, } \\
\text { Demobilization, Insurance, } \\
\text { Bonds, Overhead, Contractor's } \\
\text { Profits, Permitting and Design }\end{array}$ & $\begin{array}{l}\text { Engineering Construction Management, } \\
\text { Environmental Mitigation and } \\
\text { Regulatory Compliance, Development }\end{array}$ \\
\hline
\end{tabular}

\subsection{COST MODEL SENSITIVITY TO ESCALATION}

Component level cost data used to develop the cost model is obtained from a wide variety of sources with original cost estimate dates that range from around 1980 up through 2015 (see Appendix A). In many cases, a comprehensive study carried out many years ago provides the most reliable, scalable, and relevant cost estimate (see e.g., USBR, 1980). Escalation of these component costs is the means by which historical estimates are updated to reflect modern cost realities. Common cost indices used for escalating construction activity and equipment costs for large infrastructure projects (including hydropower) are:

1. USBR Structures (USBR, 2016);

2. USBR Equipment (USBR, 2016);

3. USBR Composite (USBR, 2016);

4. Engineering News Record (ENR) Construction Cost Indices (ENR, 2016);

5. U.S. Consumer Price Index (CPI) (BLS, 2016). 
More detail on cost escalation indices can be found in Appendix A Section A.2. The m-PSH cost model primarily uses USBR Structures for civil works cost escalation, USBR Equipment for electromechanical and electrical equipment cost escalation, and CPI for environmental mitigation, regulatory compliance, and development cost escalation. The impact of different escalation indices over various years is shown in Table 5, with the maximum escalation difference identified on the right. The impact of escalation index choice generally varies from the minimum index to the maximum index by between $12 \%$ and $24 \%$ depending on the year. The USBR structures index tends to fall near the mean to the high end in most years, with the exception of 1980, when it is the lowest of all indices.

Table 5. Cost escalation index comparison for various years. Minimum values are highlighted in gray, maximum value cells are highlighted in red.

\begin{tabular}{cccccccc}
\hline Year & $\begin{array}{c}\text { USBR } \\
\text { Structures }\end{array}$ & $\begin{array}{c}\text { USBR } \\
\text { Equipment }\end{array}$ & $\begin{array}{c}\text { USBR } \\
\text { Composite }\end{array}$ & $\begin{array}{c}\text { USACE } \\
\text { Composite }\end{array}$ & ENR & CPI & $\begin{array}{c}\text { Maximum } \\
\text { Escalation } \\
\text { Difference }\end{array}$ \\
\hline $\mathbf{1 9 8 0}$ & 2.78 & 2.87 & 2.94 & 2.81 & 3.10 & 2.88 & $\mathbf{1 2 \%}$ \\
\hline $\mathbf{1 9 8 5}$ & 2.38 & 2.23 & 2.43 & 2.28 & 2.39 & 2.20 & $\mathbf{1 0 \%}$ \\
\hline $\mathbf{1 9 9 0}$ & 2.17 & 1.86 & 2.13 & 2.01 & 2.12 & 1.81 & $\mathbf{2 0 \%}$ \\
\hline $\mathbf{1 9 9 5}$ & 1.89 & 1.62 & 1.86 & 1.77 & 1.83 & 1.56 & $\mathbf{2 1 \%}$ \\
\hline $\mathbf{2 0 0 0}$ & 1.64 & 1.52 & 1.65 & 1.62 & 1.61 & 1.38 & $\mathbf{2 0 \%}$ \\
\hline $\mathbf{2 0 0 5}$ & 1.34 & 1.35 & 1.35 & 1.31 & 1.35 & 1.21 & $\mathbf{1 2 \%}$ \\
\hline $\mathbf{2 0 1 0}$ & 1.13 & 1.11 & 1.13 & 1.10 & 1.12 & 1.09 & $\mathbf{4 \%}$ \\
\hline $\mathbf{2 0 1 5}$ & 1.00 & 1.00 & 1.00 & 1.00 & 1.00 & 1.00 & $\mathbf{0 \%}$ \\
\hline
\end{tabular}

*Maximum escalation difference is defined as the percentage increase in escalated cost from the minimum of all escalation index values to the maximum of all escalation index values for a given year.

Because of the wide disparity in original cost estimate years, the variety of potential escalation comparisons, the relevance of different indices to different components of project cost, and the use of the highest and lowest reported escalation index in some cases, it is assumed that maximum escalation uncertainty varies between $5 \%$ and $12 \%$.

\subsection{ECONOMIC MODEL VALIDATION}

The predicted LCOS of simulated projects is compared with industry estimates of LCOS for conventional PSH and other transmission scale technologies in Figure 10. Note the model includes the model validation assumptions outlined in Section 4.2 and the economic assumptions from Section 3.4, while the industry estimate includes only projects with $100 \mathrm{MW}$ of capacity and 8 hours of storage. The modeled LCOS of $\$ 172 / \mathrm{MWh}$ to $\$ 269 / \mathrm{MWh}$ is very closely aligned with the predicted range of conventional PSH technologies, and as expected, is significantly below transmission scale battery storage technologies.

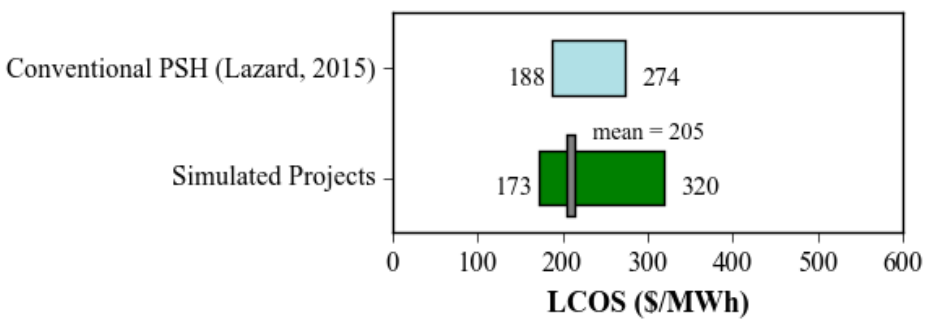

Figure 10. LCOS prediction of simulated projects with installed capacity $<500 \mathrm{MW}$ compared to industry estimated of LCOS for various transmission scale energy storage technologies (Lazard, 2015). 


\section{TEST CASE ANALYSIS}

The development of m-PSH projects may occur at a variety of scales, storage volumes, storage times, and installed capacities. Modular PSH technology is not limited by size, storage time, scalability, response time, or equipment requirements - turbine/generators and pump/motors exist today at scales appropriate for m-PSH development. The cost to build a project is the single largest inhibitor of m-PSH deployment. And the cost to build a project consists largely of the cost of storage. The existing fleet was built by taking advantage of economies of scale in construction and by using sites with some degree of existing storage infrastructure. The former assumption is not valid for m-PSH scale projects, and it is unclear the degree to which the latter assumption affects project feasibility. As a basic example, the model is used to simulate projects with capacities of less than $100 \mathrm{MW}$ using all assumptions outlined in Section 4.2, and then under the assumption that both reservoirs require the full storage volume to be excavated for both reservoirs (Figure 11). In both cases the penstock length to height ratio $(\mathrm{L}: \mathrm{H})$ is held constant at 6 and storage time at 10 hours. When upper and lower reservoirs need to be excavated from flat surfaces, $\mathrm{m}$ PSH project costs are simulated between $\$ 6,000 / \mathrm{kW}$ to $\$ 12,000 / \mathrm{kW}$ depending on capacity, head, and storage characteristics. These costs are nearly double the cost of projects developed where existing shallow depressions or excavated basins exist. It is evident that Greenfield m-PSH development that scales down the conventional PSH development paradigm requires innovation and cost reductions in the storage of water to achieve economic viability.
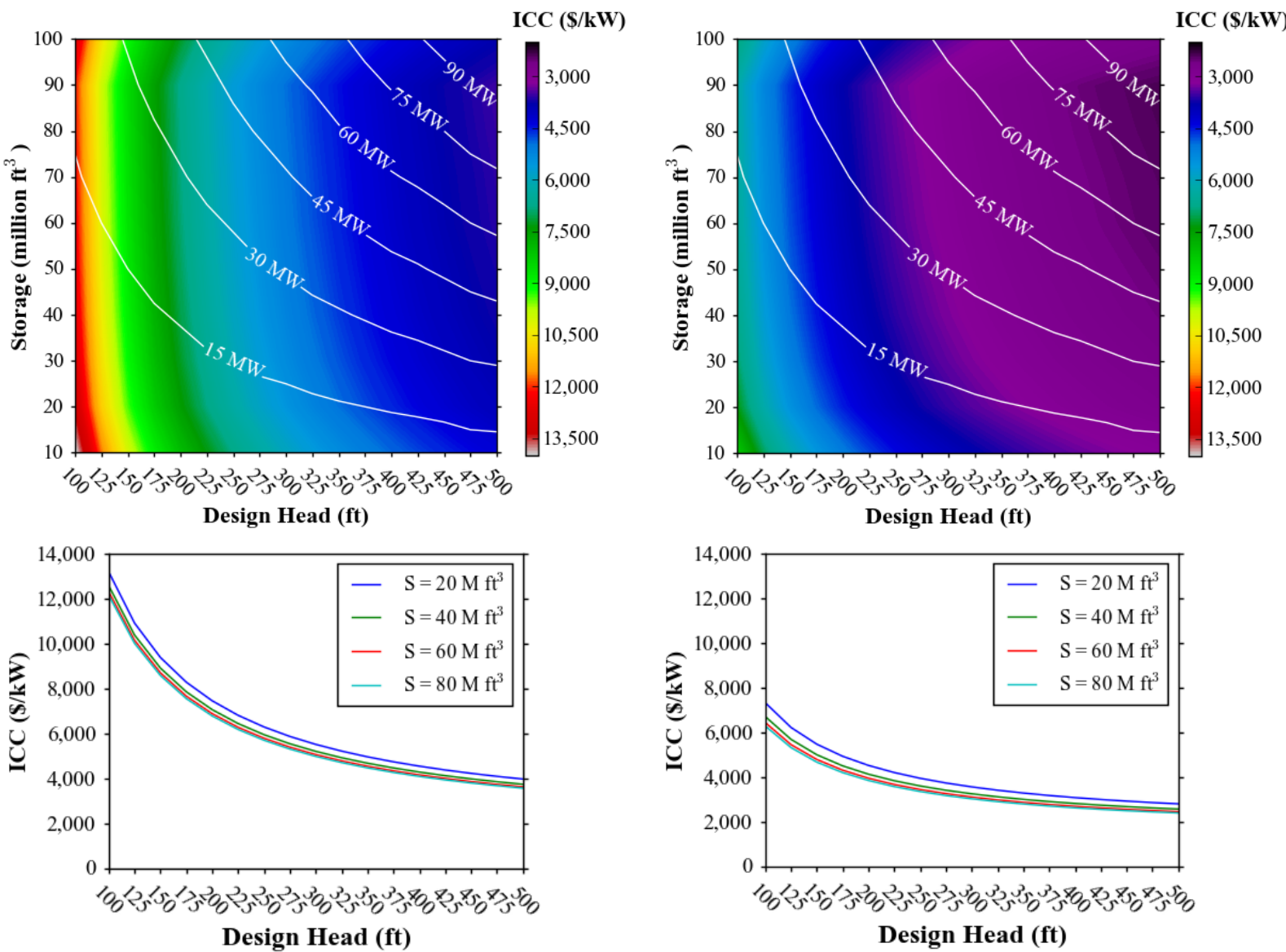

Figure 11. Simulated ICC of m-PSH projects with installed capacity of $<100 \mathrm{MW}$ : assuming construction of a new upper and lower reservoir (top left) and assuming an upper reservoir is a refurbishment of existing storage infrastructure, and the lower reservoir is largely in place (top right). Corresponding line plots at various storage volumes and head are shown below the contour plots. 
Siting m-PSH where some sort of storage infrastructure already exists is an attractive and cost effective means to lower the cost of civil works and construction. This idea is not novel - most conventional PSH projects within the existing US fleet use an existing quarry, mine, or natural reservoir for the lower storage reservoir (MWH, 2009). Under this paradigm, costs associated with storage ranges from $\$ 2,000$ to $\$ 20,000 /$ acre-ft $(\$ 0.052$ to $\$ 0.52 / \mathrm{ft} 3$ in $\$ 2015$ ). To provide some perspective, storage costs within the m-PSH model are calculated and shown in Figure 12 for a variety of storage volumes (S) (10, 20, and 30 million $\mathrm{ft}^{3}$ ), reservoir depth (50, 70, and $90 \mathrm{ft}$ ), and reservoir status (New, Refurbishment, Existing), where status refers to the percentage of material that needs to be excavated $(100 \%, 50 \%$, and $20 \%$, respectively). It is clear that under all cases, the cost of developing new reservoirs is approximately $50 \%$ to $100 \%$ greater than the target cost (i.e., upper end cost of conventional PSH storage) depending on the depth of the reservoir. In all cases, if at least $50 \%$ of the storage volume is already excavated, the storage cost target could be achieved.

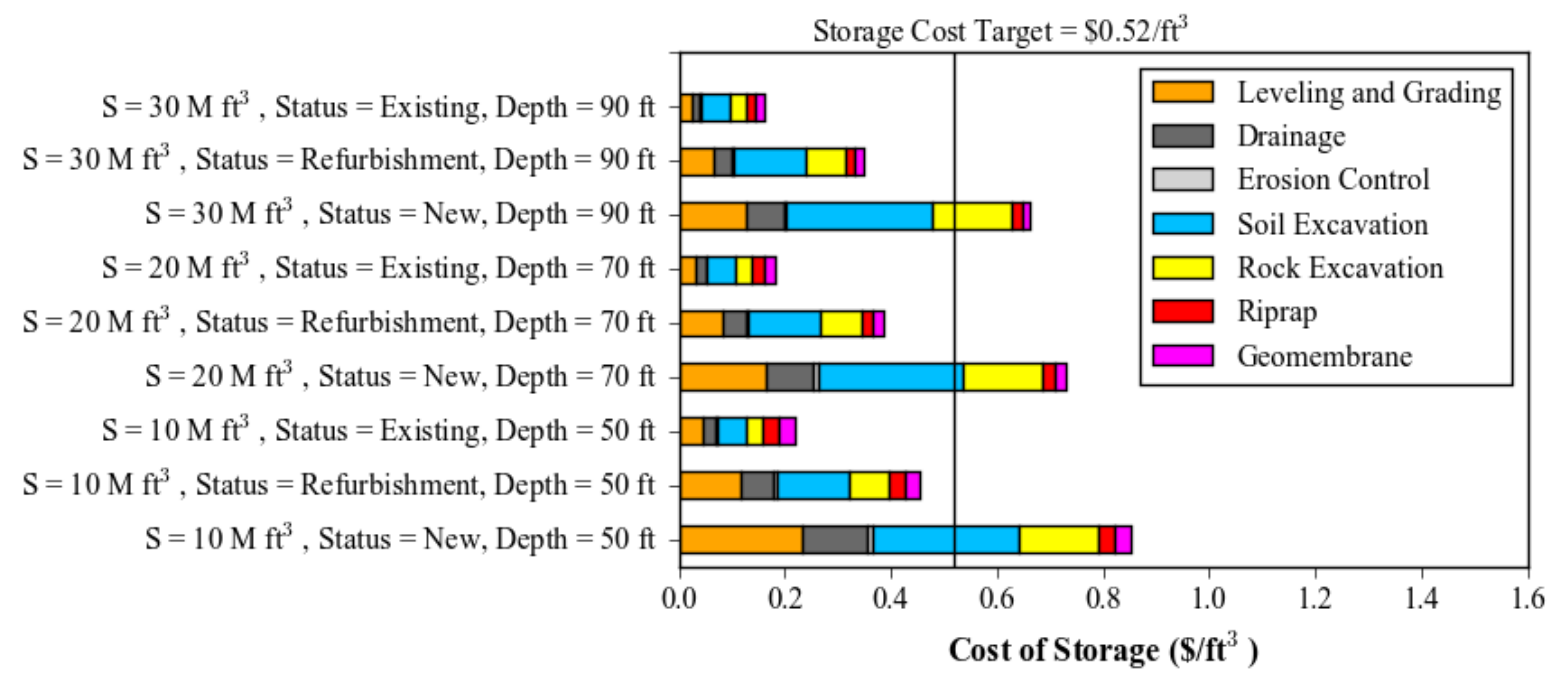

Figure 12. Costs of developing an m-PSH reservoir under different scenarios.

To enable a systematic assessment of cost model outputs, three separate test case analyses are developed and simulated. Each test case is presented in terms of ICC, cost distribution among all project categories, and LCOS. The test cases are defined on storage infrastructure merits alone. Previous case studies on the viability of $\mathrm{m}$-PSH have noted the substantial improvement in feasibility if a project is sited near some existing storage infrastructure (Witt et al., 2015). A recent European pumped storage development potential assessment also limited their analysis to sites where existing reservoirs or storage capacity was available (Gimeno-Gutiérrez \& Lacal-Arántegui, 2013). In this study, a control test case is included for reference that assumes new development of upper and lower reservoirs. Two additional test cases include tiered levels of existing storage infrastructure (Table 6).

Table 6. Definition of test cases.

\begin{tabular}{ll}
\hline & Test Case Description \\
\hline Test Case 1 (T1) & New upper and lower reservoir \\
\hline Test Case 2 (T2) & Refurbishment of upper reservoir and refurbishment of lower reservoir \\
\hline Test Case 3 (T3) & Existing upper reservoir and existing lower reservoir \\
\hline
\end{tabular}


For each test case, 1,000 projects are simulated with installed capacities below $100 \mathrm{MW}$ and storage time of 4 hours and 8 hours. A range of possible design heads and storage volumes is defined separately for each case, dependent on the amount of storage capacity desired (Figure 13).
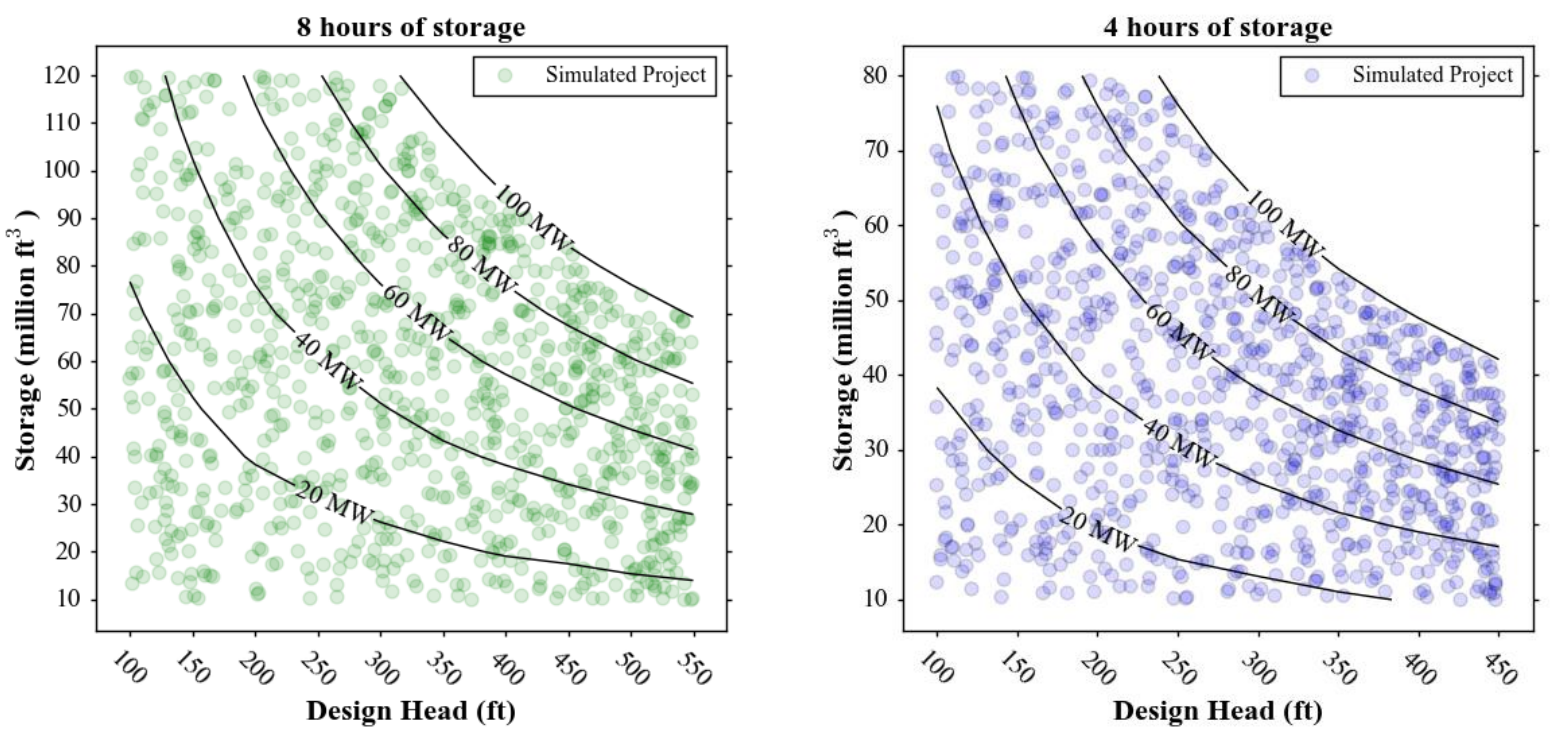

Figure 13. Representation of simulated m-PSH projects with 8 hours of storage (left) and 4 hours of storage (right). Note the difference in installed capacity associated with design head and storage volume of each project design.

Each test case is subject to common project input variables or upper limits on project design variables (Table 7). These assumptions are designed to limit the number of design possibilities, to enable development of a project with standardized equipment, and to reflect the realistic conditions under which an $\mathrm{m}-\mathrm{PSH}$ project is expected to be developed. If the assumption is given as a range, a number within that range will be assigned randomly to a given project.

Table 7. Test case major design assumptions.

\begin{tabular}{lll}
\hline Filter Category & Filter & Filter Description \\
\hline Penstock diameter & Maximum of 12ft & $\begin{array}{l}\text { Standardized penstock diameters are generally } \\
\text { available below 12ft diameter }\end{array}$ \\
\hline Transmission voltage & $15 \mathrm{kV}$ & $\begin{array}{l}\text { m-PSH projects that require significant } \\
\text { transmission voltage reflect custom sites }\end{array}$ \\
\hline Transmission line length & $2<T_{L}<10$ miles & $\begin{array}{l}\text { m-PSH projects are envisioned not as remote } \\
\text { projects but as tying into existing grid systems } \\
\text { without the need for extensive transmission lines }\end{array}$ \\
\hline $\begin{array}{l}\text { Penstock } \\
\text { length:height } \\
\text { ratio }\end{array}$ & $4<\mathrm{L}: \mathrm{H}<8$ & $\begin{array}{l}\text { The length of penstock is bounded to reflect sites } \\
\text { that are more likely to be developed, that would } \\
\text { not require extensive approval for long penstocks, } \\
\text { and that would likely not require extensive costs } \\
\text { for surge protection }\end{array}$ \\
\hline Site access road length & 2 miles $<L_{r}<5$ miles & $\begin{array}{l}\text { Site access road length is bounded to reflect sites } \\
\text { that are relatively close major load centers and do } \\
\text { not require special accommodation for heavy } \\
\text { equipment }\end{array}$ \\
\hline
\end{tabular}




\subsection{TEST CASE 1}

Test Case 1 represents locations where no existing storage works are in place, and full excavation of two reservoirs is necessary.

For 8 hours of storage, project costs do not get below $\$ 6,000 / \mathrm{kW}$ until the design head rises above $250 \mathrm{ft}$, regardless of the power output of the site (Figure 14, left). Given the same storage volume, energy density will increase with head, and thus more power can be obtained from the same volume of storage. For a given power output, costs may vary dramatically depending on head and storage volume. At 20 MW of installed capacity, for example, ICC spans a range of $\$ 12,000 / \mathrm{kW}$ to $\$ 4,000 / \mathrm{kW}$ with costs decreasing as head increases, a result of a decreased need for storage volume. At 4 hours of storage, reservoir volume requirements are reduced and ICC is substantially lower (Figure 14, right). The ICC spread for a single installed capacity is also lower than the 8 hours case. The main driver in ICC reduction is the smaller volume of storage needed to accommodate the smaller storage time at the same power capacity.
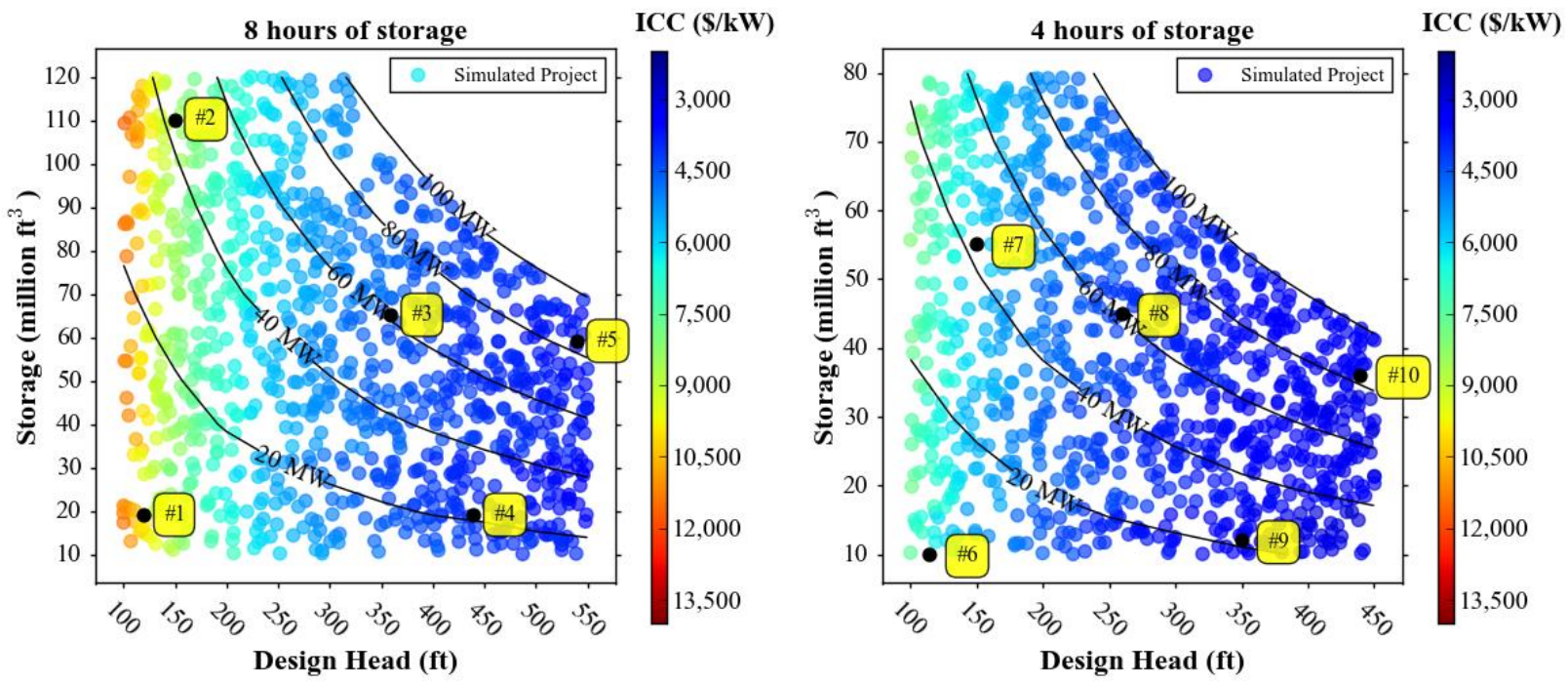

Figure 14. Cost estimates for Test Case 1 with 8 hours of storage (left) and 4 hours of storage (right).

A bar plot of individual categories (Figure 15) provides some insight into the cost distributions of the test points identified in Figure 14. The test points are chosen with head and storage volume combinations that produce roughly the same generating capacity for each storage time scenario. At 8 hours of storage and low head (test points \#1, \#3), the individual reservoir costs are nearly 2.5 times that of any other major cost category, and greater than $50 \%$ of the overall project cost. The cost of pump/turbines also becomes an increasingly larger portion of overall project cost, and is largest when high flow rates at lower relative heads are required (test point \#2), leading to larger turbine runner diameters. As head increases, storage costs see a significant decrease on a $\$ / \mathrm{kW}$ basis, and project costs overall become more evenly distributed among multiple categories. The reduction in storage costs when storage time is reduced is apparent (test points \#6-10). Storage costs still dominate overall project costs at low head and low power (test points \#6, \#7), but pump/turbine costs are generally a much larger portion of project costs. This dynamic is understood by comparing points \#5 and \#10, each with a generating capacity of roughly $82 \mathrm{MW}$. At a higher head and with more storage time (\#5), a smaller penstock, design flow, and, consequently, turbine runner diameter, can be expected, leading to a slightly lower pump/turbine cost. At a lower head with less storage time (\#10), pump/turbine costs are increased and become the largest category cost. 


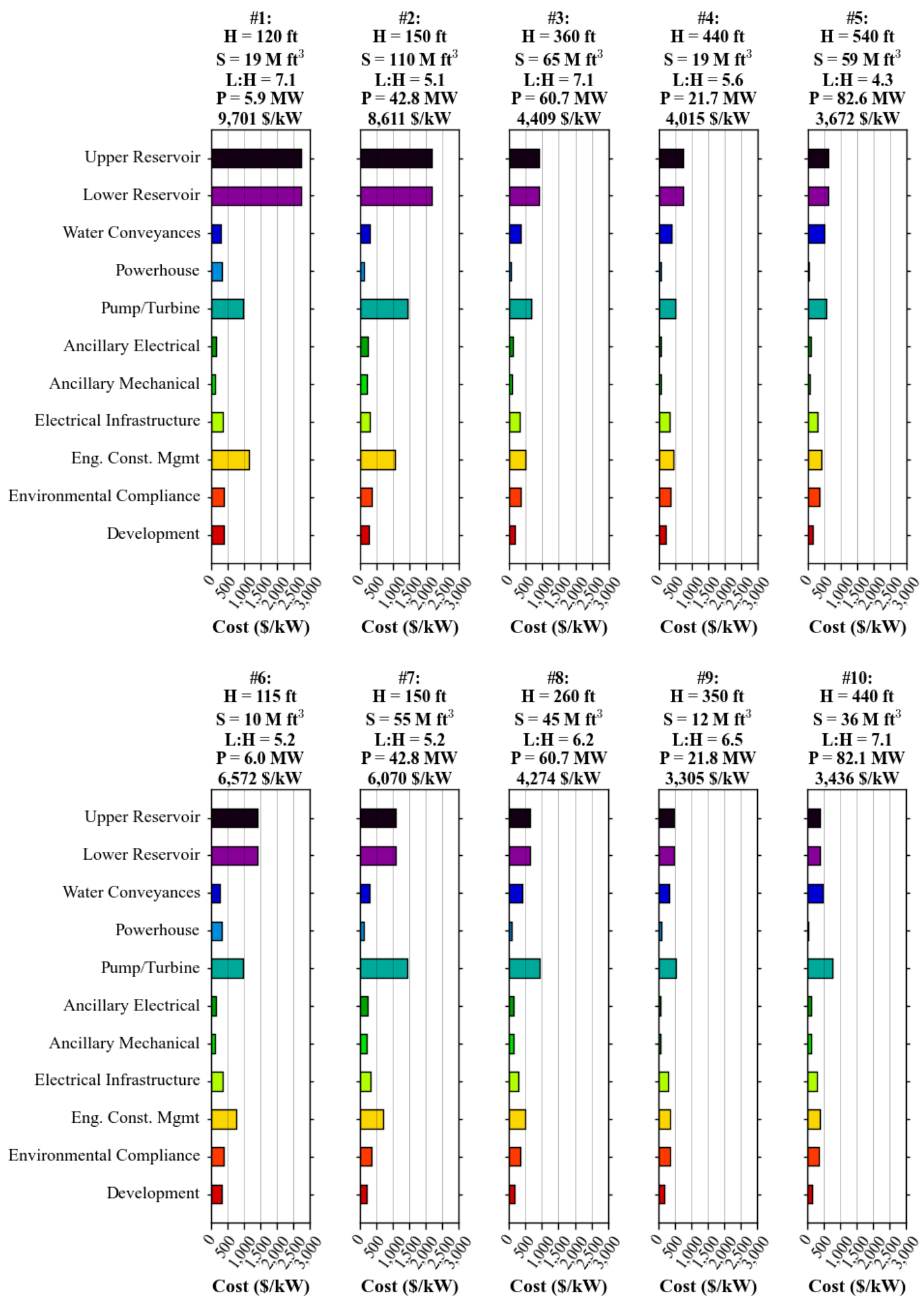

Figure 15. Cost category estimates for test points in Test Case 1 with 8 hours of storage (top) and 4 hours of storage (bottom). Civil works, electro-mechanical equipment, and electrical equipment categories include contingencies. 
The ICC in $\$ / \mathrm{kW}$ of both storage time simulations of Test Case 1 is shown in Figure 16 compared to the ICC of conventional PSH as reported in EPRI (2010). At 8 hours of storage, projects with greater than $500 \mathrm{ft}$ of head approach the estimated ICC of conventional projects. ICC at lower heads of $100 \mathrm{ft}$ can be double or triple that of ICC at heads greater than $400 \mathrm{ft}$ for the same generating capacity. With 4 hours of storage, ICC in $\$ / \mathrm{kW}$ is relatively much lower, for the same generating capacity. The reduced storage requirement results in a smaller reservoir storage need, which decreases ICC overall. The trend independent of storage time is that higher head results in lower ICC regardless of installed capacity.
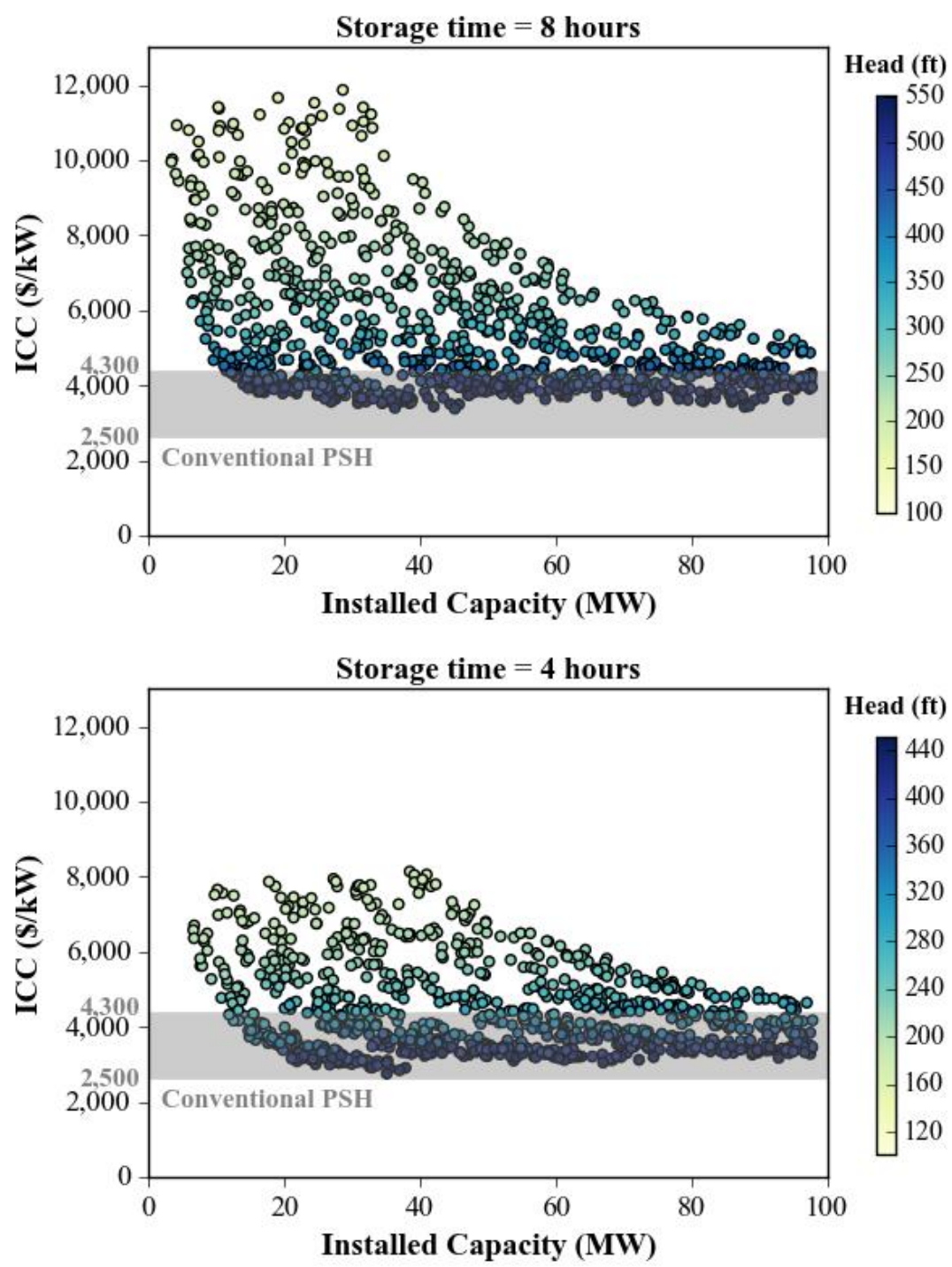

Figure 16. ICC estimates for Test Case 1 in $\$ / \mathrm{kW}$ for 8 (top) and 4 (bottom) hours of storage. Gray line indicates the ICC estimate of conventional PSH projects (EPRI, 2010). 
The ICC in $\$ / \mathrm{kWh}$ of both storage time simulations of Test Case 1 is shown in Figure 17 compared to the ICC of conventional PSH as reported in EPRI (2010). At 8 hours of storage, projects with greater than $500 \mathrm{ft}$ of head approach the estimated ICC of conventional projects. ICC at lower heads of $100 \mathrm{ft}$ can be double or triple that of ICC at heads greater than $400 \mathrm{ft}$ for the same generating capacity. With 4 hours of storage, ICC in $\$ / \mathrm{kWh}$ is relatively much higher, as expected, for the same generating capacity compared to 8 hours of storage. The reduced number of hours over which to spread the total absolute dollars of initial capital cost translates into a higher cost in $\$ / \mathrm{kWh}$ per MW of generating capacity.
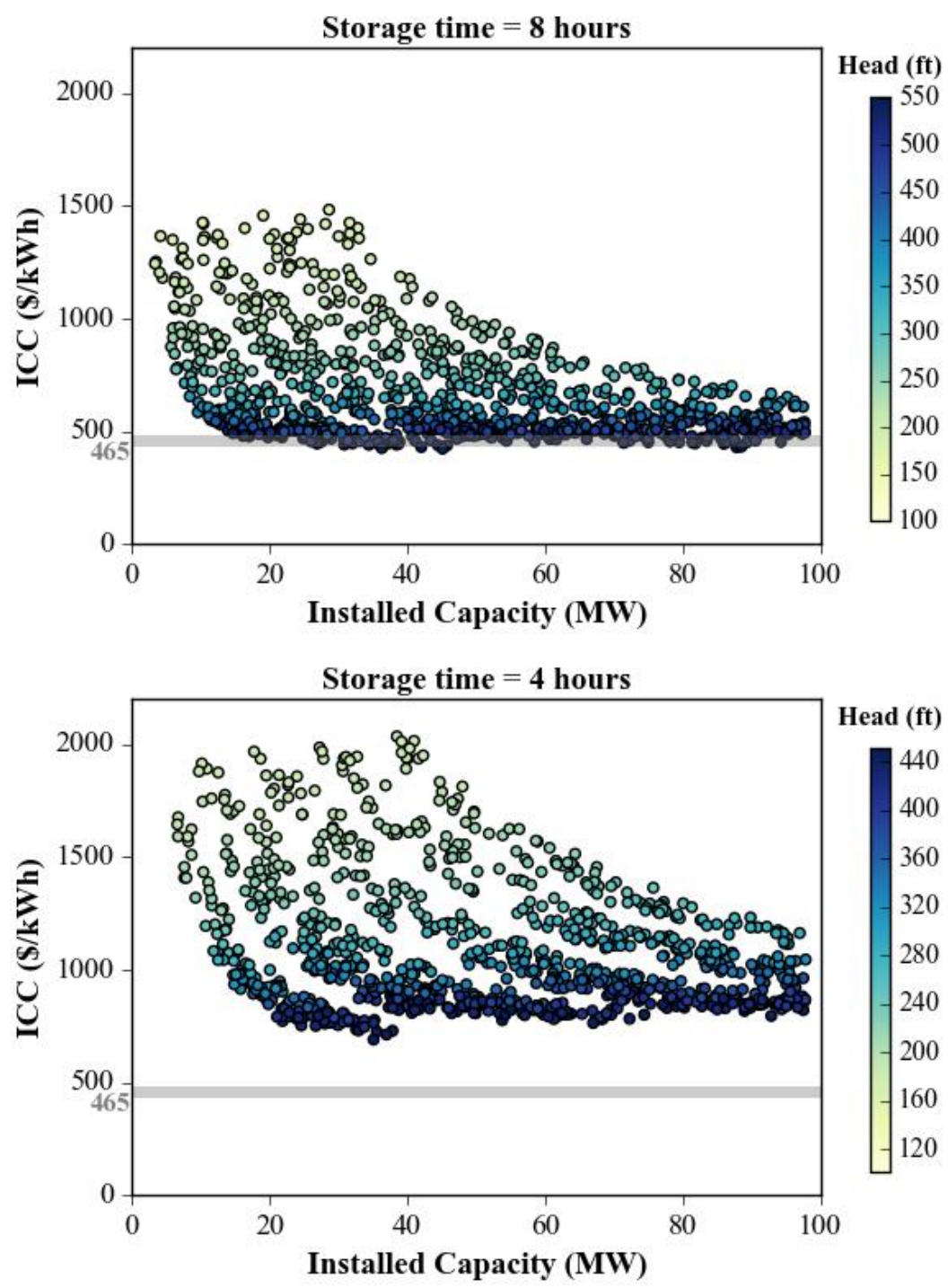

Figure 17. ICC estimates for Test Case 1 in $\$ / \mathrm{kWh}$ for 8 (top) and 4 (bottom) hours of storage. Gray line indicates the ICC estimate of conventional PSH projects (EPRI, 2010). 
The LCOS of both storage time simulations of Test Case 1 is shown in Figure 18, compared with an estimate of conventional PSH LCOS (Lazard, 2015). This most notable trend is greater storage time results in lower LCOS. This is predominantly due to the increased amount of project storage capacity that is used to levelize capital and operating costs - more storage time results in more MWh produced in a given year and over the project lifetime. The additional MWh for 8 hours of storage has a greater impact on LCOS than the lower ICC observed in the 4 hours of storage projects. As is the case for ICC, the greatest driver in lowering the LCOS appears to be increasing head, for a given installed capacity. In the 4 hour case, all simulated points are well above the band of conventional PSH LCOS, due to the increased capital costs compared to conventional projects. However, the 8 hours of storage case shows several projects competitive on an LCOS basis with conventional PSH, from less than $20 \mathrm{MW}$ to $100 \mathrm{MW}$. All of these projects are in the range of $450 \mathrm{ft}$ of head or higher, where ICC is more favorable.
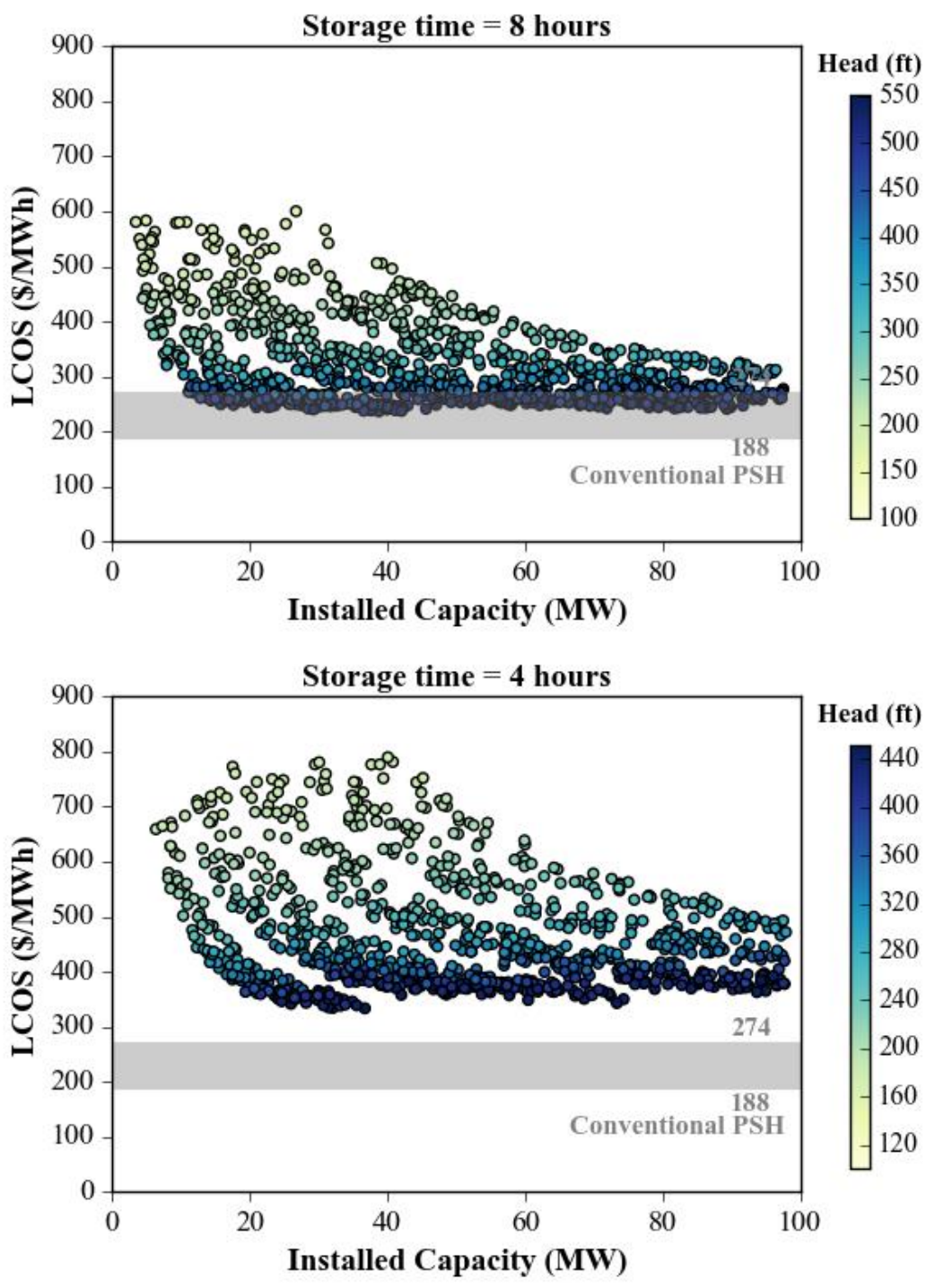

Figure 18. LCOS estimates in \$/MWh for Test Case 1 with 8 (top) and 4 (bottom) hours of storage. 


\subsection{TEST CASE 2}

Test Case 2 represents locations where some storage works are in place for both the upper and lower reservoirs, and only $50 \%$ of the storage volume excavation burden is necessary for each reservoir.

As expected, a general reduction in ICC is observed for Test Case 2 compared to Test Case 1, while the same general cost trends are maintained. For 8 hours of storage, project costs generally fall below $\$ 6,000 / \mathrm{kW}$ at design heads greater than $150 \mathrm{ft}$ (Figure 19, left), compared to the transition at $250 \mathrm{ft}$ in Test Case 1. The high cost of storage persists at low relative heads even if half of the storage volume is already excavated or in place. At higher relative head, projects converge towards $\$ 3,000 / \mathrm{kW}$ to $\$ 4,000 / \mathrm{kW}$ for both 4 hours of storage and 8 hours of storage, highlighting the dominance of non-storage costs as head is increased.
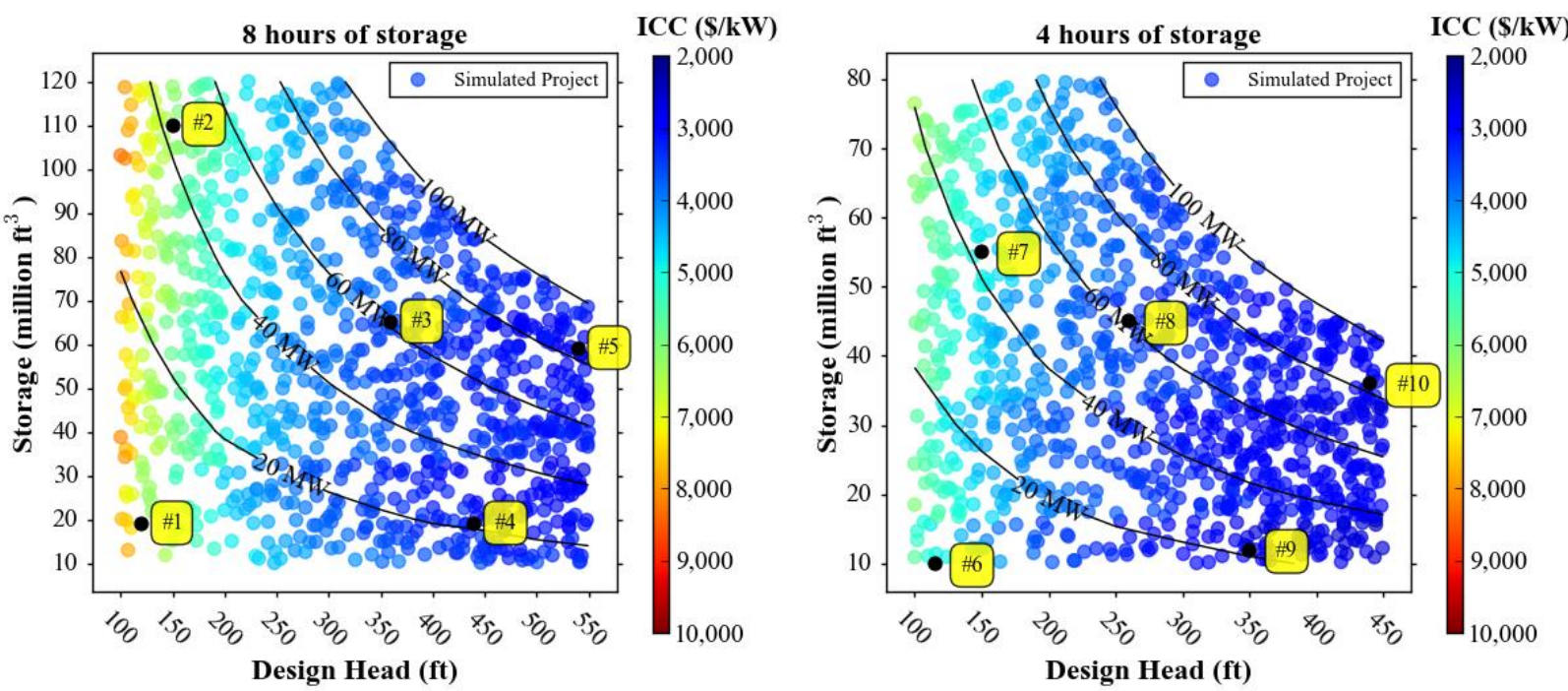

Figure 19. ICC estimates for Test Case 2 with 8 hours of storage (left) and 4 hours of storage (right).

A bar plot of individual categories (Figure 20) provides some insight into the cost distributions of the Test Case 2 test points identified in Figure 19. At low relative heads (points \#1, \#2), storage costs continue to dominate ICC. However, test point \#1 is the only point where storage costs are greater than electromechanical equipment costs for either 8 hours or 4 hours of storage. In nearly every Test Case 2 test point, the pump-turbine becomes the largest cost category. This is especially noticeable at lower relative head, medium relative power, and higher relative storage volume test points (\#2, \#7). In these cases, high flow capacities are required, which generally dictate larger turbines and a larger water conveyance. The relative cost of conveyance is increased as head and power capacity are increased, and water conveyance costs surpass reservoir costs above approximately $250 \mathrm{ft}$ of head. 


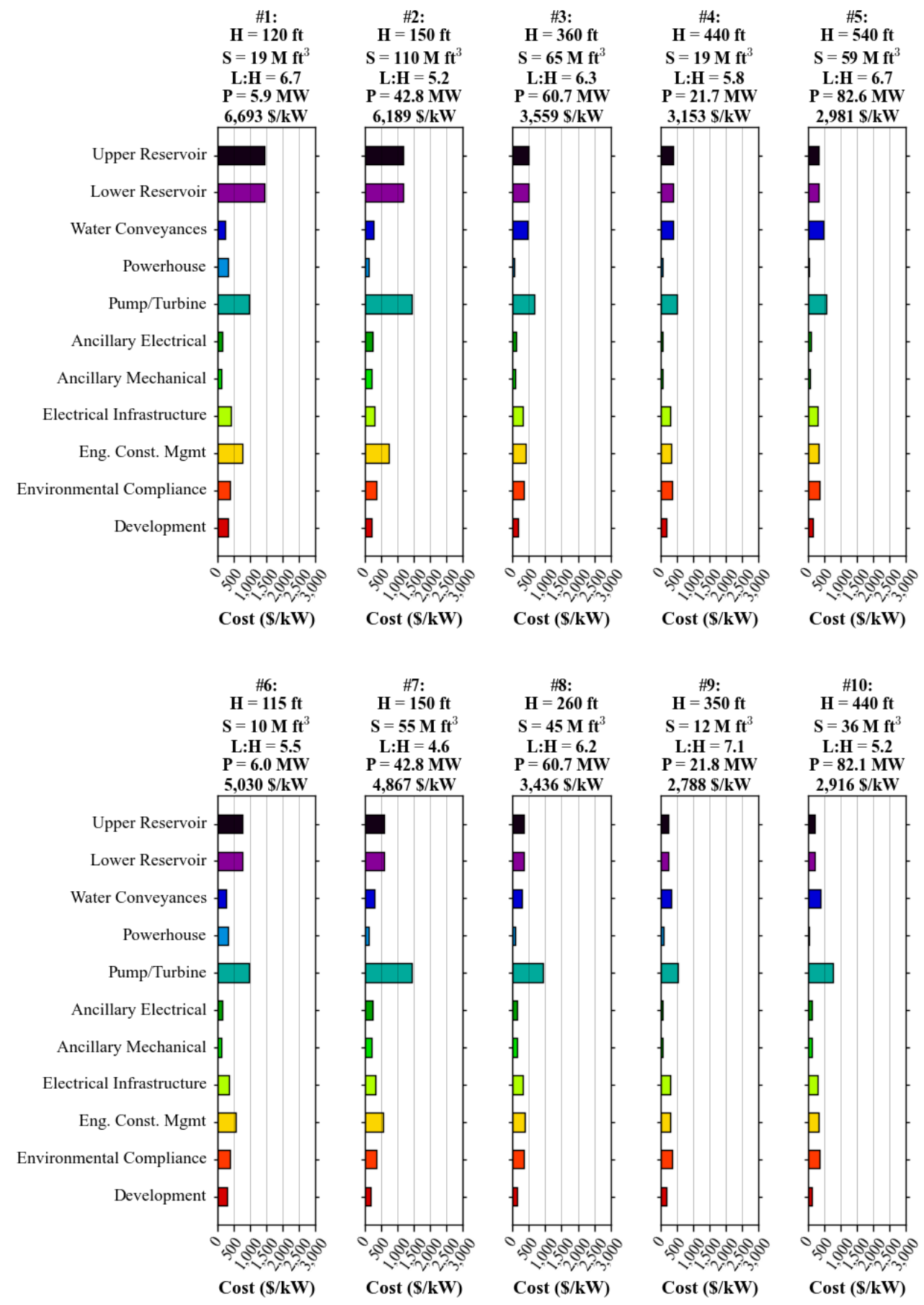

Figure 20. Cost category estimates for test points in Test Case 2 with 8 hours of storage (top) and 4 hours of storage (bottom). Civil works, electro-mechanical equipment, and electrical equipment categories include contingencies. 
The ICC in $\$ / \mathrm{kW}$ of both storage time simulations of Test Case 2 is shown in Figure 22 compared to the ICC of conventional PSH as reported in EPRI (2010). Simulated projects with 8 hours of storage fall within the conventional ICC range at many capacities as long as the design head greater than roughly 300 $\mathrm{ft}$. For 4 hours of storage, more simulated projects fall within the conventional range of ICC due to the lower storage cost burden at a comparable installed capacity.
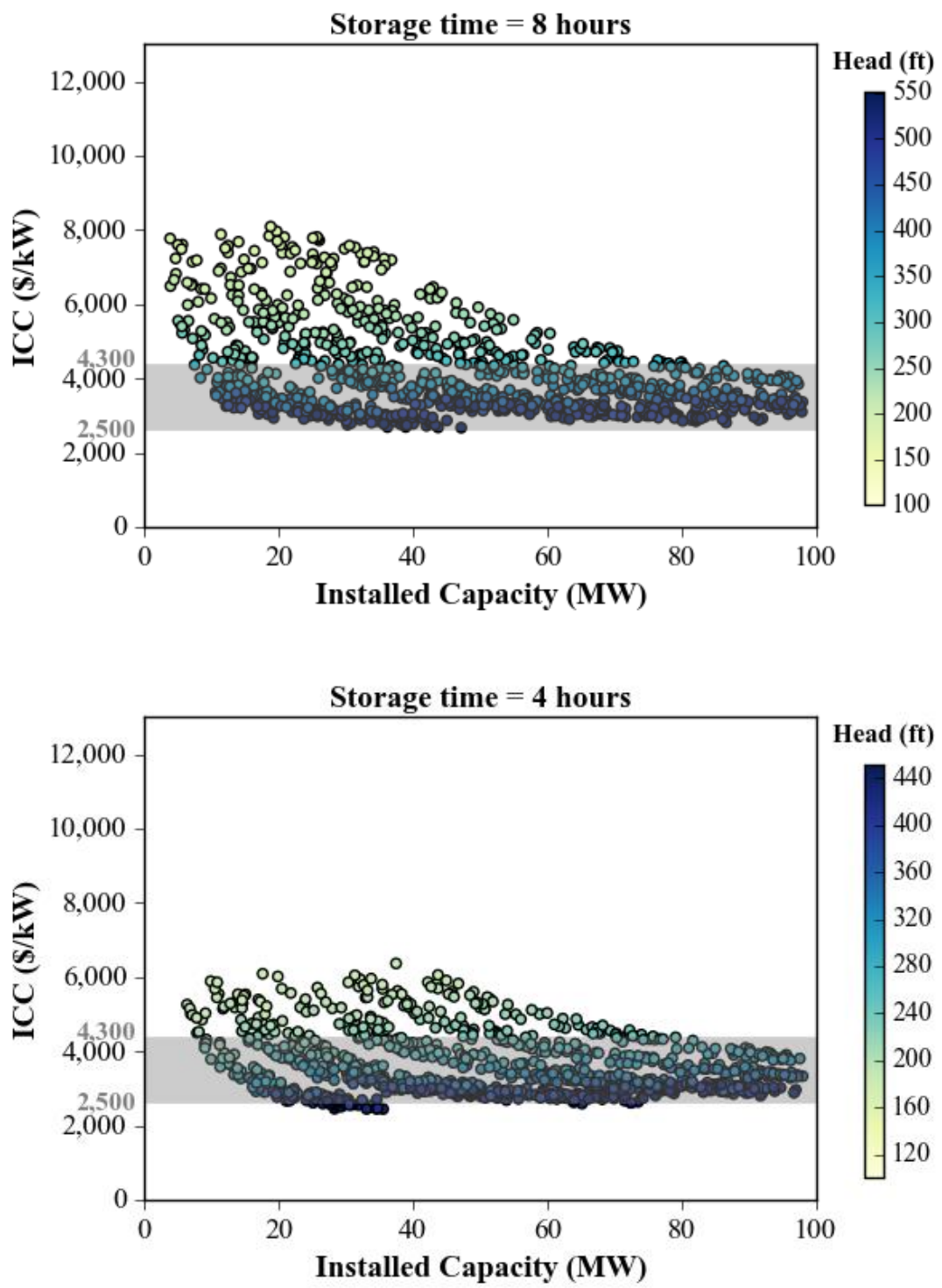

Figure 21. ICC estimates for Test Case 2 in $\$ / \mathrm{kW}$ for 8 (top) and 4 (bottom) hours of storage. Gray line indicates the ICC estimate of conventional PSH projects (EPRI, 2010). 
The ICC in $\$ / \mathrm{kWh}$ of both storage time simulations of Test Case 2 is shown in Figure 22 compared to the ICC of conventional PSH as reported in EPRI (2010). At 8 hours of storage, simulated projects with design head greater than approximately $450 \mathrm{ft}$ show a comparable ICC in $\$ / \mathrm{kWh}$ to conventional projects. At 4 hours of storage, no simulated projects show a comparable ICC in $\$ / \mathrm{kWh}$ to conventional projects. This is not surprising, given the storage times of hours to even days associated with the current PSH fleet.
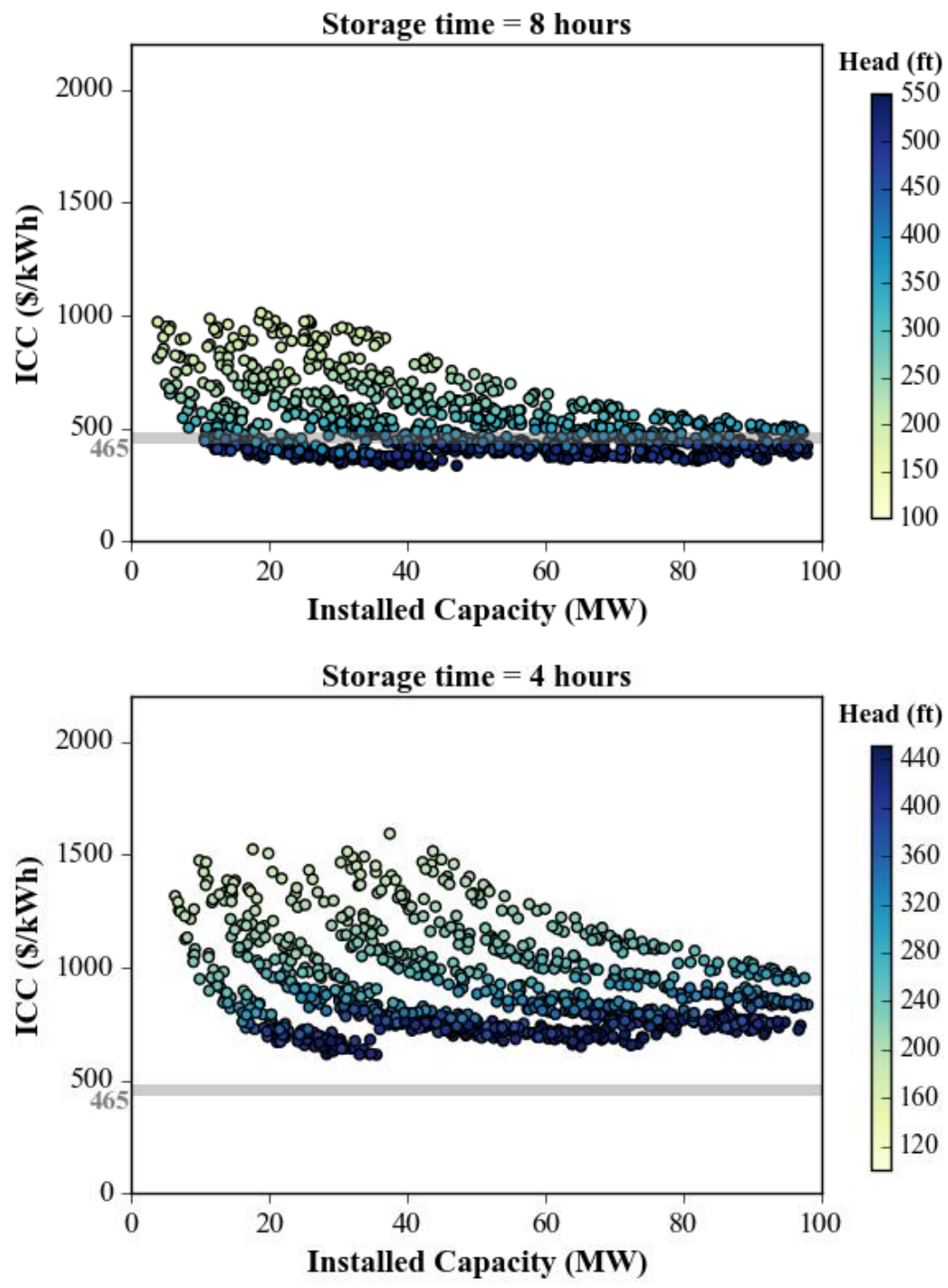

Figure 22. ICC estimates for Test Case 2 in $\$ / \mathrm{kWh}$ for 8 (top) and 4 (bottom) hours of storage. Gray line indicates the ICC estimate of conventional PSH projects (EPRI, 2010). 
The LCOS of both storage time simulations of Test Case 2 is shown in Figure 23 compared with analyst estimates of LCOS for conventional PSH (Lazard, 2015). The results are similar to the ICC in $\$ / \mathrm{kWh}$ analysis, in that more storage time per given capacity reduces the overall (levelized) cost and brings some projects in line with estimates for existing conventional PSH.
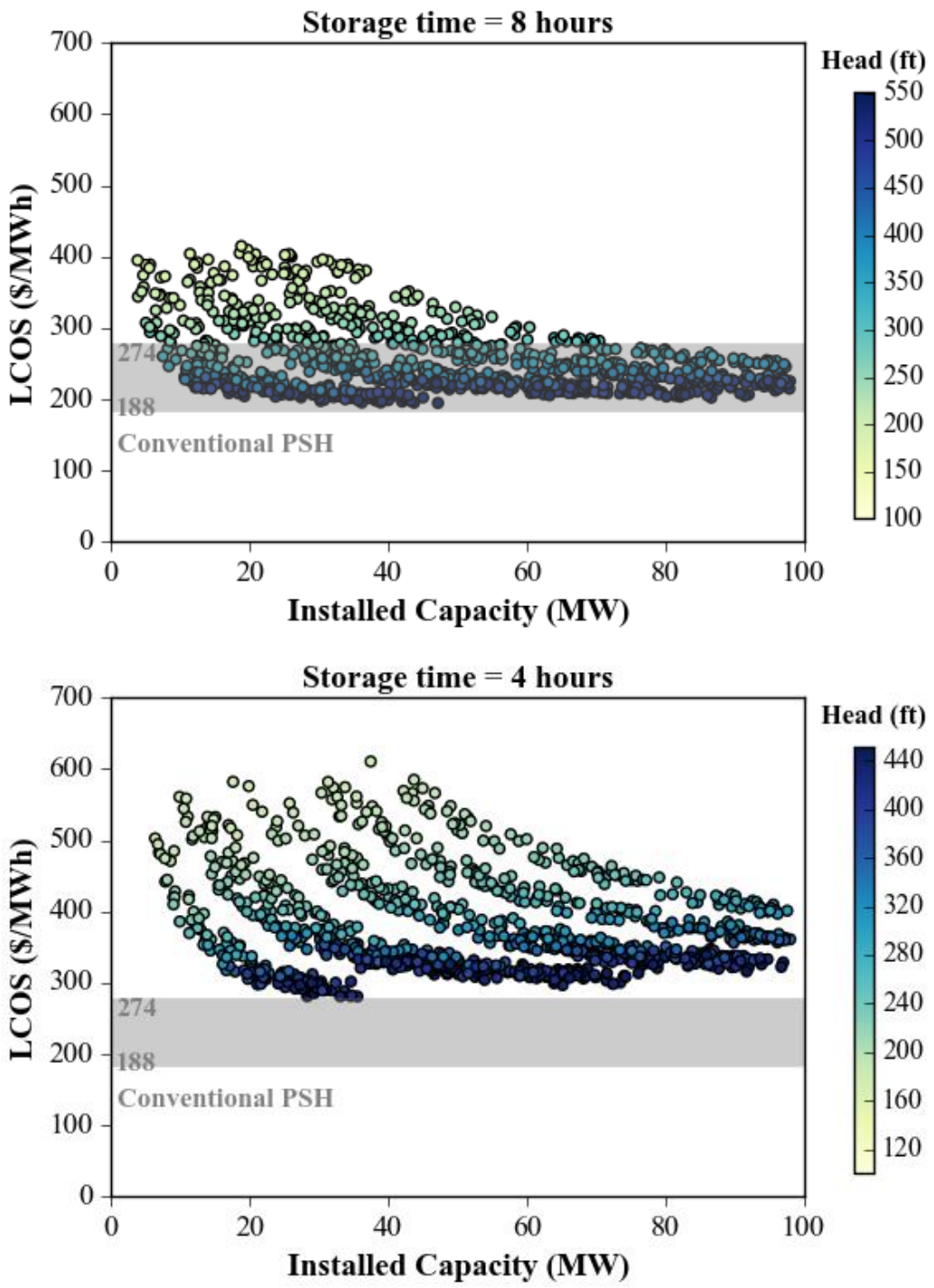

Figure 23. LCOS estimates in \$/MWh for Test Case 2 with 8 (top) and 4 (bottom) hours of storage. 


\subsection{TEST CASE 3}

Test Case 3 represents locations where substantial storage infrastructure is in place for both the upper and lower reservoirs, and only $20 \%$ of the storage volume excavation burden is necessary for each reservoir.

A subsequent reduction in ICC is observed for Test Case 3 compared to previous cases, while the same general cost trends are maintained. For 8 hours of storage, project costs generally fall below $\$ 6,000 / \mathrm{kW}$ at design heads greater than around $100 \mathrm{ft}-150 \mathrm{ft}$, (Figure 24, left), compared to $150 \mathrm{ft}$ in Test Case 2 and $250 \mathrm{ft}$ in Test Case 1 . A high cost of storage persists at low relative heads of $100 \mathrm{ft}$ even if nearly all of the storage volume is already excavated or a substantial amount of storage works are in place. As Test Case 3 is an approximation of the best case scenario of $\mathrm{m}-\mathrm{PSH}$, it can be reasonably assumed that $\mathrm{m}-\mathrm{PSH}$ projects with 8 hours of storage are not economically feasible with less with design heads of less than roughly $150 \mathrm{ft}$. For 4 hours of storage, ICC descends below $\$ 4,000 / \mathrm{kW}$ at roughly $200 \mathrm{ft}$ of design head.
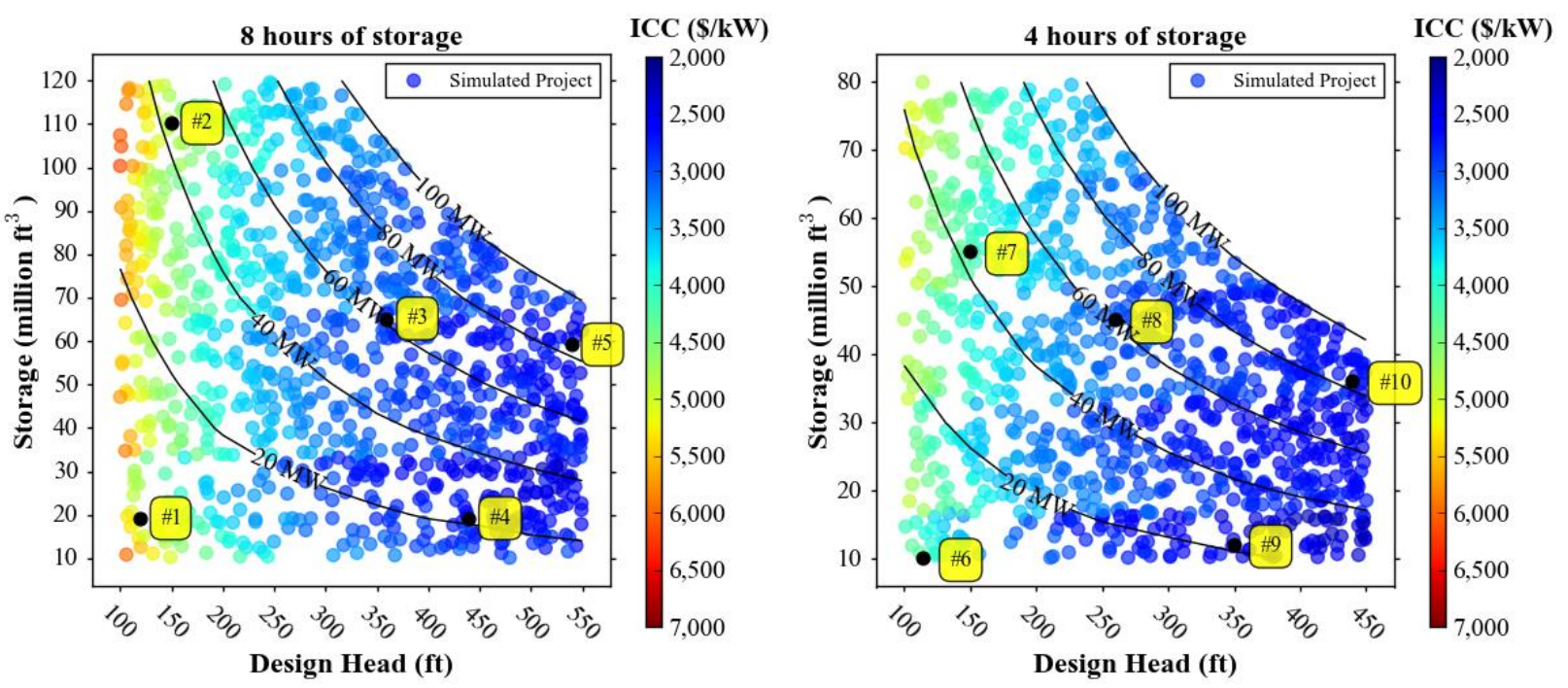

Figure 24. Cost estimates for Test Case 3 with 8 hours of storage (left) and 4 hours of storage (right).

A bar plot of individual categories (Figure 25) provides some insight into the cost distributions of the Test Case 3 test points identified in Figure 24. In all cases, electromechancial equipment costs become the dominant cost category once storage costs have been significantly reduced, followed by water conveyance costs at high relative head. It is interesting to note that at higher relative head (test points \#5, 10), the ICC associated with 8 hours of storage is less than the ICC associated with 4 hours of storage for the same installed capacity. A turbine with a higher relative design head and lower relative design discharge tends to be more economical at the same installed capacity, leading to economic advantages and cost savings that propagate down through ancillary electrical and mechanical costs, and powerhouse costs. As in Test Case 3, the relative cost of the water conveyance is increased as head and power capacity are increased. 


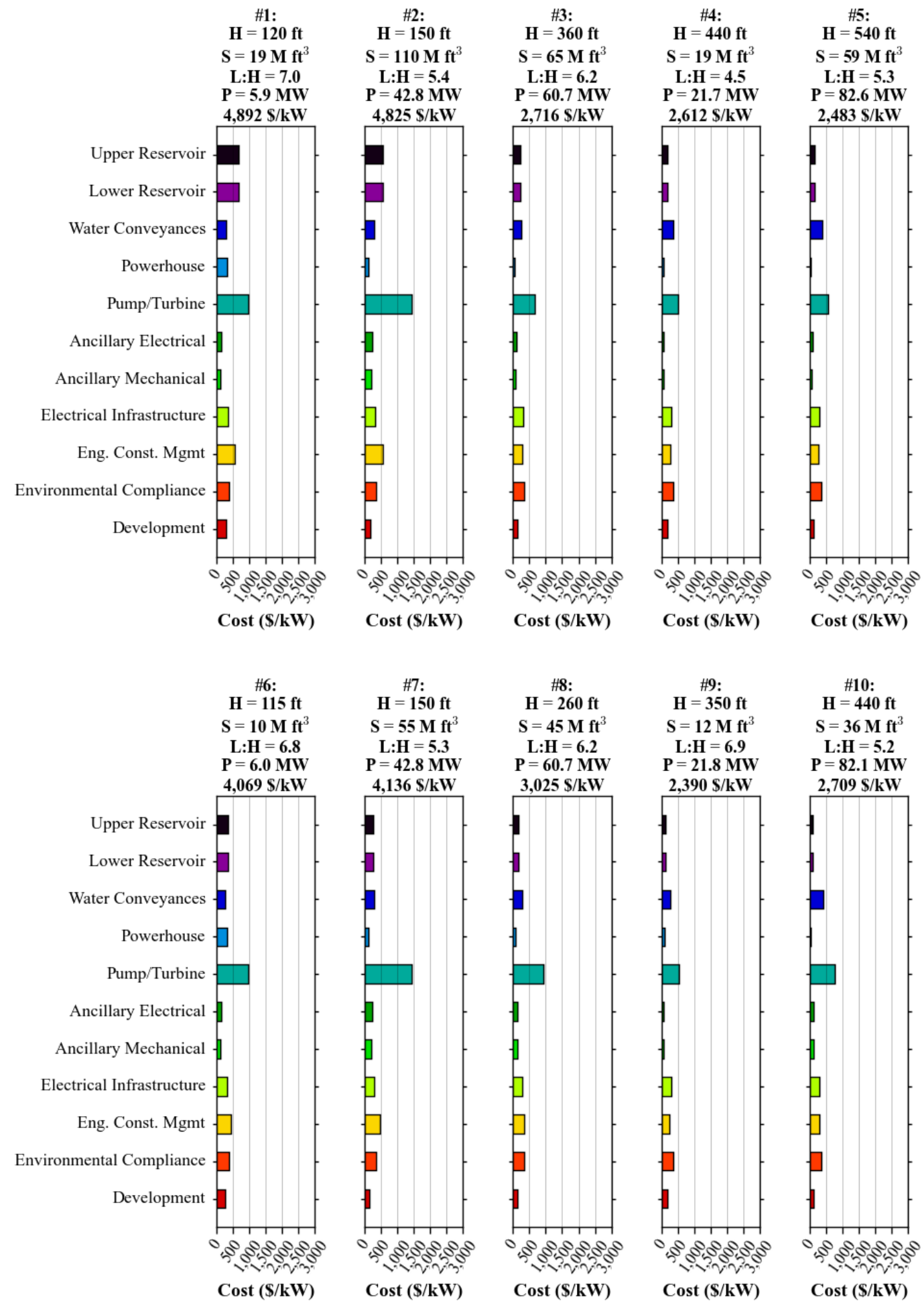

Figure 25. Cost category estimates for test points in Test Case 3 with 8 hours of storage (top) and 4 hours of storage (bottom). Civil works, electro-mechanical equipment, and electrical equipment categories include contingencies. 
The ICC in $\$ / \mathrm{kW}$ of both storage time simulations of Test Case 3 is shown in Figure 26 compared to the ICC of conventional PSH as reported in EPRI (2010). In both cases, the highest relative head simulated projects exhibits ICCs that fall slightly below those of conventional projects, while most simulated projects fall within the range of ICC of conventional projects. The difference in ICC for a given installed capacity for 8 hours of storage compared to 4 hours of storage becomes very small once the costs of storage are reduced.
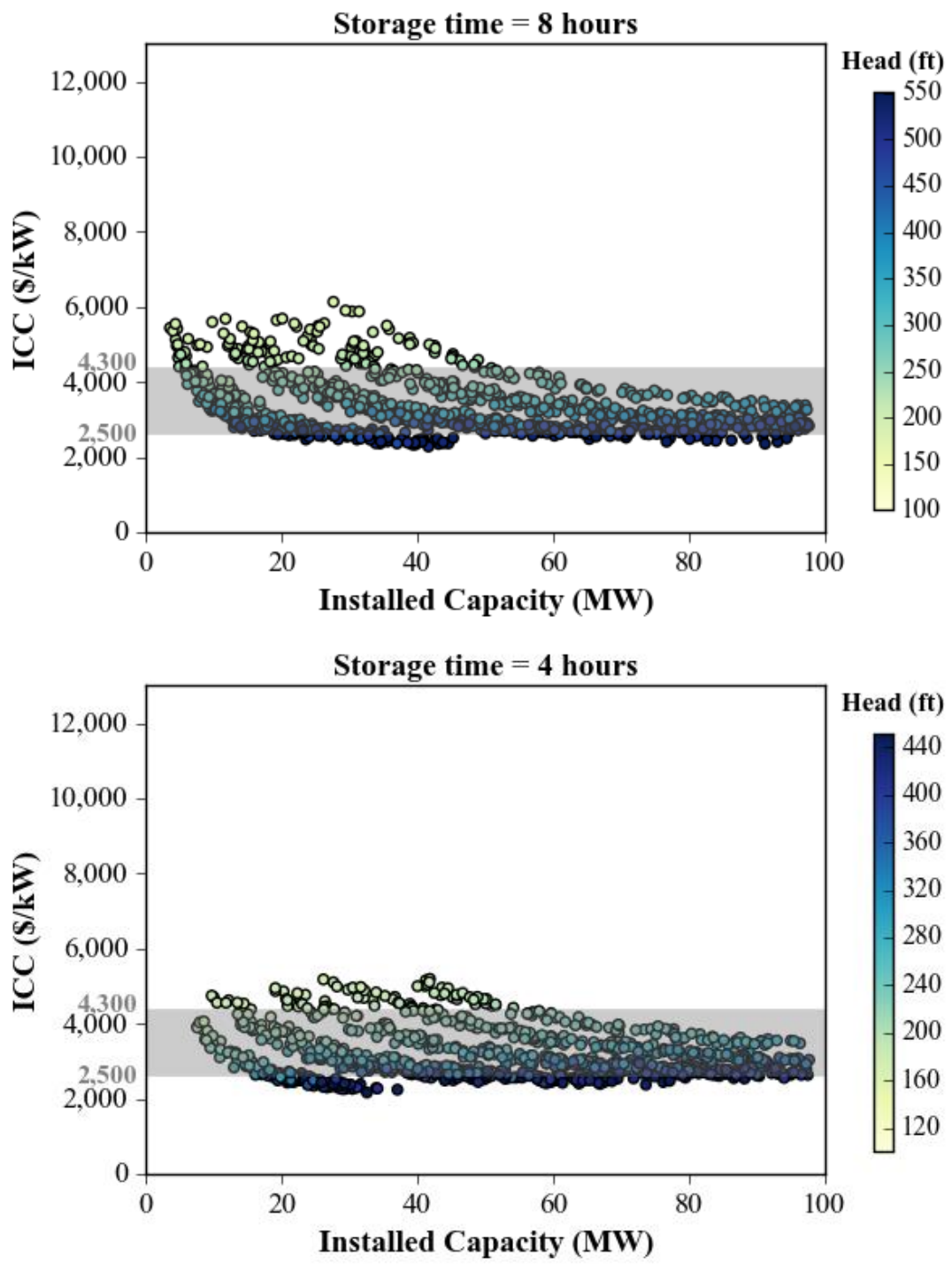

Figure 26. ICC estimates for Test Case 3 in $\$ / \mathrm{kW}$ for 8 (top) and 4 (bottom) hours of storage. Gray line indicates the ICC estimate of conventional PSH projects (EPRI, 2010). 
The ICC in $\$ / \mathrm{kWh}$ of both storage time simulations of Test Case 3 is shown in Figure 27 compared to the ICC of conventional PSH as reported in EPRI (2010). Compared to previous test cases, the largest difference for simulated projects with 8 hours of storage is that lower design heads are brought into the realm of comparable ICC with conventional projects. Despite the reduction in absolute dollars, the ICC in $\$ / \mathrm{kWh}$ for 4 hours of storage remains higher than conventional plants. However, projects with 4 hours of storage may not be operated like conventional PSH plants, and the comparison on a pure $\$ / \mathrm{kWh}$ basis may be misleading as the operational strategies and revenue structures may be wholly different.
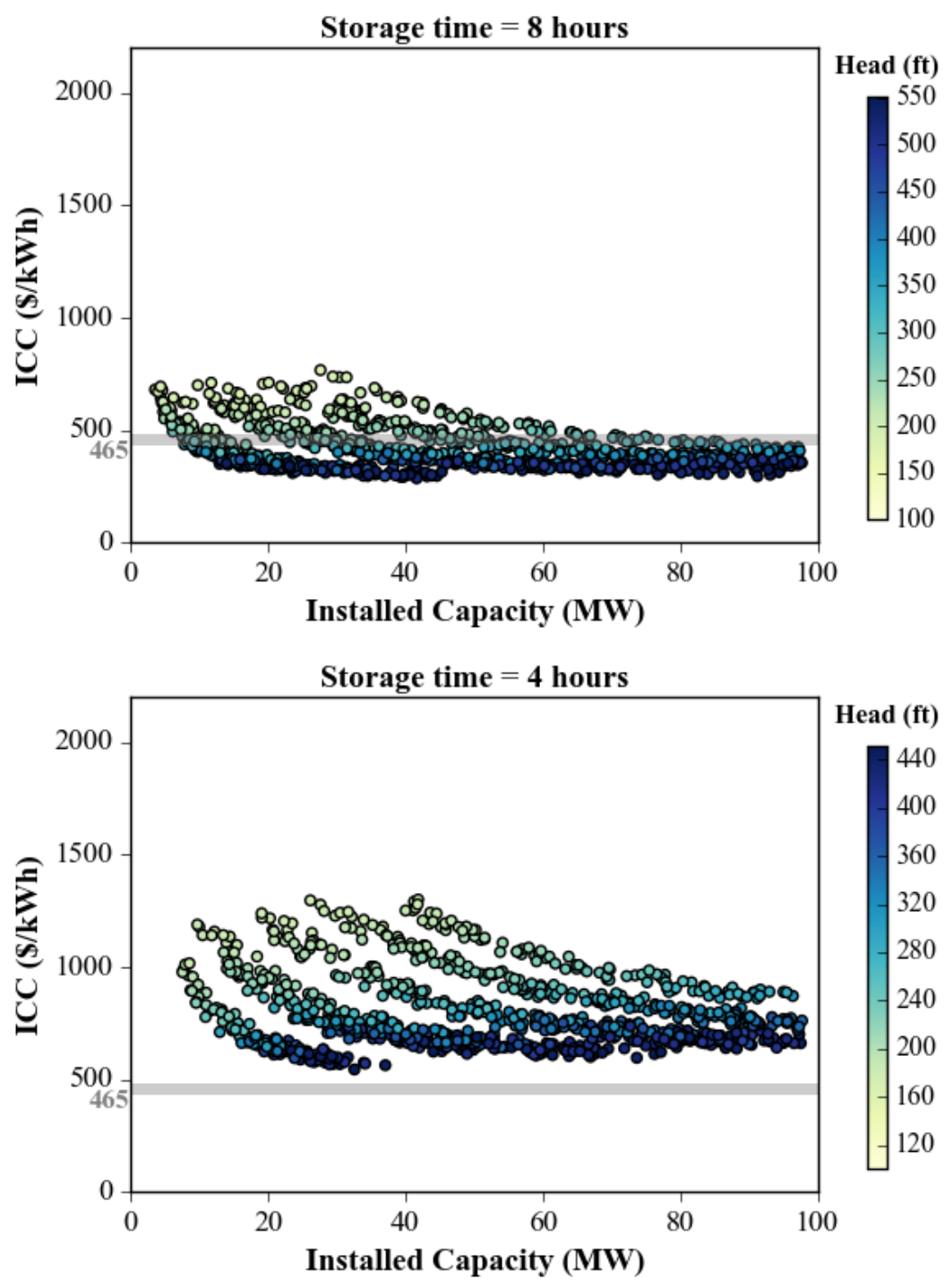

Figure 27. ICC estimates for Test Case 3 in $\$ / \mathrm{kWh}$ for 8 (top) and 4 (bottom) hours of storage. Gray line indicates the ICC estimate of conventional PSH projects (EPRI, 2010). 
The LCOS of both storage time simulations of Test Case 3 is shown in Figure 28. For 8 hours of storage, simulated projects are squarely within the range of conventional projects for nearly all capacities and heads. For 4 hours of storage, only simulated projects with the highest relative head show an LCOS within the band of conventional PSH LCOS, while most projects are greater, within a range of 280/MWh to $\$ 520 / \mathrm{MWh}$. A greater spread in LCOS is also observed for projects with 4 hours of storage.
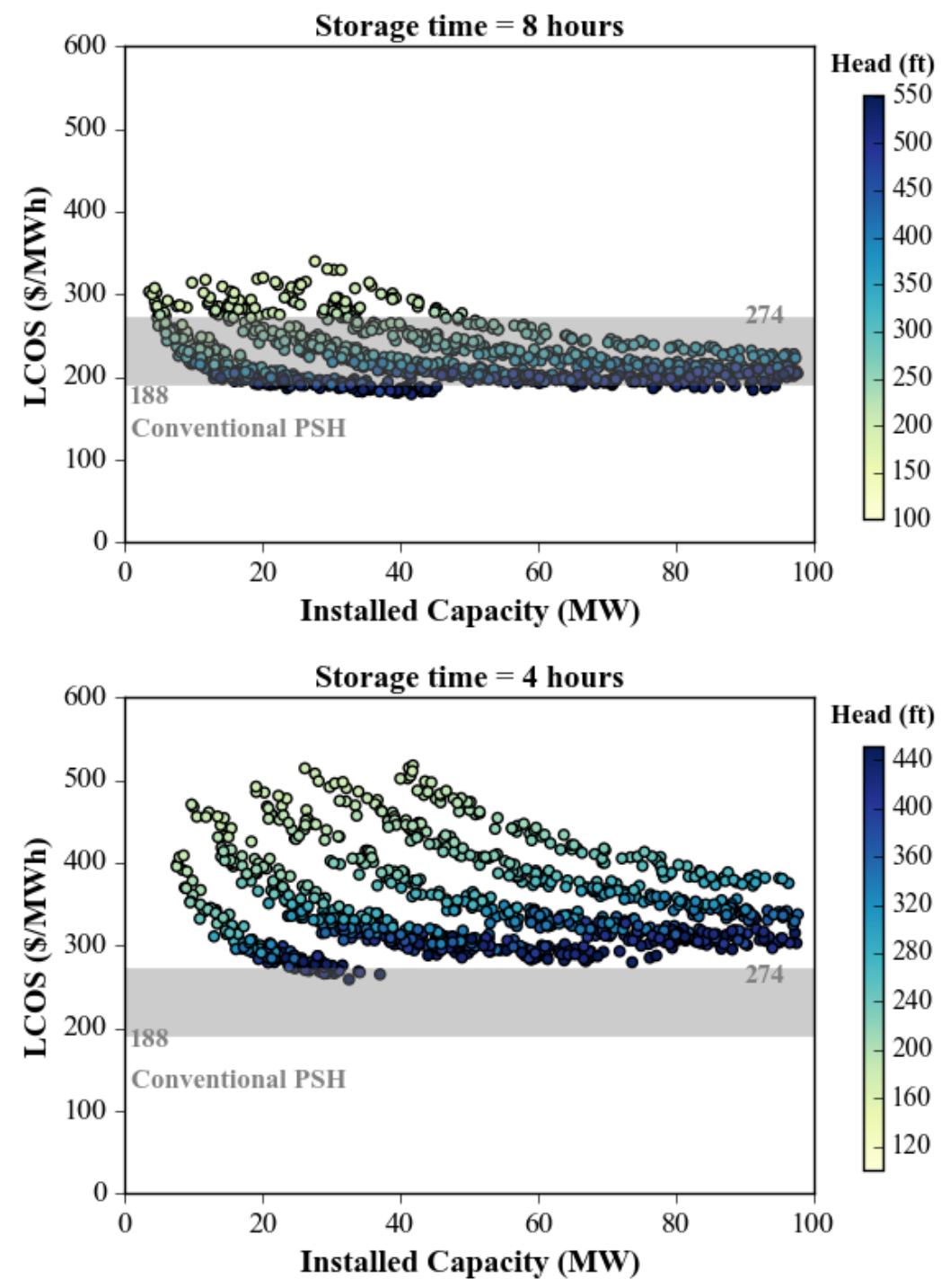

Figure 28. LCOS estimates in \$/MWh for Test Case 3 with 8 (top) and 4 (bottom) hours of storage. 


\subsection{TEST CASE SUMMARY}

A summary of low, mean, and high ICC for distinct ranges of installed capacities for each test case are shown in Table 8 and Table 9.

Table 8. Test Case Summary - ICC in $\$ / \mathbf{k W}$ for 8 hours of storage

\begin{tabular}{|c|c|c|c|c|}
\hline Test Case & $\begin{array}{c}\text { Generating } \\
\text { Capacity (MW) }\end{array}$ & Low Cost $(\$ / k W)$ & Mean Cost $(\$ / k W)$ & High Cost $(\$ / k W)$ \\
\hline \multirow{4}{*}{ Test Case 1} & $0-25$ & 3,757 & 6,548 & 11,659 \\
\hline & $25-50$ & 3,652 & 5,628 & 11,750 \\
\hline & $50-75$ & 3,546 & 4,825 & 7,671 \\
\hline & $75-100$ & 3,439 & 4,397 & 5,947 \\
\hline \multirow{4}{*}{ Test Case 2} & $0-25$ & 2,885 & 4,877 & 8,081 \\
\hline & $25-50$ & 2,871 & 4,390 & 7,966 \\
\hline & $50-75$ & 2,894 & 3,800 & 5,936 \\
\hline & $75-100$ & 2,836 & 3,541 & 4,582 \\
\hline \multirow{4}{*}{ Test Case 3} & $0-25$ & 2,587 & 3,816 & 5,935 \\
\hline & $25-50$ & 2,586 & 3,492 & 5,887 \\
\hline & $50-75$ & 2,517 & 3,115 & 4,485 \\
\hline & $75-100$ & 2,442 & 2,968 & 3,786 \\
\hline
\end{tabular}

Table 9. Test Case Summary - ICC in \$/kW 4 hours of storage

\begin{tabular}{lcccc}
\hline Test Case & $\begin{array}{c}\text { Generating } \\
\text { Capacity }(\mathbf{M W})\end{array}$ & Low Cost $\mathbf{\$} / \mathbf{k W})$ & Mean Cost $\mathbf{( \$ \mathbf { k W } )}$ & High Cost $\mathbf{( \$ \mathbf { k W } )}$ \\
\hline \multirow{3}{*}{ Test Case 1 } & $0-25$ & 3,014 & 5,035 & 7,871 \\
\cline { 2 - 5 } & $25-50$ & 2,764 & 4,637 & 8,141 \\
\cline { 2 - 5 } & $50-75$ & 3,058 & 4,238 & 6,500 \\
\hline \multirow{3}{*}{ Test Case 2 } & $75-100$ & 3,185 & 3,981 & 5,457 \\
\cline { 2 - 5 } & $0-25$ & 2,681 & 4,065 & 6,097 \\
\cline { 2 - 5 } & $25-50$ & 2,458 & 3,766 & 6,373 \\
\hline \multirow{3}{*}{ Test Case 3 } & $50-75$ & 2,604 & 3,523 & 5,468 \\
\cline { 2 - 5 } & $75-100$ & 2,816 & 3,389 & 4,412 \\
\cline { 2 - 5 } & $0-25$ & 2,359 & 3,378 & 5,958 \\
\hline & $25-50$ & 2,181 & 3,309 & 4,663 \\
\hline
\end{tabular}

The main cost trends observed in simulated projects are as follows:

- Higher relative heads decrease ICC in terms of $\$ / \mathrm{kW}$ and $\$ / \mathrm{kWh}$;

- By siting projects in locations where some storage works already exist, or where the excavation burden is less than what it would compared to a reservoir excavated from a flat surface, substantial cost savings are realized. In these cases, electromechancial costs become the largest driver of total ICC, followed by water conveyance costs as head is increased;

- Projects with 4 hours of storage show higher relative ICC in terms of $\$ / \mathrm{kWh}$ and higher LCOS than projects with 8 hours of storage at the same installed capacity. They show lower ICC in terms of $\$ / \mathrm{kW}$ due to the lower storage requirement, and subsequently, reduced storage cost;

- Even with no storage infrastructure in place, projects with the highest simulated design head $(\sim 500 \mathrm{ft})$ showed comparable ICC and LCOS to conventional PSH projects. 


\section{SENSITIVITY ANALYSIS}

A significant modeling challenge is the ability to capture unique project characteristics that impact technology choices, storage size, and overall project costs under realistic development scenarios. Several baseline assumptions have been made in model development to systematically approximate resource characteristics and probable development decisions. To assess the cost model response to differences in model assumptions, a sensitivity analysis of specific test points for 8 hours of storage in Test Case 2 is carried out (Figure 19, top). The sensitivity analysis is carried out in two sections, one assessing parameters related to project costs, and another assessing parameters related to LCOS.

\subsection{ICC SENSITIVITIES}

Variables with significant influence over project costs are identified in Table 10. The default value is provided, and a lower and upper limit of probable values is used to bound the sensitivity analysis. In each case, the default values are held constant, and only the variable of interest is allowed to vary within the prescribed limits.

Table 10. Model variables and corresponding ranges for ICC sensitivity analysis

\begin{tabular}{|c|c|c|c|c|}
\hline & Variable & $\begin{array}{c}\text { Default } \\
\text { value }\end{array}$ & $\begin{array}{c}\text { Lower } \\
\text { limit }\end{array}$ & $\begin{array}{c}\text { Upper } \\
\text { limit }\end{array}$ \\
\hline \multirow{5}{*}{$\underset{0}{0}$} & Rock Excavation Costs & $\$ 34 / y^{3}$ & $\$ 18 / \mathrm{yd}^{3}$ & $\$ 45 / y^{3}$ \\
\hline & Soil Excavation Costs & $\$ 7 / y^{3}$ & $\$ 5 / \mathrm{yd}^{3}$ & $\$ 14 / y d^{3}$ \\
\hline & Electromechanical Contingency & $15 \%$ & $10 \%$ & $25 \%$ \\
\hline & Civil Works Contingency & $20 \%$ & $15 \%$ & $30 \%$ \\
\hline & Engineering Construction Management & $15 \%$ & $20 \%$ & $10 \%$ \\
\hline \multirow{4}{*}{ 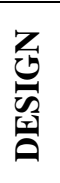 } & Reservoir Depth & $50 \mathrm{ft}$ & $25 \mathrm{ft}$ & $75 \mathrm{ft}$ \\
\hline & Penstock Length:Height Ratio & - & 4 & 8 \\
\hline & Transmission Line Length (miles) & - & 2 & 10 \\
\hline & Generating Unit efficiency & $90 \%$ & $80 \%$ & $92 \%$ \\
\hline
\end{tabular}

The sensitivity of project costs is shown in Figure 29 for Test Case 2 Point \#1 (top), which had approximately $120 \mathrm{ft}$ of head and $6 \mathrm{MW}$ of generating capacity, and Test Case 2 Point \# 5 (bottom), which had approximately $540 \mathrm{ft}$ of head and $83 \mathrm{MW}$ of generating capacity. As can be expected, higher project costs carry with them larger sensitivities to perturbations in the underlying cost assumptions. At low head and low power (top), the most sensitive cost variables include soil excavation cost, generating unit efficiency, and reservoir depth. The largest cost sensitivity is reservoir depth - shallower storage reservoirs require disproportionately more excavation, leading to a substantial increase in project costs. The overall variation in ICC from the baseline is a $9.1 \%$ cost reduction through a $26 \%$ cost increase, all due to a potential variation in reservoir depth. At high head and higher relative power (bottom), the most sensitive cost parameters are penstock L:H ratio, generating unit efficiency, and reservoir depth. The penstock is a larger cost component of the overall project due to the higher head, and variability in $\mathrm{L}: \mathrm{H}$ has a larger economic impact on the project. The overall variation in ICC from the baseline is a $7.2 \%$ cost reduction through a $13 \%$ cost increase due to variations in L:H and reservoir depth, respectively. 


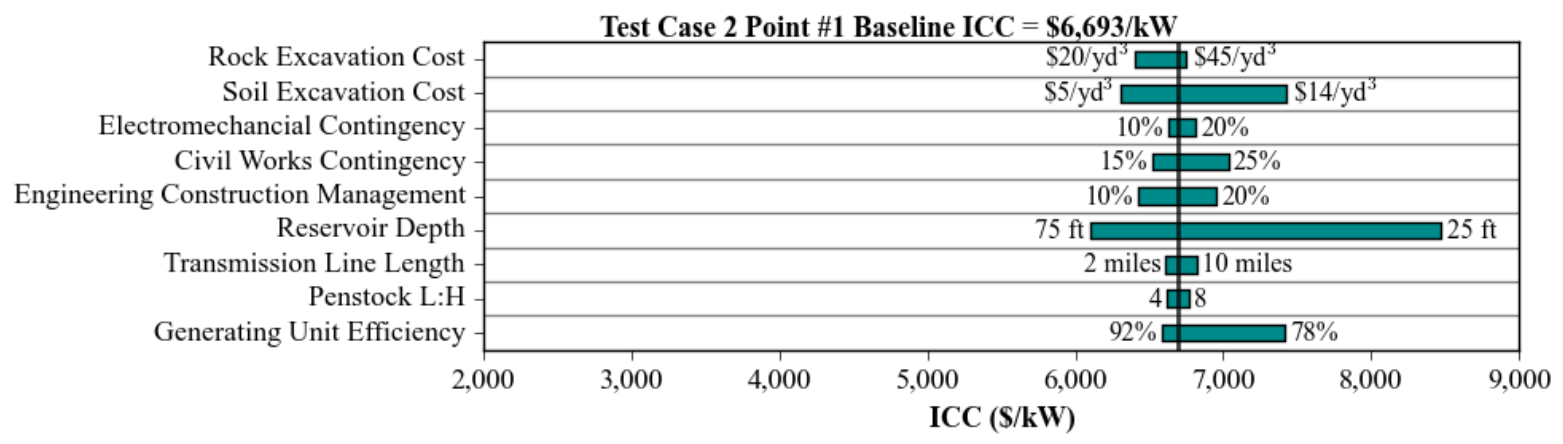

Test Case 2 Point \#5 Baseline ICC $=\$ 2,981 / \mathrm{kW}$

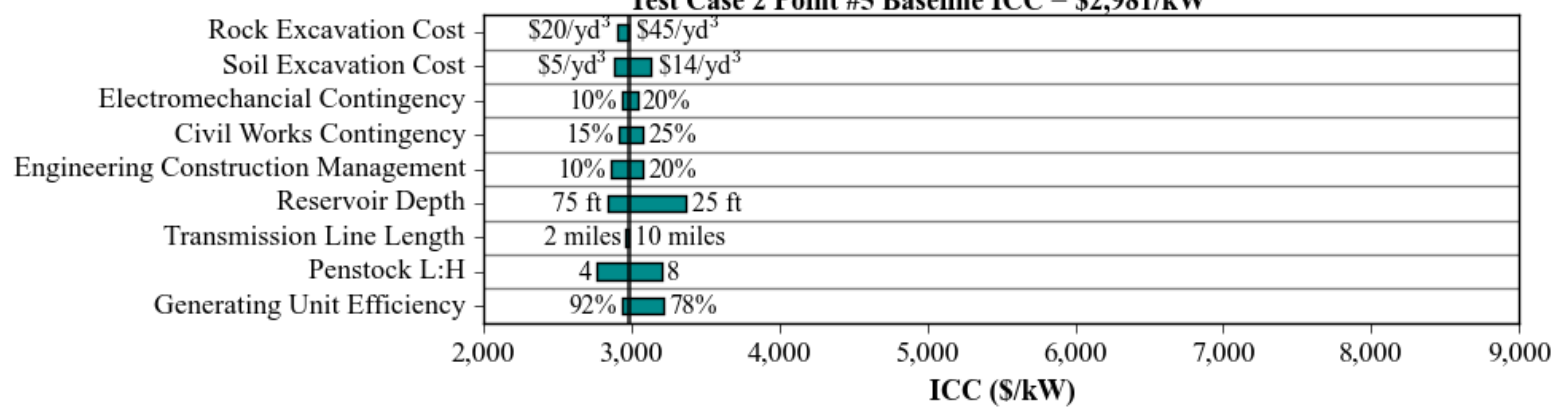

Figure 29. Cost sensitivities for Test Case 2 test points \#1 (top) and \#5 (bottom). Each bar represents a variation in ICC based on the perturbation of the individual category of the $y$-axis within the limits identified in the figure text.

\subsection{LCOS SENSITIVITIES}

Variables with significant influence over LCOS are identified in Table 10. The default value is provided, and a lower and upper limit of probable values is used to bound the sensitivity analysis. In each case, the default values are held constant, and only the variable of interest is allowed to vary within the prescribed limits.

Table 11. Model variables and corresponding ranges for LCOS sensitivity analysis

\begin{tabular}{lccc}
\hline Variable & $\begin{array}{c}\text { Default } \\
\text { value }\end{array}$ & $\begin{array}{c}\text { Upper } \\
\text { limit }\end{array}$ & $\begin{array}{c}\text { Lower } \\
\text { limit }\end{array}$ \\
\hline Discount rate & $10 \%$ & $12 \%$ & $8 \%$ \\
\hline Days of full discharge per year & 300 & 320 & 280 \\
\hline Roundtrip efficiency & $82 \%$ & $70 \%$ & $85 \%$ \\
\hline Pumping tariff & $\$ 50 / \mathrm{MWh}$ & $\$ 70 / \mathrm{MWh}$ & $\$ 30 / \mathrm{MWh}$ \\
\hline Annual O\&M (fixed) & $\$ 12 / \mathrm{MWh}$ & $\$ 18 / \mathrm{MWh}$ & $\$ 7 / \mathrm{MWh}$ \\
\hline Replacement cost at 20 years & $20 \%$ of EM & $40 \%$ of EM & $10 \%$ of EM \\
\hline Project Life & 40 years & 50 years & 30 years \\
\hline
\end{tabular}

The sensitivity of LCOS is shown in, again for Test Case 2 Point \#1 (Figure 30, top) and Test Case 2 Point \# 5 (Figure 30, bottom), each with 8 hours of total storage. In all cases, the largest component of LCOS is the combined components of ICC (taken as the undiscounted ICC) and the financing impact ICC, which comprise between $60 \%-70 \%$ of LCOS. The residual value is nearly independent of project size, remaining negligent at less than $0.5 \%$ of baseline LCOS in all cases. 
At low head and low power (top), the most sensitive LCOS variables are the discount rate, the capacity factor, defined as the number of days of full discharge per year, and the pumping tariff. Changes in the discount rate from $8 \%$ to $12 \%$ drive the LCOS roughly $11 \%$ lower and higher, respectively, from the baseline value. Changes in the capacity factor have a more limited impact on LCOS. Within the existing fleet of PSH plants, the number of unit service hours per year is roughly 2,500 on average, corresponding to 313 full days at 8 hours of discharge (Uria-Martinez et al., 2015). It is anticipated that m-PSH plants could on average achieve a similar level of performance. The pumping tariff has a targeted impact on the pumping cost portion of the LCOS only, though a $\$ 20 / \mathrm{MWh}$ increase in pumping tariff from the baseline can increase LCOS by roughly $10 \%$. At high head and high relative power (bottom), similar LCOS sensitivity dynamics are observed, though the same variance in pumping tariff produces a greater percentage change in LCOS. The largest sensitivity is to changes in the annual average pumping tariff, which drives LCOS roughly $14 \%$ lower and higher than the baseline.
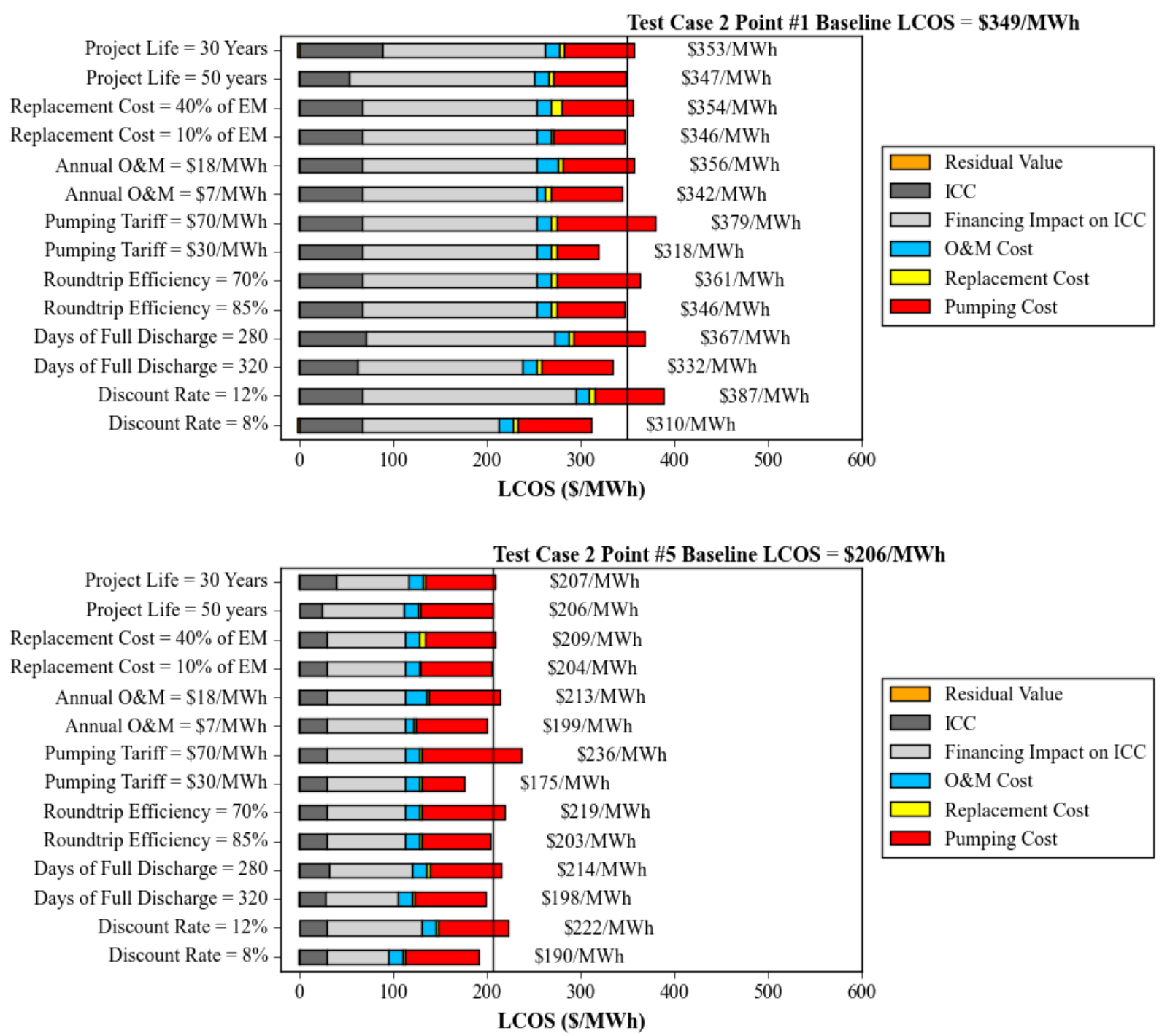

Figure 30. LCOS sensitivities for Test Case 2 test points \#1 (top) and \#5 (bottom). Each bar represents a variation in LCOS based on the perturbation from the default value identified on the y-axis. Financing impact on ICC is taken as the undiscounted portion of ICC. 


\subsection{SENSITIVITY ANALYSIS SUMMARY}

The sensitivity analysis can be used to put an overall uncertainty estimate on the impact that individual model inputs have on predicted ICC and LCOS for m-PSH projects reported herein.

Table 12. Input uncertainty impact on ICC and LCOS.

\begin{tabular}{lcccc}
\hline & \multicolumn{2}{c}{ Higher cost projects } & \multicolumn{2}{c}{ Lower cost projects } \\
\hline & $\begin{array}{c}\text { Upper Deviation } \\
\text { from Baseline }\end{array}$ & $\begin{array}{c}\text { Lower Deviation } \\
\text { from Baseline }\end{array}$ & $\begin{array}{c}\text { Upper Deviation } \\
\text { from Baseline }\end{array}$ & $\begin{array}{c}\text { Lower Deviation } \\
\text { from Baseline }\end{array}$ \\
\hline ICC & $+26 \%$ & $-10 \%$ & $+13 \%$ & $-7 \%$ \\
\hline LCOS & $+11 \%$ & $-11 \%$ & $+14 \%$ & $-14 \%$ \\
\hline
\end{tabular}




\section{COMPARITIVE ANALYSIS}

Developing a comparative cost estimate of electrical energy storage systems is a challenging task wrought with significant uncertainty and judgement, differences in category cost definition and component inclusion in total capital costs, and lack of transparency in methodologies and costs. These issues have been addressed in depth in a recent comprehensive review of electrical energy storage (EES) technology cost estimates from academia, industry, and government (Zakeri and Syri, 2015), which highlighted the following:

- The majority of cost estimates in the literature are made on a total capital cost basis, as the notion of lifecycle costs has not been determined with certainty for emerging EES technologies that lack long-term cost statistics and practical field experiences;

- Similar to m-PSH, many EES technologies are demonstration or pre-deployment scale, and cost data is difficult to parametrically scale to make a comparative analysis;

- Other EES technologies may be based on site specific data (PHS) or on a single data point (Compressed Air Energy Storage) that does not represent a bulk trend of deployment from which a meaningful statistical analysis can be conducted;

- Uncertainty in the cost of single battery technologies is significant - in some cases, the range of uncertainty is greater than the difference in costs between different battery technologies. This leads to large cost ranges that tend to lose meaning in a comparative analysis;

Additional energy storage cost comparisons conducted by energy industry analysts (Lazard, 2015) and surveys of OEMs and developers (Akhil et al., 2013) are also frequently cited as reliable energy storage cost estimates, though they exhibit the same challenges as noted by Zakeri and Syri (2015).

In this section, the results of the test cases are compared on a $\$ / \mathrm{kWh}$ basis and LCOS basis against EES technology cost estimates from Lazard (2015) for two separate scenarios: transmission scale projects with $100 \mathrm{MW}$ of capacity and 8 hours of storage, and gas peaking replacement projects, with $25 \mathrm{MW}$ of capacity and 4 hours of storage. These estimates are selected for their relative ease of comparison and their explicitly defined capacity and storage parameters, and associated costs. The comparison is made with caution, and comes with several caveats:

- Costs are based on analyst estimates with no transparency into cost structure or categories included in the analysis;

- The LCOS methodology is not disclosed. An analysis using the LCOS methodology outlined in Section 3.5 and the assumptions detailed by Lazard predicted LCOS within 5\% - 10\% of those reported;

- The cost of EES facilities do not appear to be included in the LCOS estimate. These costs are included in the m-PSH model, and thus EES costs may be slightly underrepresented on a comparative basis;

- A better understanding of the infrastructure and facilities needed to accommodate the plant particulars, and the environmental protections associated with each technology, would provide a more holistic comparison with the m-PSH costs predicted in this report;

- Batteries generally incur annual disposal and recycling costs - it is not clear if these costs are incorporated into annual O\&M estimates;

- Batteries experience a decline in performance after multiple recharge and discharge cycles that may manifest in as little as a few years - it does not appear that this degradation is accounted for in the levelized estimate of annual energy generation.

- Zinc-based battery technologies are included for comparative purposes, though the report makes the following note: "Zinc technologies are not currently widely commercially deployed. Capital costs are likely lower than other energy storage technologies due to survey participants' willingness to incorporate possible future capital cost decreases into current quotes/estimates." 


\subsection{TRANSMISSION SCALE PROJECTS}

Simulations of ICC in $\$ / \mathrm{kWh}$ for m-PSH test cases with approximately $100 \mathrm{MW}$ of generating capacity and 8 hours of storage are shown compared against analyst estimates of comparable EES technologies in Figure 31. Under all test case scenarios, the range of ICC is much smaller and substantially lower than nearly all other EES technologies. Even under Test Case 1, where full excavation of two reservoirs is required, the mean ICC is at the low end of all other EES options, with the exception of Zinc (which is likely underreported, as noted in Section 7) and Compressed Air (which contains a single data point).

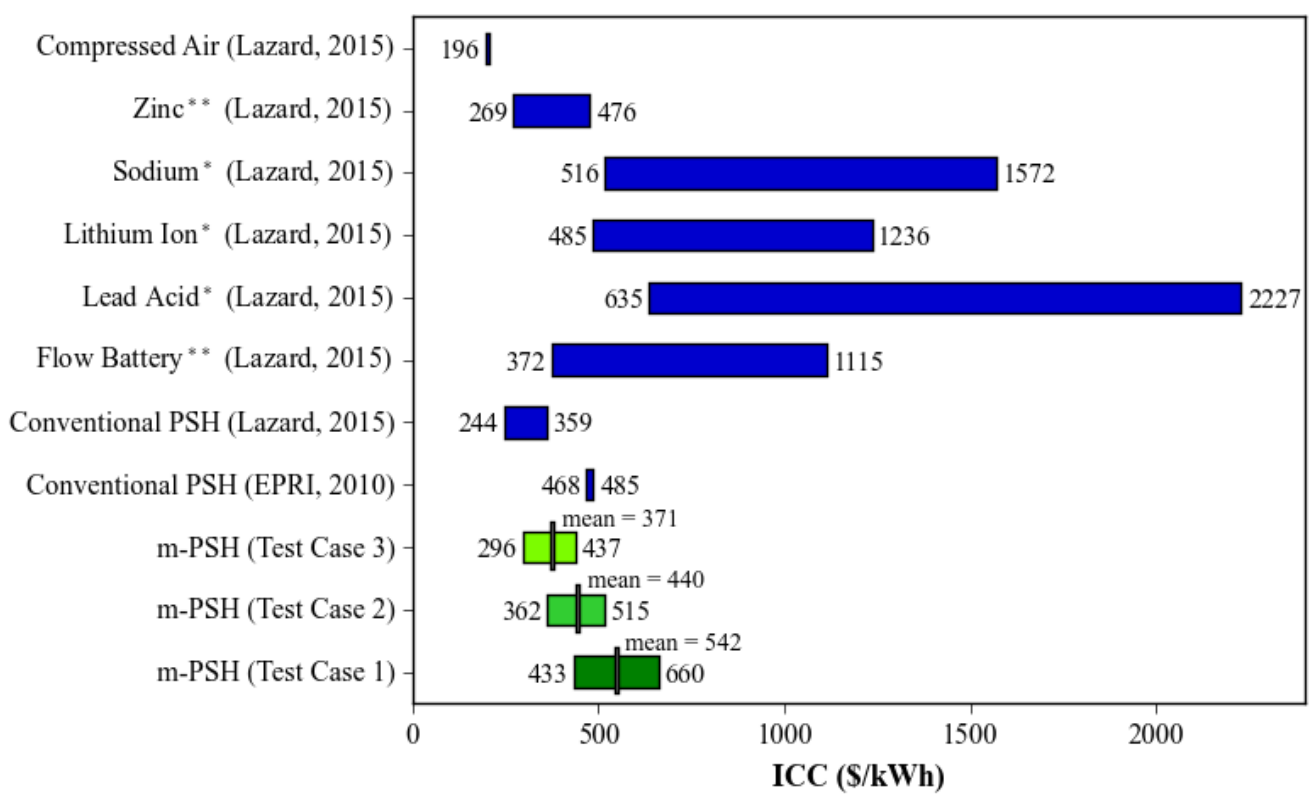

Figure 31. ICC estimates in $\$ / \mathbf{k W h}$ for Test Case 1 (no existing storage works), Test Case 2 (50\% existing storage works), and Test Case 3 (80\% existing storage works) with 90 MW - 100 MW of generating capacity and 8 hours of storage (green) compared to estimates of comparable EES technologies (blue). * indicates limited commercial applications available at this scale, $* *$ indicates early demonstration at this scale based on estimates from EPRI (2010).

Simulations of LCOS in \$/MWh for m-PSH test cases with approximately $100 \mathrm{MW}$ of generating capacity and 8 hours of storage are shown compared against analyst estimates of comparable EES technologies in Figure 32. As was the case with ICC, the range of LCOS is much smaller and substantially lower than nearly all other EES technologies (ostensibly modeled under similar economic assumptions). The smaller range of ICC compared to other EES technologies is the largest driver of LCOS improvement. It is also noted that assumptions like useful plant life of 40 years, low annual degradation, and high roundtrip efficiency are technical characteristics that have been proven for conventional PSH technologies, and would likely apply to m-PSH technologies. These technical characteristics are unproven for large scale battery storage projects, and thus cast a larger uncertainty on the range of LCOS estimates provided. The challenge inherent to all energy storage technologies is apparent when the LCOS range of natural gas peaking plants is superimposed on the figure. The low LCOS of gas peaking plants, driven largely by low natural gas fuel prices, allows them to be competitive on the margin where energy storage plants with many hours of storage typically compete. The simulations indicate there are circumstances where m-PSH could be deployed today, using existing technologies, at comparable LCOS to both demonstration scale battery technologies and operational gas peaking plants. As the price of natural gas rises from current historic lows, the impact of fuel prices on gas peaking plant LCOS will push the band further to the right. 


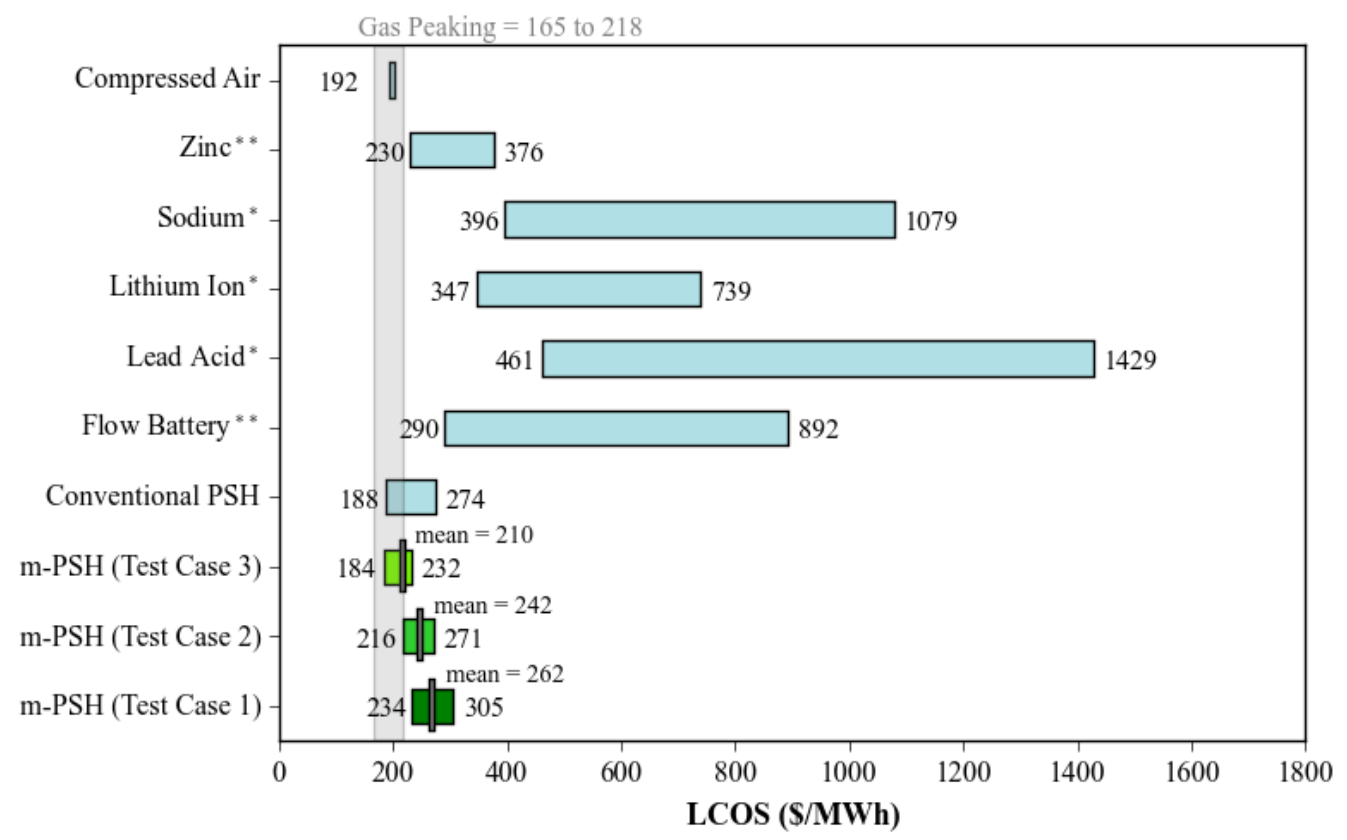

Figure 32. LCOS comparison for m-PSH projects in all test cases with $90 \mathrm{MW}-100 \mathrm{MW}$ of generating capacity and 8 hours of storage (green) compared to analyst estimates of comparable EES technologies (blue) (estimates obtained from Lazard, 2015). * indicates limited commercial applications available at this scale, ** indicates early demonstration at this scale based on estimates from EPRI (2010).

\subsection{PEAKING REPLACEMENT PROJECTS}

Simulations of ICC in $\$ / \mathrm{kWh}$ for m-PSH test cases with approximately $25 \mathrm{MW}$ of generating capacity and 4 hours of storage are shown compared against analyst estimates of comparable EES technologies in Figure 33. While most test cases show costs comparable or lower than competing EES technologies, the range of potential ICC is much larger than transmission scale projects, reflecting the cost differences, noted in previous sections, associated with the range of potential head and storage volume scenarios. Lower cost ICC estimates tend to reflect relatively higher head projects, and vice versa.

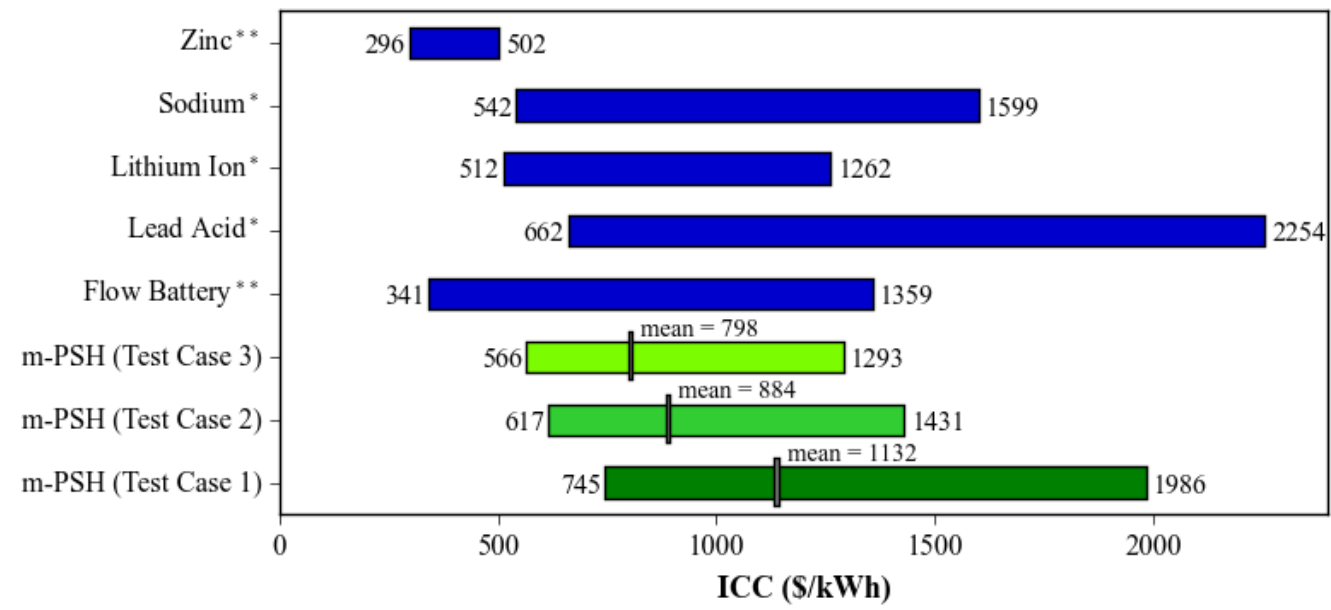

Figure 33. ICC estimates in $\$ / \mathrm{kWh}$ for $\mathrm{m}-\mathrm{PSH}$ projects in all test cases with $20 \mathrm{MW}-30 \mathrm{MW}$ of generating capacity and 4 hours of storage (green) compared to analyst estimates of comparable EES technologies (blue)

(data obtained from Lazard, 2015). * indicates limited commercial applications available at this scale, ** indicates early demonstration at this scale based on estimates from EPRI (2010). 
Simulations of LCOS in \$/MWh for m-PSH test cases with approximately $25 \mathrm{MW}$ of generating capacity and 4 hours of storage are shown compared against analyst estimates of comparable EES technologies in Figure 34. All test cases show competitive m-PSH LCOS, with a low-end estimate (corresponding to higher head projects) that falls below most commercially available battery technologies. Even with the large variability in simulated head and storage volume, the range of potential m-PSH LCOS is much tighter than estimates from other technologies, highlighting both a prospective opportunity for m-PSH under all test cases, and the large uncertainty that persists with respect to how batteries could be deployed at larger scales. Assuming smaller scale m-PSH projects could be deployed with lower investment and development risk, with smaller impacts, and with reduced environmental footprints, LCOS results indicate relatively low cost energy storage could be realized under many different deployment scenarios.

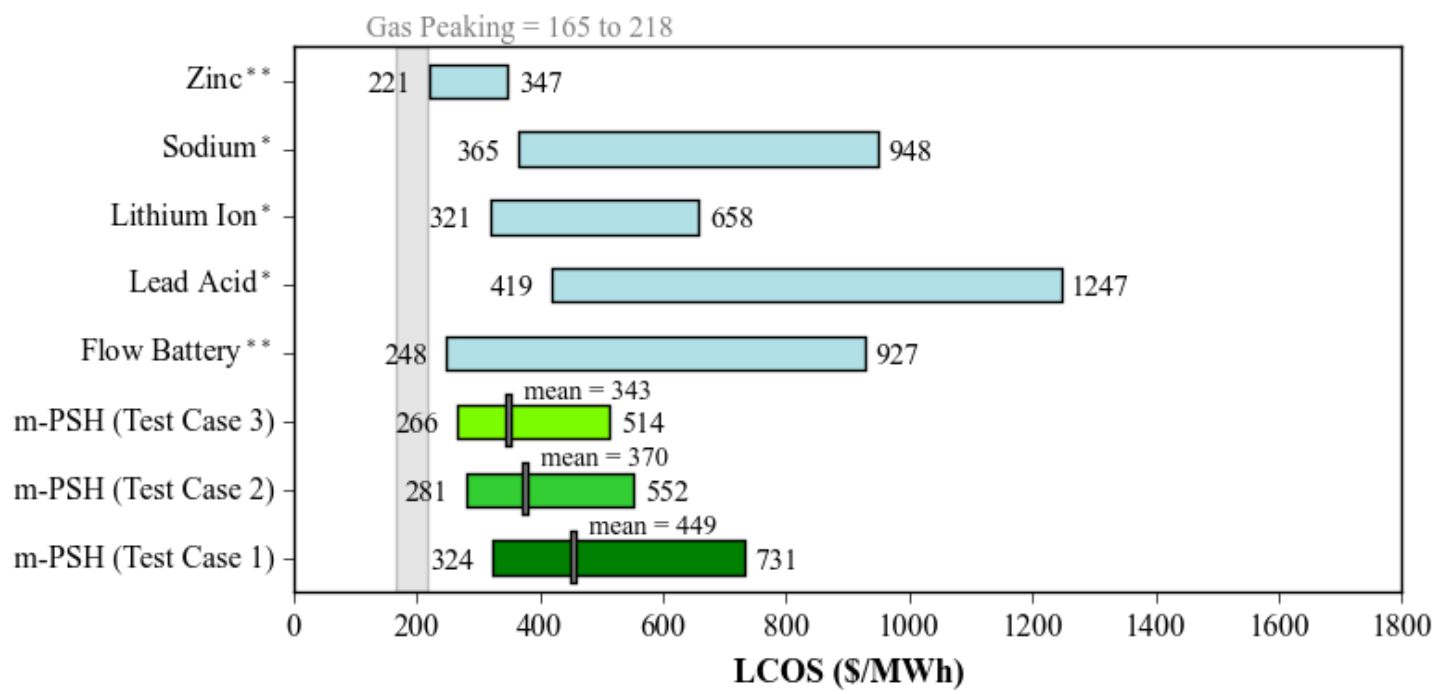

Figure 34. LCOS comparison for m-PSH projects in all test cases with $20 \mathrm{MW}-30 \mathrm{MW}$ of generating capacity and 4 hours of storage (green) compared to analyst estimates of comparable EES technologies (blue) (estimates obtained from Lazard, 2015). * indicates limited commercial applications available at this scale, ** indicates early demonstration at this scale based on estimates from EPRI (2010).

\subsection{COMPARITIVE ANALYSIS SUMMARY}

The results of m-PSH project cost simulations are compared with electrical energy storage technologies of various maturity and scale. For m-PSH projects with roughly $100 \mathrm{MW}$ of installed capacity and 8 hours of storage, ICC in $\$ / \mathrm{kWh}$ an LCOS are extremely competitive with estimates of commercial and demonstration stage costs for comparable electrical energy storage technologies, even under Test Case 1 conditions when two new storage reservoirs are required. For m-PSH projects with approximately 25 MW of installed capacity and 4 hours of storage, ICC in $\$ / \mathrm{kWh}$ an LCOS are at the low end of estimates of commercial and demonstration stage costs for comparable electrical energy storage technologies under all test cases.

It is stressed again that a common comparative basis is needed for a realistic comparison of the ICC and LCOS of energy storage projects. Many cost estimates of battery technologies do not include the cost of site preparation, foundation work, or project management that are nearly always included in conventional PSH project cost estimates and that are included in the m-PSH project costs simulated herein. 


\section{CONCLUSIONS AND RECOMMENDATIONS}

A comprehensive cost model has been developed to predict, simulate, and assess the costs to develop, build, and install small scale, modular pumped storage hydropower projects. Major findings and conclusions are summarized as follows:

- Development of m-PSH scale projects is technically feasible with existing technologies and construction techniques. The cost to build the project is the largest deterrent to m-PSH deployment;

- Existing storage works provide the critical path towards achieving m-PSH economic feasibility. Test cases developed to analyze the cost implications of varying levels of existing storage works showed when two new reservoirs are required, a project is generally uneconomic unless it can be developed at a high head greater than $500 \mathrm{ft}$. If instead the excavation burden is only $20 \%$ of a completely new reservoir, a much greater range of m-PSH projects are brought into the realm of economic feasibility. The reduced excavation burden not only reduces the physical volume of earth that requires movement, it also reduces the construction time and overall preparation costs associated with preparing the reservoir for long-term storage;

- The relationship between head and storage volume is a critical driver of m-PSH feasibility. Lower relative head projects require a greater amount of storage volume to produce the same installed capacity as projects at a higher relative head. That greater storage volume comes at a cost that increases non-linearly as head is reduced;

- Projects with 8 hours of storage and 4 hours of storage and installed capacities of less than 100 MW are analyzed in detail. Projects with 4 hours of storage show some economic promise in terms of ICC in $\$ / \mathrm{kW}$ at lower relative heads than projects with 8 hours of storage, a result of the lower storage cost burden. However, both ICC in terms of $\$ / \mathrm{kWh}$ and LCOS are relatively higher at 4 hours of storage, leading to questions of market value, location, and operational strategy. Projects with 4 hours of storage sited in regions with high demand for shorter duration, higher power storage could be economically attractive at lower relative head than projects designed with 8 hours of storage. These projects may operate under different conditions, assumptions, and strategies than the conventional PSH fleet, and a direct cost comparison may be misleading if these factors are not taken into account. Projects with 8 hours of storage are competitive in terms of ICC and LCOS with numerous electrical energy storage technologies mainly at higher relative design heads, even if limited or no storage works are in place;

- $\mathrm{m}-\mathrm{PSH}$ projects with design head under $150 \mathrm{ft}$ are uneconomical under almost every potential scenario simulated, unless two reservoirs are mostly in place and the penstock length to height ratio is very small. The reductions in storage volume that accompany an increase in head for the same power output are the most important drivers towards cost reductions;

- Following the cost of storage, the cost of electro-mechanical equipment is the biggest cost driver for $\mathrm{m}-\mathrm{PSH}$ at lower relative head and power, while the cost of a water conveyance becomes a large cost driver at higher head, especially when the upper and lower reservoirs are horizontally separated by longer distances;

- Remote projects that require extensive transmission lines and challenging site access play an important role in determining project feasibility. Cost estimates of projects with these features were not considered, as they are unlikely to achieve widespread economic feasibility;

- There are substantial benefits in terms of levelized cost with increasing storage time. Projects with 8 hours of storage were shown to be consistently competitive with a variety of existing and potential electrical energy storage technologies on an initial capital cost and levelized cost of storage basis. The added benefits of long useful life, proven technology, high roundtrip efficiency, and low performance degradation over time make m-PSH an attractive alternative;

- A comparative analysis shows m-PSH facilities exhibit a levelized cost of storage range that is on par or better than battery alternatives at many scales, even if both reservoirs need to be excavated 
and constructed. These results can be interpreted with two possible explanations: (1) there is limited m-PSH resource available in the US to develop, or (2) the financial and investment risks and the regulatory and environmental unknowns associated with development, even on a small scale, are hindering pursuit of m-PSH development;

- There is a need for better cost certainty with respect to the parametric equations used to scale PSH component level costs. There is currently a large degree of uncertainty associated with project costs, as there are no existing m-PSH projects from which to validate or spot check cost accuracy.

The cost model provided detailed insight into the dynamics of m-PSH projects over a variety of scales, topographical and geographical landscapes, and potential deployment situations. Based on the analysis provided herein, the following recommendations are offered for future m-PSH research:

- There is a critical need to better understand the resource potential of m-PSH in the United States. The changing paradigm of smaller scale m-PSH projects coupled with the pressing need for innovation and cost reductions in electrical energy storage demands a better quantification of $\mathrm{m}$ PSH type resources in the US and a fresh look at where m-PSH projects may be viable;

- The fleet of conventional scale PSH was built largely using sites with some existing storage works. The most promising m-PSH projects were shown to take advantage of existing storage works, though these types of sites were modeled on economic merits alone. The results presented herein can be put into a more tangible context if better insight is gained into what kind of m-PSH resources are widely and readily available in the US;

- It is important to have a common basis for economic and financial comparisons across electrical energy storage technologies. Existing comparisons can be improved and made more reliable by offering explicit detail on how lifecycle costs and cost assumptions are developed for mature, recently deployed, new, and future energy storage technologies;

- Following improvements in the cost of storage, either through cost reductions in the civil works associated with storage construction or through strategic siting, innovative technical research and development should be focused on reducing the largest cost drivers of m-PSH development. At lower relative heads, the cost of electromechanical equipment is substantial, and could be improved through new designs and manufacturing strategies for modular reversible pumpturbines. At higher relative heads, both electromechanical equipment and water conveyance costs become large project cost categories. New penstock materials, joining techniques, and construction strategies that utilize a combination of conventional and alternative materials have the potential to reduce overall project costs. Constructing the penstock in stages, with different materials for lower and higher pressure sections, could lead to cost reductions in water conveyance systems. These cost reductions become more pronounced with increases in head and penstock length;

- Conventional PSH plants were built for large scale energy storage. There is a potential for smaller scale, cost effective energy storage with m-PSH plants that would operate much different from the conventional fleet. New models and simulations are needed to better understand how mPSH can be strategically used as an energy storage technology. Analyses should move beyond conventional transmission scale services such as energy arbitrage and ancillary services, and include distributed energy storage benefits, including commercial and industrial use, demand charge reduction, time-of-use management, and renewables integration at small scales;

- There seems to be increased movement towards making certain energy storage technologies eligible for an Investment Tax Credit (ITC) when they are coupled with other renewable energy generation technologies, namely solar. Under these circumstances, the economic feasibility of $\mathrm{m}$ PSH could certainly be improved. The benefits of using m-PSH to enable greater penetration of intermittent renewables while benefitting from the ITC should be explored. 


\section{REFERENCES}

Akhil, A., Huff, G., Currier, A., Kaun, B., Rastler, D., Chen, S., Cotter, A., Bradshaw, D., Gauntlett, W. (2013). DOE/EPRI 2013 Electricity Storage Handbook in Collaboration with NRECA.

BLS (Bureau of Labor Statistics). (2016). Consumer Price Indexes. Available online at http://www.bls.gov/cpi/, accessed online March 2016.

Chalise D.R, O'Connor P., Deneale S., Waldoch C. (2016). Hydropower Integrated Design and Economic Assessment Tool for Use in Preliminary Feasibility Assessments - Modeling Frameworks. Proc., HydroVision International Conference, Minneapolis, MN. July 2016.

Deane, J. P., Ó Gallachóir, B. P., \& McKeogh, E. J. (2010). Techno-economic review of existing and new pumped hydro energy storage plant. Renewable and Sustainable Energy Reviews, 14(4), 12931302.

Electric Power Research Institute. (2010). Electricity Energy Storage Technology Options.

Electric Power Research Institute. (2011). Quantifying the Value of Hydropower in the Electric Grid: Plant Cost Elements.

ENR (Engineering News Record). (2016). Construction Cost Indices, Engineering News Record. Available online at http://enr.construction.com/economics/, accessed online March 2016.

ESHA (European Small Hydropower Association). (2004). Guide on How to Develop a Small Hydropower Plant. Accessed at http://www.esha.be/fileadmin/esha files/documents/publications/GUIDES/GUIDE SHP/GUIDE_SH P EN.pdf

FERC (Federal Energy Regulatory Commission). (2016). Federal Energy Regulatory Commission Form 1 Guidelines. Available at http://www.ferc.gov/docs-filing/forms/form-1/form-1.pdf accessed online September 2016.

Gimeno-Gutiérrez, M., \& Lacal-Arántegui, R. (2013). Assessment of the European potential for pumped hydropower energy storage: A GIS-based assessment of pumped hydropower storage potential.

Hadjerioua, B., Bishop, N. J., Uria-Martinez, R., \& Hopping, E. (2014). Evaluation of the Feasibility and Viability of Modular Pumped Storage Hydro (m-PSH) in the United States - Preliminary First Case Study, Coal Mine.

Hadjerioua, B., Uria-Martinez, R., Shanafield, H., Wei, Y., McCulla, J., Alsharif, A. M., \& Bishop, N. J. (2011). National Resource Assessment of Pumped Storage Hydropower (PSH).

IHS. (2015). Grid-Connected Energy Storage Report - 2015. Retrieved from <https://technology.ihs.com/512285/grid-connected-energy-storage-report-2015>

INL (Idaho National Lab). (2003). Estimation of Economic Parameters of U.S. Hydropower Resources. INEEL/EXT-03-00662.

Knight Piésold Consulting. (2010). BC Hydro Evaluation of Pumped Storage Hydroelectric Potential.

Lazard. (2015). Lazard's levelized cost of storage analysis - version 1.0. < https://www.lazard.com/media/2391/lazards-levelized-cost-of-storage-analysis-10.pdf>

MWH. (2009). Technical Analysis of Pumped Storage and Integration with Wind Power in the Pacific Northwest.

NRC (Natural Resources Canada). (2004). RETScreen International: Small Hydro Project Analysis. Minister of Natural Resources Canada 2001-2004. 
O’Connor, P., Zhang, K., Deneale, S. T., Chalise, D. R., \& Centurion, E. (2015a). Hydropower Baseline Cost Modeling. Oak Ridge, TN: ORNL/TM-2015/14.

O'Connor, P.W., Zhang, Q.F., DeNeale, S.T., Chalise, D.R., Centurion, E, and Maloof, A. (2015b). Hydropower Baseline Cost Modeling version 2. Oak Ridge, TN: ORNL/TM 2015/471.

O'Connor, P.W., Chalise, D.R., DeNeale, S.T., Waldoch C. (2016). The Hydropower Integrated Design and Economic Assessment Model: Documentation and Selected Applications. Oak Ridge, TN: ORNL/TM 2016/587. Publication is Under Development.

State of Michigan. (2003). Tanks. Retrieved June 15, 2016, from https://www.michigan.gov/documents/Vol2-35UIP11Tanks_121080_7.pdf

U.S. Army Corps of Engineers (USACE). (1979). Feasibility Analysis in Small Hydropower Planning. TP 65, August 1979.

U.S. Army Corps of Engineers (USACE). (2013a). Civil Works Construction Cost Index System, Army Corps of Engineers. Available online at http://www.publications.usace.army.mil/Portals/76/Publications/EngineerManuals/EM_1110-21304.pdf, accessed online September 2016.

U.S. Bureau of Reclamation (USBR). (1980). Reconnaissance Evaluation of Small, Low-Head Hydroelectric Installation. Bureau of Reclamation, Water and Power Resources Service, Denver.

U.S. Bureau of Reclamation (USBR). (2011). Hydropower Resource Assessment at Existing Reclamation Facilities. Bureau of Reclamation, Power Resources Office, Denver, 2011.

U.S. Bureau of Reclamation (USBR). (2016). Bureau of Reclamation Construction Cost Trends 2016. http://www.usbr.gov/pmts/estimate/cct08-11.pdf (accessed January 6, 2016).

U.S. Department of Energy, \& Sandia National Laboratories. (2015). Global Energy Storage Database. Retrieved January 1, 2016, from http://www.energystorageexchange.org/.

Uria-Martinez, R., Johnson, M., \& O’Connor, P. (2015). 2014 Hydropower Market Report.

Welch, T. (2016). How Does Pumped Hydro Fit in the Future Energy Storage Mix? Proc., HydroVision International Conference, Minneapolis, MN.

Witt, A., Hadjerioua, B., Uria-Martinez, R., \& Bishop Jr., N. A. (2015). Evaluation of the Feasibility and Viability of Modular Pumped Storage Hydro (m-PSH) in the United States. Oak Ridge, TN: ORNL/TM-2015/ 559.

Yang, C. J., \& Jackson, R. B. (2011). Opportunities and barriers to pumped-hydro energy storage in the United States. Renewable and Sustainable Energy Reviews, 15(1), 839-844.

Zakeri, B., \& Syri, S. (2015). Electrical energy storage systems: A comparative life cycle cost analysis. Renewable and Sustainable Energy Reviews, 42, 569-596. 


\section{APPENDICES}

A. DESIGN AND COST METHODOLOGIES

B. FURTHER DISCUSSION ON STORAGE TYPE 


\section{APPENDIX A. DESIGN AND COST METHODOLOGIES}

\section{A.1. DESIGN ${ }^{6}$}

After a user specifies the minimum number of inputs, the model then designs a reference conceptual plant based on a combination of parametric, heuristic and engineering-based design approaches ${ }^{7}$. The model incorporates component-level design of civil works, electro-mechanical equipment, and electrical infrastructure. Additional project features such as engineering and construction management and environmental mitigation are not explicitly designed in the model. The following section describes basic design principles of major m-PSH components.

\section{A.1.1. CIVIL WORKS}

\section{A.1.1.1. SITE PREPARATION}

Site preparation works include preliminary site activities completed prior to beginning the construction. It includes 1) site access road 2) leveling and grading, 3) drainage, and 4) erosion control (Table 13). Access road and laydown area is an important feature of project planning. The access road development may include construction of a new road, upgrading an existing infrastructure. The levelling and grading works mostly involve the modification of existing terrain (eg. cut or fill), which results changes in the topography and the drainage pattern. Well planned borrow, cutting, and filling with proper grading and collection points (catch basins) are provided to remove surface water and sub drains are provided to collect subsurface water. Erosion can cause a problem during construction when water flows through side slopes (cut or fill) in the project area.

Table 13. Site preparation design in m-PSH model.

\begin{tabular}{cccccc}
\hline Items & Symbol & Units & Formula & Coefficient & Comment \\
\hline Site Access & & mile & Default $=0.5$ miles & & User input \\
Access road length & $\mathrm{L}_{\mathrm{r}}$ & & & \\
Site Preparation & & $\mathrm{A}_{\mathrm{s}}$ & $\mathrm{ft}^{2}$ & & Calculated \\
Storage Area & $\mathrm{A}_{\mathrm{g}}$ & $\mathrm{yd}^{2}$ & $\mathrm{~A}_{\mathrm{s}} \mathrm{F}_{\mathrm{t}}^{+} / 9$ & $\mathrm{~F}_{\mathrm{t}}=1.5,2$, or 3 & \\
Leveling and Grading Area & $\mathrm{A}_{\mathrm{d}}$ & $\mathrm{yd}^{2}$ & $\mathrm{~A}_{\mathrm{s}} \mathrm{F}_{\mathrm{t}}^{+} / 9$ & $\mathrm{~F}_{\mathrm{t}}=1.5,2$, or 3 & \\
Drainage Area & &
\end{tabular}

$\dagger$ Coefficients correspond to a terrain complexity of Low, Medium, or High, respectively.

* Storage Area is calculated using volume and depth of storage. Detail calculation is provided under storage design

The access road design may vary from project to project. No explicit road design is provided in the model. The model uses user defined access road length. The m-PSH model computes leveling \& grading, and drainage area by multiplying storage area with user defined terrain factor 1.5, 2 or 3 for low, medium, or high terrain complexity. The erosion control area is assumed smaller portion of grading area, $10 \%$, $20 \%$, or $50 \%$ for the low, medium, or high terrain complexity. Additional preparatory works such as land acquisition, camp facilities, power facilities during construction, drinking water supply, etc. are not explicitly design in the model. The cost of these components should be reflected through civil works contingency.

6 The ORNL hydropower cost model report (O'Connor et al., 2016) and integrated hydropower cost model (Chalise et al., 2016) provide additional details about the design methodology adopted in the development of this model.

7 A parametric method is based on equations, a heuristic method is based on average percent. 


\section{A.1.1.2. UPPER AND LOWER STORAGE}

The m-PSH model consists of upper and lower storage system for the electricity production. The storage size influences the project capacity which ultimately impacts the project cost. The model provides two options: reservoir or tank for creating both upper and lower storage system. Table 14 provides design summary of storage system used in the m-PSH model.

Table 14. Storage design in m-PSH model.

\begin{tabular}{|c|c|c|c|c|c|}
\hline Items & Symbol & Units & Formula & Coefficient & Comment \\
\hline \multicolumn{6}{|l|}{ Excavation } \\
\hline Gross Storage Volume & $\mathrm{V}_{\mathrm{sg}}$ & $\mathrm{ft}^{3}$ & & & User input \\
\hline Dead Storage Percent & $\mathrm{P}_{\mathrm{ds}}$ & $\%$ & Default $=2 \%$ & & User Input \\
\hline Active Storage Volume & $\mathrm{V}_{\mathrm{s}}$ & $\mathrm{ft}^{3}$ & $\mathrm{~V}_{\mathrm{sg}}\left(1-\mathrm{P}_{\mathrm{ds}}\right)$ & & \\
\hline Storage Depth & $\mathrm{D}_{\mathrm{s}}$ & $\mathrm{ft}$ & Default $=50 \mathrm{ft}$ & & User input \\
\hline Storage Area ${ }^{*}$ & $\mathrm{~A}_{\mathrm{s}}$ & $\mathrm{ft}^{2}$ & $1.71 \mathrm{~V}_{\mathrm{s}} / \mathrm{D}_{\mathrm{s}}$ & & \\
\hline \multicolumn{6}{|l|}{ Reservoir } \\
\hline Riprap Area & $\mathrm{A}_{\mathrm{r}}$ & $\mathrm{yd}^{2}$ & {$\left[\left\{\mathrm{~A}_{\mathrm{s}}\left(0.063 \mathrm{~A}_{\mathrm{s}+} \mathrm{D}_{\mathrm{s}}^{2}\right)\right\}^{0.5}\right] / 3$} & & \\
\hline Rock Size & $\mathrm{S}_{\mathrm{r}}$ & inch & 10 & & Assumption \\
\hline Riprap Volume & $\mathrm{V}_{\mathrm{r}}$ & $\mathrm{yd}^{3}$ & $0.028 \mathrm{~A}_{\mathrm{r}} \mathrm{S}_{\mathrm{r}}$ & & \\
\hline Geo Membrane Area & $\mathrm{A}_{\mathrm{m}}$ & $\mathrm{yd}^{2}$ & $\mathrm{~A}_{\mathrm{r}}+0.25 \mathrm{~A}_{\mathrm{s}}$ & & \\
\hline
\end{tabular}

* Storage Area corresponds to a trapezoid square pyramid with top surface dimension $=2 \mathrm{x}$ bottom surface dimension. See next page for a diagram of storage reservoir with dimensions used in the model

A brief description of each storage component is provided below.

\section{Storage Reservoir}

A storage reservoir can be created by 1) building an enclosed dike or damming a small stream 2) building an excavated pond 3) using an existing reservoir or natural lake or large river system. A simple trough trapezoidal shape reservoir is used in the model (Figure 35). The model used a basic design of excavated pond for the new storage reservoir construction. The excavated pond is made by digging a pit or dugout in nearly level area. An example of the relationship between site preparation and storage design parameters is provided in Figure 36.

- Excavation: it is the process of moving earth, rock or other material while building a reservoir. The volume of excavation is assumed equal to the volume of storage reservoir.

- Rip-rap structures: face of reservoir must be protected against erosion or wave action, ice or impact of floating debris. To minimize such structural damage, rocks or hard stones (rip-raps) are provided. The volume of rip-rap is calculated by multiplying the rip-rap area with rock or stone size (default: 10 inch).

- Geo-membrane: it is a synthetic polymer used as seepage barriers in the reservoir. The useful life of geomembrane is 10 to 20 years (USBR, 2014). Geo-membrane is provided in faces and bed of the reservoir.

- Berm Structures: it can provide extra protection to the top surface of the reservoir. It is generally created by utilizing excavated soil and other materials. Current model does not explicitly design the berm structure. 


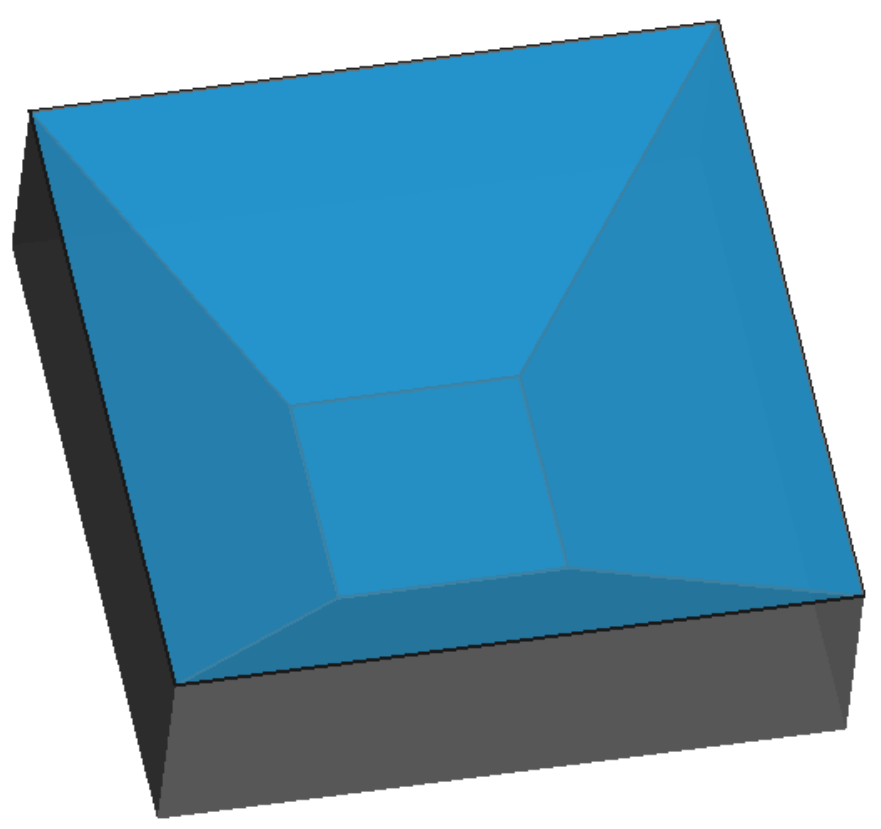

Figure 35. m-PSH reservoir system.

Area and volume calculation of the square trapezoidal reservoir is given below.

Top surface width $=x, \quad$ Bottom surface width $=0.5 x, \quad$ Depth $=D_{\text {s }}$

Top Surface Area $(A)=x^{2}, \quad$ Side Slope $=1: 1$

Bottom Surface Area $(a)=(0.5 x)^{2}=0.25 A$

Storage Volume $\left(V_{s}\right)=\frac{1}{3} D_{s}\left(x^{2}+(0.5 x)^{2}\right), \quad$ with $\quad A=\frac{3 V_{s}}{1.75 D_{s}}$

Riprap Area $\left(A_{r}\right)=$ Lateral Area $=\sqrt{9 \mathrm{~A}\left(0.0625 \mathrm{~A}+D_{s}{ }^{2}\right)}$

Geomembrane Area $(\mathrm{Ag})=$ Lateral Area + Bottom Surface Area $=$

$$
A_{g}=\sqrt{9 \mathrm{~A}\left(0.0625 \mathrm{~A}+{D_{s}}^{2}\right)}+0.25 \mathrm{~A}
$$

8 Lateral Area $=2(x+0.5 x) \sqrt{\frac{x-0.5 x}{2}+D_{s}^{2}}=\sqrt{9 x^{2}\left(0.0625 x^{2}+D_{s}{ }^{2}\right)}=\sqrt{9 \mathrm{~A}\left(0.0625 \mathrm{~A}+{D_{s}}^{2}\right)}$ 


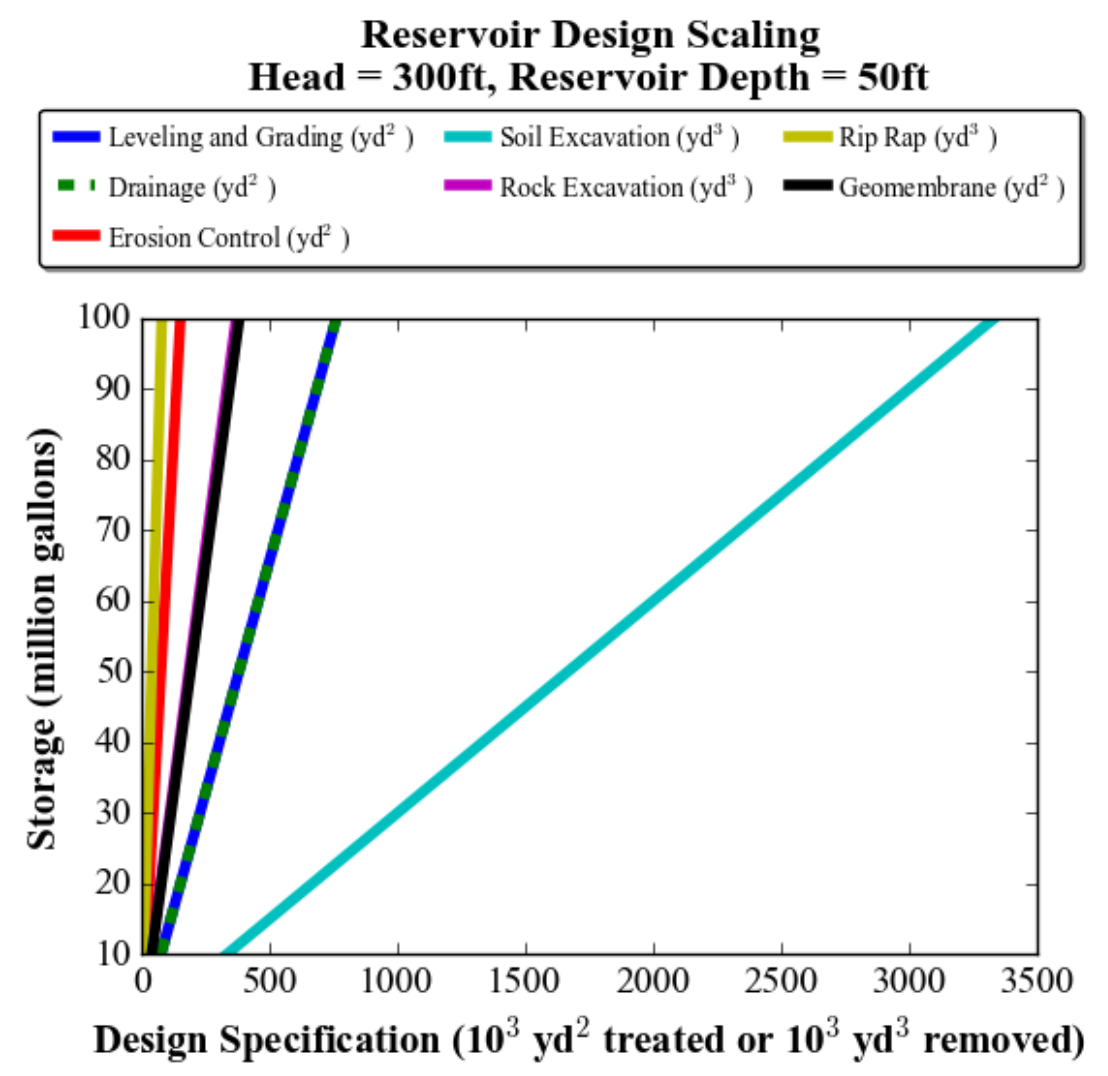

Figure 36. Relationships between site preparation and storage design parameters. Storage volume (y-axis) increases with increase in design specification ( $x$-axis).

In addition to berm structures, additional reservoir accessories including spillway, inlet/outlet works, etc. are not explicitly design in the model. The cost of these components should be reflected through civil works contingency.

\section{Storage and Generating Capacity ${ }^{9}$}

A certain volume of water above intake is maintained in the reservoir, which is used to avoid catastrophic dam failure due to negative water pressure in the intake. This inactive storage, also called dead storage volume, is not directly use for electricity production. The remaining volume (total storage minus dead storage) is called live storage or active storage is used for electricity production. The storage system should be design to handle total storage volume (i.e., dead plus live storage volume). The model computes dead storage volume as $2 \%$ of gross storage volume. The model also allows user to allocate higher dead storage volume. The live storage volume is used to calculate design flow for electricity production as,

9 Many hydropower and PSH projects contain spillways and overflow structures. The current m-PSH model does not provide a separate design for these items. Hence, the cost of these items should be reflected via the civil works contingency. 


$$
\text { Design flow, } Q(\text { in } c f s)=\frac{V s}{3600 T}
$$

where $V s=$ active storage volume in $\mathrm{ft}^{3}, T=$ storage time in hrs.

The design flow is used to compute project installed capacity as,

$$
\text { Installed Capacity, } P(\text { in } M W)=\frac{Q H \eta}{11841}
$$

where $H=$ design head (ft), $\eta=$ generating unit efficiency $(\%)$

The installed capacity is ultimately used to compute an hourly energy generation as,

$$
E(\text { in } M W h)=P T
$$

\section{Storage Tank}

Alternative to storage reservoir system, storage tank option 1) weld steel water tank, or 2) bolted steel water tank, or 3) concrete water tank is provided in the model. A typical life of storage tank varies from 20 to 55 years (Michigan State, 2003). Tank life reduces due to corrosive material or atmospheric condition. A special coating or double walls can lengthen the duration of tank. The model uses a maximum unit tank volume of 10 million gallons. When the maximum unit tank volume exceeded, the model designs multiple equal size tank. No detail tank design is performed in the model. 


\section{A.1.1.3. WATER CONVEYANCE SYSTEM}

The water conveyance system conveys water from upper storage to lower storage during generation or conveys water from lower storage to the upper storage during pumping cycle. The conveyance system consists of upstream structures (intake, intake gate), diversion structure (penstock pipe and accessories), shut-off valve or control valve and downstream structures (tailrace). A brief description of each of these components is provided below.

\section{Intake}

Intake structures regulate the flow of water into a penstock and contain a trash rack to prevent any debris from entering the penstock. The model uses design flow to determine the intake size and number of intakes (Table 15). The intake structure may also be specified as a new, existing, and or rehabilitation type.

Table 15. Intake design in m-PSH model.

\begin{tabular}{|c|c|c|c|c|}
\hline Items & Symbol & Units & Formula & Source/Comment \\
\hline \multicolumn{5}{|l|}{ Intake } \\
\hline Design Flow & $\mathrm{Q}$ & cfs & & see note \\
\hline Intake Maximum Velocity & $\mathrm{V}_{\operatorname{maxi}}$ & $\mathrm{ft} / \mathrm{s}$ & 3 & USBR, 1980 \\
\hline Intake Maximum Gate Area & $A_{\text {maxig }}$ & $\mathrm{ft}^{2}$ & Slide $=2500$, Radial $=2000$ & Vortex Hydra, 2015 \\
\hline Intake Maximum Flow & $\mathrm{Q}_{\operatorname{maxi}}$ & cfs & $\mathrm{A}_{\text {maxig }} \mathrm{V}_{\operatorname{maxi}}$ & \\
\hline Number of Intakes & $\mathrm{N}_{\mathrm{i}}$ & & $\mathrm{Q} / \mathrm{Q}_{\operatorname{maxi}}$ & \\
\hline Intake Unit Flow & $\mathrm{Q}_{\mathrm{iu}}$ & $\mathrm{cfs}$ & $\mathrm{Q} / \mathrm{N}_{\mathrm{i}}$ & \\
\hline
\end{tabular}

Note: $\mathrm{Q}=\mathrm{V}_{\mathrm{sg}} / 3,600 \mathrm{~T}$, where $\mathrm{V}_{\mathrm{sg}}$ is volume of storage in $\mathrm{ft}^{3}$ and $\mathrm{T}$ is time of storage in $\mathrm{hrs}$.

\section{Intake Gate (10 $^{10}$}

The intake gate is used to adjust the water level in the penstock. The design flow and maximum intake gate velocity are used to determine the size of intake gate (Table 16). The model uses maximum intake velocity of $3 \mathrm{ft} / \mathrm{s}$ and maximum design flow of 2000 (slide gate) to $2500 \mathrm{ft}^{2}$ (radial gate). When unit gate area exceeds its maximum value, multiple equal size gates are designed.

Table 16. Intake gate design in m-PSH model.

\begin{tabular}{cllcc}
\hline Items & Symbol & Units & Formula & Source/Comment \\
\hline Intake Gate & & & & \\
Intake Gate Type & $\mathrm{T}_{\mathrm{ig}}$ & & Slide, Radial & User Input \\
Intake Gate Flow & $\mathrm{Q}_{\mathrm{gi}}$ & $\mathrm{cfs}$ & $\mathrm{Q}$ & \\
Intake Maximum Velocity & $\mathrm{V}_{\text {maxi }}$ & $\mathrm{ft} / \mathrm{s}$ & 3 & USBR, 1980 \\
Intake Maximum Gate Area & $\mathrm{A}_{\text {maxig }}$ & $\mathrm{ft}^{2}$ & Slide $=2500$, Radial $=2000$ & Vortex Hydra, 2015 \\
Intake Gate Area & $\mathrm{A}_{\mathrm{ig}}$ & $\mathrm{ft}^{2}$ & $\mathrm{Q} / \mathrm{V}_{\operatorname{maxi}}$ & \\
\hline
\end{tabular}

10 The model uses radial and slide gate as an intake gate. Alternatively, pump storage project can have stop logs as an intake gate. Either they are open or they are closed for a maintenance issue. For all operation scenarios they are in the open position. For stop-logs as in intake gate, use the shutoff valve upstream of the pumped turbine to effect shut-off or control operation from generation to pump mode and vice versa. 


\section{Penstock}

The penstock conveys water between two reservoirs during generation and pumping cycle. In general, the penstock can be of free standing, buried or encased in concrete type. However, the model uses only free standing or open surface penstock. The model allows steel penstock, HDPE pipe, or a combination of both steel and HDPE pipe to transmit the water. The penstock design is based on design flow and computed penstock pressure (Table 17). The model assumes circular penstock and requires a userdefined ratio of penstock length and design head ( $\mathrm{L}: \mathrm{H}$ ratio). The length of penstock is based on design head and L: $\mathrm{H}$ ratio. The penstock diameter is determined using design flow, and maximum penstock velocity $(10,12$, or $14 \mathrm{ft} / \mathrm{s})$.

Table 17. Penstock design in m-PSH model.

\begin{tabular}{|c|c|c|c|c|}
\hline Items & Symbol & Units & Formula & Source/Comment \\
\hline Penstock & & & & ESHA, 2004 \\
\hline Penstock Max Velocity ${ }^{*}$ & $\mathrm{~V}_{\operatorname{maxp}}$ & $\mathrm{ft} / \mathrm{s}$ & Default $=10$ & User Input \\
\hline Penstock Max Diameter & $d_{\operatorname{maxp}}$ & $\mathrm{ft}$ & Default $=12$ & User Input \\
\hline Penstock Length & $\mathrm{L}_{\mathrm{p}}$ & $\mathrm{ft}$ & & Assumption 4 to $8 \mathrm{H}$ \\
\hline No of Penstock & $N_{p}$ & & $4 \mathrm{Q} /\left(\pi \mathrm{V}_{\operatorname{maxp}} \mathrm{d}_{\operatorname{maxp}}{ }^{2}\right)$ & See note \\
\hline Penstock Flow & $Q_{p}$ & $\mathrm{cfs}$ & $\mathrm{Q} / \mathrm{N}_{\mathrm{p}}$ & \\
\hline Penstock Unit Diameter & $d_{p}$ & $\mathrm{ft}$ & $\left(4 \mathrm{Q}_{\mathrm{p}} / \pi \mathrm{V}_{\operatorname{maxp}}\right)^{0.5}$ & \\
\hline Penstock Unit Area & $A_{\text {ip }}$ & $\mathrm{ft}^{2}$ & $\pi \mathrm{d}_{\mathrm{p}}^{2} / 4$ & \\
\hline Penstock Design Capacity & $\mathrm{Q}_{\mathrm{u}}$ & $\mathrm{cfs}$ & $A_{i p} V_{\operatorname{maxp}}$ & \\
\hline Valve Closing Time & $t_{c}$ & $\mathrm{~s}$ & Default $=3$ & \\
\hline Acceleration due to Gravity & $\mathrm{g}$ & $\mathrm{ft} / \mathrm{s}^{2}$ & 32.17 & \\
\hline Gross Hydrostatic Pressure ${ }^{11}$ & $\mathrm{P}_{\mathrm{o}}$ & $\mathrm{ft}$ & $\mathrm{H}$ & \\
\hline Allievi Constant & $\mathrm{N}_{\mathrm{a}}$ & & $\left(\mathrm{L}_{\mathrm{p}} \mathrm{V}_{\operatorname{maxp}} / \mathrm{g} \mathrm{P}_{\mathrm{o}} \mathrm{t}_{\mathrm{c}}\right)^{2}$ & \\
\hline Maximum Over Pressure & $\Delta \mathrm{P}$ & $\mathrm{ft}$ & $P_{o}\left\{0.5 \mathrm{~N}_{\mathrm{a}} \pm\left(0.25 \mathrm{~N}_{\mathrm{a}}{ }^{2}+\mathrm{N}_{\mathrm{a}}\right)^{0.5}\right\}$ & \\
\hline Total pressure by Penstock & $\mathrm{P}$ & $\mathrm{ksi}$ & $433 \mathrm{E}^{-6}\left(\mathrm{P}_{\mathrm{o}}+\Delta \mathrm{P}\right)$ & \\
\hline Weld Efficiency** & $\mathrm{k}_{\mathrm{f}}$ & & $\begin{array}{l}\text { X-ray inspected weld \& stress } \\
\text { relieved }=1\end{array}$ & \\
\hline $\begin{array}{c}\text { Allowable Tensile Stress of } \\
\text { Steel }\end{array}$ & $\sigma_{\mathrm{f}}$ & ksi & 24 & Use Grade 60 Steel \\
\hline $\begin{array}{l}\text { Extra Thickness for } \\
\text { Corrosion }\end{array}$ & $e_{s}$ & inch & $1 / 8$ & \\
\hline Penstock Wall Thickness & $t_{p}$ & inch & $\left(\mathrm{Pd}_{\mathrm{p}} / 2 \sigma_{\mathrm{f}} \mathrm{k}_{\mathrm{f}}\right)+\mathrm{e}_{\mathrm{s}}$ & \\
\hline Penstock Volume & $\mathrm{V}_{\mathrm{p}}$ & $\mathrm{ft}^{3}$ & $\left(\pi d_{p} t_{p} / 12\right) L_{p}$ & \\
\hline Density of MS Steel & $\rho_{\mathrm{s}}$ & tonne/ $/ \mathrm{ft}^{3}$ & 0.2205 & \\
\hline Penstock Weight & $\mathrm{W}_{\mathrm{p}}$ & tonne & $\mathrm{V}_{\mathrm{p}} \rho_{\mathrm{s}}$ & \\
\hline Total Penstock Weight & $\mathrm{W}_{\mathrm{tp}}$ & tonne & $N_{p} W_{p}$ & \\
\hline
\end{tabular}

Note: Penstock design corresponds to circular pipe design. Q is design flow in cfs. $\mathrm{N}_{\mathrm{p}}$ should be round up to integer number.

*Generally provided as 10,12 , or $14 \mathrm{ft} / \mathrm{s}$ for small hydropower (USBR, 1980).

** Either spiral or butt and seam welded penstock is used.

11 The model uses gross hydrostatic pressure for penstock design. Generally transient pressure which lies above gross hydrostatic pressure is used for detail engineering design. Typical penstocks are designed for peak and minimum transient pressure. 


\section{Penstock Support}

Anchor blocks or thrust blocks ${ }^{12}$ and saddles are used as penstock support. The model only designs saddle support. The penstock saddle supports should prevent penstock pipe from sagging and overstressed. Number of saddle support is determined based on unit weight of saddle support and penstock diameter (Table 18). The volume and weight of saddle support is estimated using weight of penstock and water. Other penstock supports such as anchor block design, is excluded from the model.

Table 18. Penstock support design in m-PSH model.

\begin{tabular}{|c|c|c|c|c|}
\hline Items & Symbol & Units & Formula & Source/Comment \\
\hline Penstock Supports* & & & & ESHA, 2004 \\
\hline Density of Steel & $\rho_{\mathrm{s}}$ & $\mathrm{lb} / \mathrm{ft}^{3}$ & 493.17 & \\
\hline Density of Water & $\rho_{\mathrm{w}}$ & $\mathrm{lb} / \mathrm{ft}^{3}$ & 62.4 & \\
\hline Penstock Horizontal Angle & $\theta$ & $\operatorname{deg}$ & $\operatorname{Sine}^{-1}(1 / \mathrm{L}: \mathrm{H})$ & see note \\
\hline Weight of Penstock & $\mathrm{W}_{\mathrm{p}}^{\prime}$ & $\mathrm{lb} / \mathrm{ft}$ & $\pi\left(d_{p}+t_{p}\right) t_{p}^{\prime} \rho_{s}^{\prime}$, where $t_{p}=t_{p} / 12$ & see note \\
\hline Weight of Water & $\mathrm{W}_{\mathrm{w}}^{\mathrm{i}}$ & $\mathrm{lb} / \mathrm{ft}$ & $\pi \mathrm{d}_{\mathrm{p}}^{2} / 4 \rho_{\mathrm{w}}$ & \\
\hline Total Weight & $\mathrm{W}_{\mathrm{t}}^{\prime}$ & $\mathrm{lb} / \mathrm{ft}$ & $\mathrm{W}_{\mathrm{p}}+\mathrm{W}_{\mathrm{w}}$ & \\
\hline $\begin{array}{c}\text { Maximum Length Between } \\
\text { Supports }\end{array}$ & $\mathrm{L}_{\text {smax }}$ & $\mathrm{ft}$ & $\left.182.61\left[\left(\mathrm{~d}_{\mathrm{p}}+0.0147\right)^{4}-\mathrm{d}_{\mathrm{p}}{ }^{4}\right)\right]^{1 / 3} / \mathrm{W}_{\mathrm{t}}^{\prime}$ & \\
\hline $\begin{array}{c}\text { Vertical Component of } \\
\text { Weight }\end{array}$ & $\mathrm{W}_{\mathrm{v}}$ & $\mathrm{lb}$ & $\mathrm{W}_{\mathrm{t}}^{\prime} \mathrm{L}_{\mathrm{smax}} \operatorname{Cos} \theta$ & \\
\hline Unit Weight of Concrete & $\mathrm{W}_{\mathrm{uc}}$ & $\mathrm{lb} / \mathrm{ft}^{3}$ & 140 & \\
\hline Unit Volume of Concrete & $\mathrm{V}_{\mathrm{cs}}$ & $\mathrm{yd}^{3}$ & $\mathrm{~W}_{\mathrm{v}} / 27 \mathrm{~W}_{\mathrm{uc}}$ & \\
\hline Penstock No of Supports & $\mathrm{N}_{\mathrm{p}}$ & & $\mathrm{L}_{\mathrm{p}} / \mathrm{L}_{\mathrm{smax}}$ & \\
\hline Total Volume of Concrete & $\mathrm{V}_{\mathrm{tcs}}$ & $\mathrm{yd}^{3}$ & $\mathrm{~N}_{\mathrm{p}} \mathrm{V}_{\mathrm{cs}}$ & \\
\hline
\end{tabular}

Note: $\mathrm{L}$ : $\mathrm{H}$ is ratio of penstock length and design head. $\mathrm{d}_{\mathrm{p}}$ is penstock diameter in $\mathrm{ft}, \mathrm{t}_{\mathrm{p}}$ is penstock thickness in inch. *Corresponds to water flowing through circular pipe.

\section{Shut-off Valve}

The shut-off valve is either fully open or fully closed and controls penstock water flow through the turbine. The model allows user to select butterfly or spherical valve. The model assumes one valve for each reversible pump turbine unit and two valves for each standard pump turbine unit (i.e. when both pump are turbine are placed separately). The valve diameter is assumed as equal to the penstock diameter (Table 19).

Table 19. Shut-off valve design in m-PSH model.

\begin{tabular}{clccc}
\hline Items & Symbol & Units & Formula & Source/Comment \\
\hline Shut-off Valve & & & Butterfly, Spherical & User Input \\
Valve Type & $\mathrm{V}_{\mathrm{t}}$ & & $\mathrm{d}_{\mathrm{ip}}$ & see note \\
Valve Inlet Diameter & $\mathrm{d}_{\mathrm{vi}}$ & $\mathrm{ft}$ & $\pi \mathrm{d}_{\mathrm{vi}}{ }^{2} / 4$ & \\
Valve Unit Area & $\mathrm{A}_{\mathrm{vu}}$ & $\mathrm{ft}^{2}$ & & \\
\hline
\end{tabular}

Note: $\mathrm{d}_{\mathrm{ip}}$ is inside penstock diameter in $\mathrm{ft}$

\section{Tailrace}

The tailrace conveys water from the turbine to a lower storage or conveys water from the lower storage to a pump. The model computes tailrace dimensions (length, width, and height) in terms of turbine runner diameter for the selected turbine types using USBR (1980) design (Table 20). The model also allows user

12 The cost of anchor block should be reflected via adjusting civil works contingency percent. 
to manually overwrite the estimated tailrace length. The tailrace can be specified as a new, existing, or refurbishment type.

Table 20. Tailrace design in m-PSH model

\begin{tabular}{clccc}
\hline Items & Symbol & Units & Formula & Source/Comment \\
\hline Tailrace & & & & USBR, 1980 \\
Length of Tailrace & $\mathrm{L}_{\mathrm{t}}$ & $\mathrm{ft}$ & Default $=5.4 \mathrm{D}+12$ & User Input \\
Width of Tailrace & $\mathrm{B}_{\mathrm{t}}$ & $\mathrm{ft}$ & $3.3 \mathrm{D}$ & see note \\
Depth of Tailrace & $\mathrm{D}_{\mathrm{t}}$ & $\mathrm{ft}$ & $1.5 \mathrm{D}$ & \\
Tailrace Volume & $\mathrm{V}_{\mathrm{t}}$ & $\mathrm{ft}^{3}$ & $\mathrm{~L}_{\mathrm{t}} \mathrm{B}_{\mathrm{t}} \mathrm{H}_{\mathrm{t}}$ & \\
Total Tailrace Volume & $\mathrm{V}_{\mathrm{tt}}$ & $\mathrm{yd}^{3}$ & $0.037 \mathrm{~V}_{\mathrm{t}}$ & \\
\hline
\end{tabular}

Note: $\mathrm{D}$ corresponds to turbine runner diameter in $\mathrm{ft}$, computed under electromechanical section. Current tailrace dimensions are adapted from USBR (1980) Vertical Francis Turbine

\section{A.1.1.4. POWERHOUSE}

The model uses preliminary engineering based approach to design a single and multiple unit powerhouse. USBR (1980) provides powerhouse dimensions such as length, width and height in terms of runner diameter for the selected turbine technology (Figure 37).

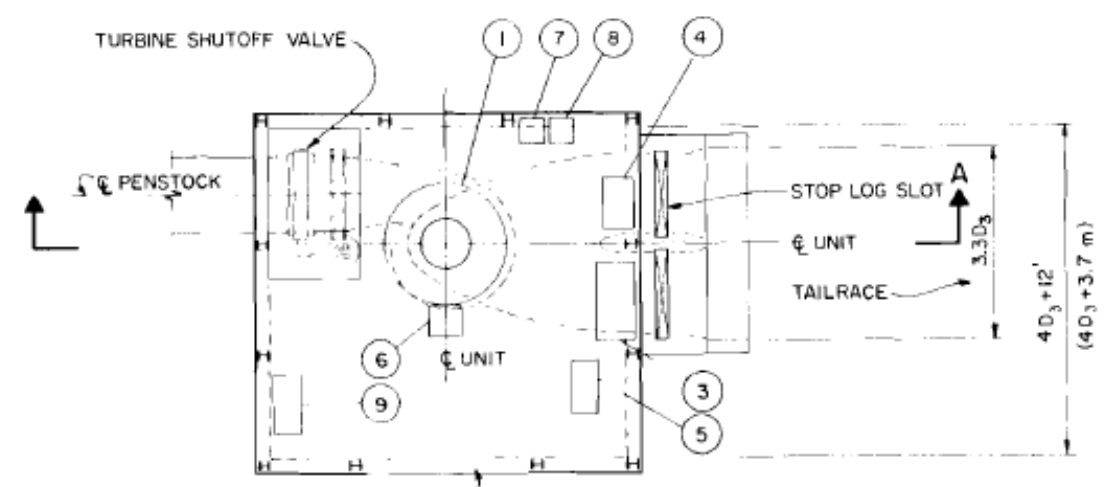

a) Plan view

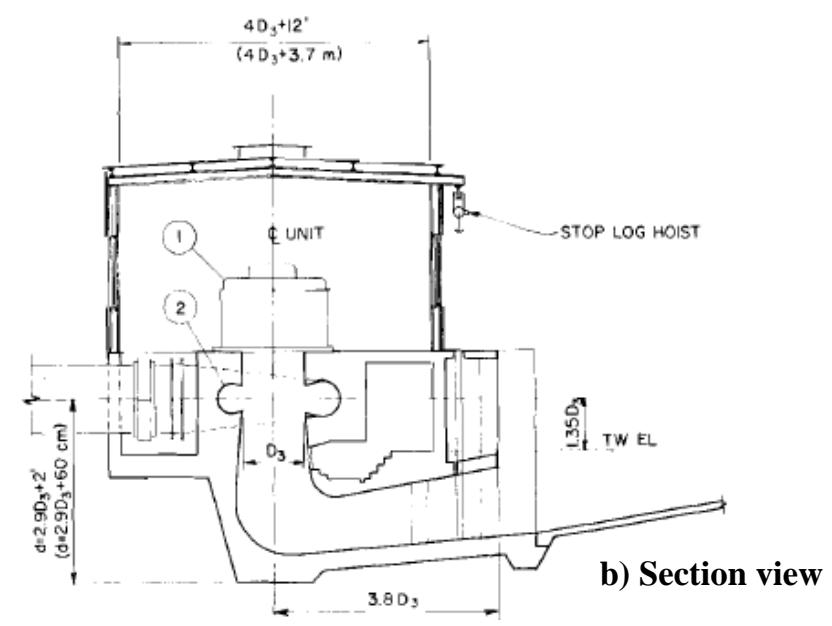

Figure 37. Typical plan of a vertical unit Francis powerhouse ${ }^{13}$ (USBR, 1980)

13 The section view shows typical cross section of Francis turbine for conventional hydropower for illustration purpose only. Typical Francis pump-turbine cross section will be different. 
Table 21 provides a simplified powerhouse design using USBR (1980) Francis turbine attributes. The calculation of runner diameter is described separately under electromechanical equipment design section. The powerhouse floor thickness and wall thickness is assumed as $2 \mathrm{ft}$, this value can be manually overwritten by user. The powerhouse surface area is determined by multiplying the computed length and width of a powerhouse. The model computes powerhouse excavation volume based on the computed powerhouse area. The model assumes $50 \%$ rock and $50 \%$ soil materials for the powerhouse excavation ${ }^{14}$ works.

Table 21. Powerhouse design in m-PSH model.

\begin{tabular}{|c|c|c|c|c|}
\hline Items & Symbol & Unit & Formula & Source \\
\hline Turbine Runner Diameter ${ }^{15}$ & $\mathrm{D}$ & $\mathrm{ft}$ & $0.617 \mathrm{Q}_{\mathrm{p}}^{0.429} \mathrm{H}^{-0.093}$ & See note* \\
\hline Number of Turbine Unit & $\mathrm{N}$ or $\mathrm{n}$ & & $\mathrm{N}_{\mathrm{p}}$ & See note \\
\hline Powerhouse Dimensions & & & & USBR, 1980 \\
\hline Thickness of Wall & $\mathrm{t}_{\mathrm{w}}$ & $\mathrm{ft}$ & 2 & Assumption \\
\hline Thickness of Floor & $t_{f}$ & $\mathrm{ft}$ & 2 & Assumption \\
\hline Length & $\mathrm{L}_{\mathrm{ph}}$ & $\mathrm{ft}$ & & \\
\hline $\begin{array}{l}\text { Single Unit } \\
\text { Multiple Units }\end{array}$ & & & $\begin{array}{l}4 \mathrm{D}+12+2 \mathrm{t}_{\mathrm{w}} \\
2(4 \mathrm{D}+6)+3.3 \mathrm{D}(\mathrm{n}-2)+2 \mathrm{t}_{\mathrm{w}}\end{array}$ & \\
\hline Width of Powerhouse & $\mathrm{B}_{\mathrm{ph}}$ & $\mathrm{ft}$ & $4 \mathrm{D}_{\max }+12+2 \mathrm{t}_{\mathrm{w}}$ & see note \\
\hline Depth of Excavation & $\mathrm{D}_{\mathrm{ph}}$ & $\mathrm{ft}$ & $2.9 \mathrm{D}_{\max }+\mathrm{t}_{\mathrm{f}}$ & \\
\hline Height above ground level & $\mathrm{H}_{\mathrm{phf}}$ & $\mathrm{ft}$ & 18 & Assumption \\
\hline $\begin{array}{l}\text { Powerhouse Surface Area } \\
\text { Powerhouse Excavation Volume }\end{array}$ & $\begin{array}{l}\mathrm{A}_{\mathrm{ph}} \\
\mathrm{V}_{\mathrm{ph}} \\
\end{array}$ & $\begin{array}{l}\mathrm{ft}^{2} \\
\mathrm{yd}^{3}\end{array}$ & $\begin{array}{l}\mathrm{L}_{\mathrm{ph}} \mathrm{B}_{\mathrm{ph}} \\
\mathrm{L}_{\mathrm{ph}} \mathrm{B}_{\mathrm{ph}} \mathrm{D}_{\mathrm{ph}} / 27 \\
\end{array}$ & \\
\hline \multicolumn{5}{|c|}{$\begin{array}{l}\text { Note: } \mathrm{Q}_{\mathrm{p}} \text { is penstock flow in cfs, } \mathrm{H} \text { is design head in } \mathrm{ft}, \mathrm{Np} \text { is total number of penstock, } \mathrm{D}_{\max } \text { is maximum runner } \\
\text { diameter among turbine units (in } \mathrm{ft} \text { ) } \\
\text { * Regression analysis results using } 16 \text { data from Gordon (2001). }\end{array}$} \\
\hline \multicolumn{5}{|c|}{$\begin{array}{l}\text { A relationship between various powerhouse design components including installed capacity, surface area } \\
\text { and excavation volume, used in the m-PSH model is provided in Figure } 38 \text {. As seen in the figure, an } \\
\text { apparent positive correlation exists between design head and installed capacity, which demonstrates that } \\
\text { the project capacity increases with increase in design head. In addition, the figure shows that unit surface } \\
\text { area or unit excavation generally decreases with project head or capacity, indicating that larger project can } \\
\text { have economies of scale associated with larger hydropower development. }\end{array}$} \\
\hline
\end{tabular}

14 Unlike powerhouse, the soil and rock excavation percentage are assumed $90 \%$ and $10 \%$, respectively for storage reservoir construction in the model.

15 This turbine runner diameter is based on a standard turbine runner only. The m-PSH model uses this formula to compute runner diameter for both standard and reversible pump-turbine system. 


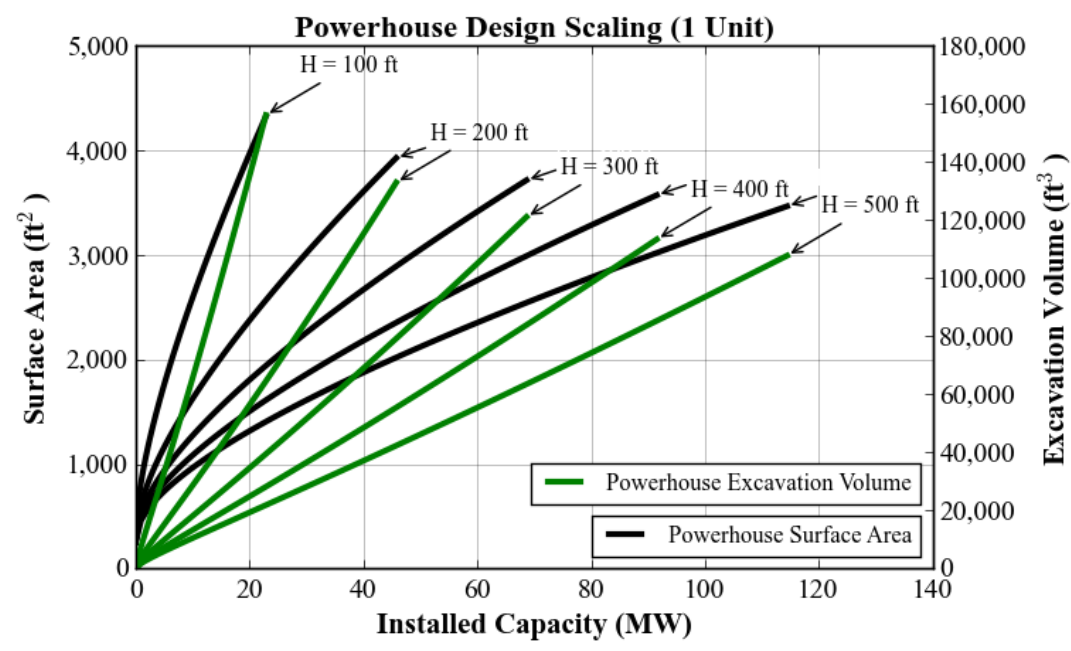

Figure 38. Example of powerhouse design scaling.

\section{A.1.2. ELECTROMECHANICAL EQUIPMENT DESIGN}

The electro-mechanical equipment converts energy available in flowing water into electrical energy. It is an important project feature and is located inside the powerhouse. It includes powertrain equipment and ancillary electrical and mechanical equipment. Brief descriptions of major electromechanical components used in the model are described below.

\section{Turbine-Generator}

The Turbine-Generator converts potential energy of moving water to mechanical energy. It includes runner, shaft, and wicket gate and draft tube. The model computes turbine runner diameter using design flow and head (Table 22). Generator is coupled with turbine through turbine shaft and converts mechanical energy into electrical energy. It includes stator, rotor, exciter and other required power electronics and mechanical components. In addition, a governor is provided in the turbine as main controller to control the speed or power output. No explicit design is provided for the generator and other components of turbine in the model.

Table 22. Turbine design in m-PSH model

\begin{tabular}{lllll}
\hline Items & Symbol & Unit & Formula & Source \\
\hline Design Head & $\mathrm{H}$ & $\mathrm{ft}$ & & User Input \\
Turbine Design Flow & $\mathrm{Q}_{\mathrm{t}}$ & $\mathrm{cfs}$ & $\mathrm{Q}_{\mathrm{p}}$ & see note \\
& $\mathrm{D}$ & $\mathrm{ft}$ & $0.617 \mathrm{Q}^{0.429} \mathrm{H}^{-0.093}$ & ORNL1 $^{*}$ \\
Turbine Runner Diameter & & & & \\
\hline
\end{tabular}

Note: $Q_{p}$ corresponds to penstock design flow. $P=Q_{t} H \eta / 11800$ (Capacity in $\left.M W\right), \eta$ is turbine efficiency 
*Regression analysis results using 16 data from Gordon (2001).

\section{Pump}

The pump ${ }^{16}$ converts mechanical energy to hydraulic energy. The model uses centrifugal pump to transfer water from lower reservoir to the upper reservoir. No explicit design of pump is provided in the model.

\section{Efficiency}

The model assumes $90 \%$ generating unit efficiency and $82 \%$ round trip efficiency as a default, which can be overwritten by the user.

\section{Ancillary Electrical \& Mechanical Works}

Both ancillary electrical and mechanical system are used as a non-generating equipment during plant operation. The ancillary electrical system includes station power system (SPS), station auxiliary transformer, instruments \& control. The ancillary plant mechanical system includes lubrication system, raw water (cooling) system, compressed air, and station maintenance equipment. No explicit design of ancillary electrical and mechanical works is provided in the model.

\section{A.1.3. ELECTRICAL INFRASTRUCTURE DESIGN}

Electrical infrastructure collects power from generators and delivers to the grid. It includes transmission line, transformers, and switchyard and substation. Currently, there is no explicit design for electrical infrastructure works in the model. Instead, a user defined transmission line length and transformer voltage is used.

16 In a pumped turbine, the pumping cycle generally controls the hydraulic design to make the pumping operations as efficient as possible to reduce pumping energy demand. 


\section{A.2. COST}

Cost estimation ${ }^{17}$ provides the probable cost of a project within a range of uncertainty. Different types of cost estimation are available to match the purpose of estimation. Most common type of cost estimations are:

- Detail estimate: it is the most accurate method of estimation and includes cost of everything. This type of estimates requires a complete project drawing. Detail cost estimation is performed just before starting a project construction and could include a quotation for material and equipment.

- Unit based estimate: this is the approximate method of cost estimation. Cost is estimated by multiplying computed dimension (e.g. length, area, volume, etc.) and standard unit rate. It uses linear relationship between unit rate and dimension of project components. This simple cost estimation is suitable for early stage project development.

- Parametric estimate: this method uses equations to estimate the project cost. The cost equation provides empirical relation between project parameters and cost. It is more complex than unit based cost estimation. This type of cost estimation is performed in conceptual project design.

The m-PSH model uses parametric and unit based estimate to compute project cost. AACE (2014) assigns quantitative cost uncertainty based on project maturity and end use. Parametric and unit based estimates falls under AACE class 5 category, which accuracy typically ranges from $-50 \%$ (low end) to $+100 \%$ (high end).

The m-PSH model estimated cost using above methods spans over the period of time. Escalation of these costs to a current or common period is essential to provide more accurate up to date project cost information. Cost indices are widely used to convert historical cost to a current cost estimate.

The m-PSH model uses four types of historical cost indices to escalate original cost to $2015 \$$.

1. U.S. Bureau of Reclamation (USBR) Construction Cost Trends (CCT) and USBR Composite Index (USBR, 2016)

2. Engineering News-Record (ENR) Construction Cost Indices (ENR, 2016)

3. U.S. Consumer Price Index (CPI) (BLS, 2016)

These are the common cost indices used by the hydropower industry. Figure 39 provides a graphical comparison of all cost indices used in the model, from 1980 to 2015.

17 The ORNL hydropower cost model report (O'Connor et al., 2016) and integrated hydropower cost model (Chalise et al., 2016) provide additional details about the design methodology adopted in the development of this model. 


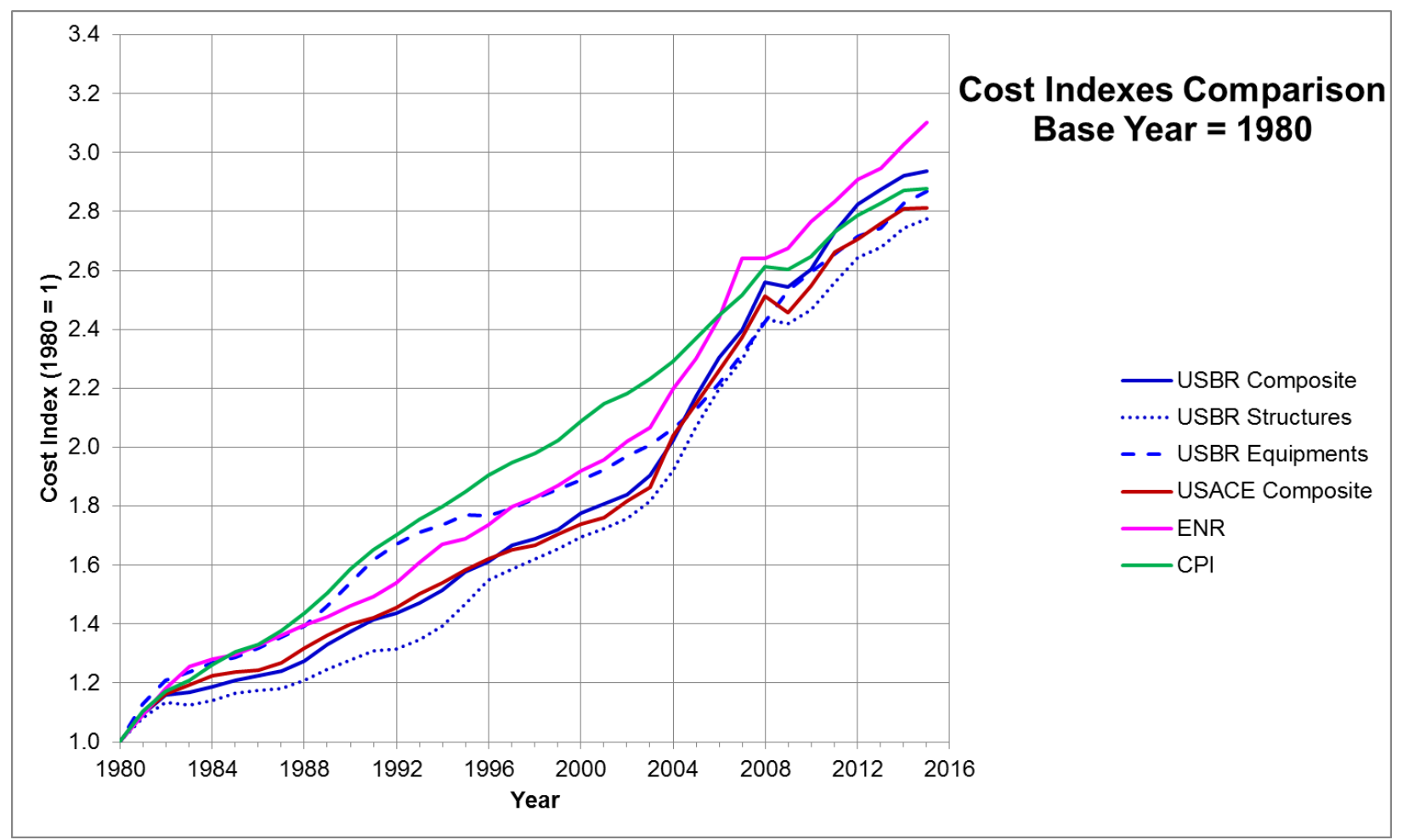

Figure 39. Cost indices comparison (modified from O’Connor et al., 2015a).

The USBR CCT provides historical quarterly cost indices of 35 different categories including dam, power plants, and composite trend. The original cost indices were derived from the USBR hydropower plants constructed in the mid-1980s. Since then USBR has involve in fewer construction projects. The model uses annual average value of three cost indices such as

- Powerplant - Structures and Improvements

- $\quad$ Powerplant - Equipment

- Composite Index

ENR provides historical monthly Construction Cost Index and Building Cost Index for 20 cities and national average. Both cost indices were derived from material prices and labor rates. It is one of the oldest cost index method, and widely used in the construction industry. The model uses national average value of annual ENR Construction Cost Index.

RS Means provides historical quarterly cost index for 30 major US cities along with national average. It is mostly used by light commercial industry. The model uses national average value of annual ENR Construction Cost Index.

The Bureau of Labor Statistics publishes historical monthly Consumer Price Index of goods and services for urban consumers. It is less commonly used in the construction industry. 
The model uses a bottom-up approach to estimate initial capital cost (ICC). The ICC, also referred to as direct construction cost, is broken down to five major categories.

1. Civil Works: includes site preparation, storage, water conveyances and powerhouse costs

2. Electro-mechanical Equipment: includes turbine-generator, pump and equipment accessories costs.

3. Electrical Infrastructure: includes transmission line, transformers, switchyard, and substation costs.

4. Engineering and Construction Management: includes engineering design, procurement, administration, and project commissioning costs.

5. Environmental Mitigation and Regulatory Compliance: includes one or more type of mitigation technologies such as fish and wildlife mitigation, recreation mitigation, historical and archeological mitigation, water quality monitoring, and fish passage.

Each category, with the exception of engineering and construction management, is further partitioned into sub-categories that reflect major cost drivers.

In addition to ICC, the model also estimates project development cost, which includes all nonconstruction activities from project inception to financial close (e.g. permitting, licensing, site acquisition, initial engineering, and financial costs).

The following section provides a brief description of major m-PSH cost components. 


\section{A.2.1. CIVIL WORKS}

\section{A.2.1.1. SITE PREPARATION}

The site preparation cost in m-PSH model includes the cost of site access road development and site development works (e.g. levelling \& grading, drainage, and erosion control activities) (Table 23). NRC (2004) provides an empirical relationship between site access road length and cost in 2001 CAD. An escalation factor of 1.09 was used to converts access road cost from 2001 CAD to 2015\$. USBR (1980) cost curves provides an empirical relationship between site development area and cost. An escalation factor of 3.41 based on USBR CCT Power Plant CCT Index was used to converts site development cost from $1978 \$$ to $2015 \$$.

Table 23. Site preparation cost estimates in m-PSH model.

\begin{tabular}{cccccc}
\hline Items & Unit & Quantity & Rate & Cost (2015\$) & $\begin{array}{c}\text { Source/Modified } \\
\text { from }\end{array}$ \\
\hline Site Access & $\mathrm{km}$ & $\mathrm{L}_{\mathrm{r}}$ & 15,770 & $\begin{array}{c}27,370 \mathrm{~L}_{\mathrm{r}}{ }^{0.9} \mathrm{~F}_{\mathrm{t}}^{\dagger} \mathrm{F}_{\mathrm{c}}^{\dagger} \\
\left(\mathrm{F}_{\mathrm{t}}=1,3, \text { or 5) }\right.\end{array}$ & $\mathrm{NRC}, 2004$ \\
$\begin{array}{c}\text { Site Access } \\
\text { Road }\end{array}$ & & & & $26 \mathrm{~A}_{\mathrm{g}} \mathrm{F}_{\mathrm{c}}^{\dagger}$ & \\
$\begin{array}{c}\text { Site Preparation } \\
\text { Leveling and } \\
\text { Grading } \\
\begin{array}{c}\text { Drainage } \\
\text { Erosion Control }\end{array}\end{array}$ & $\mathrm{yd}^{2}$ & $\mathrm{~A}_{\mathrm{g}}$ & 26 & $14 \mathrm{~A}_{\mathrm{d}} \mathrm{F}_{\mathrm{c}}^{\dagger}$ & $\mathrm{USBR}, 1980$ \\
\hline
\end{tabular}

*All costs are escalated to $2015 \$$ using USBR CCT Structure Index.

$* *$ Cost equation is originally in $2001 \mathrm{CAD}$. A conversion rate $1 \mathrm{CAD}=0.68 \$$ is used $\dagger$ Coefficients correspond to a terrain complexity of Low, Medium, or High, respectively. $\$$ Coefficients correspond to type of a construction New $=1$, Refurbishment $=0.5$, or Existing $=0.2$, respectively .

\section{A.2.1.2. UPPER AND LOWER RESERVOIR}

\section{Storage Reservoir}

The storage reservoir cost includes cost of excavation, riprap, and geomembrane works (Table 24). The m-PSH model's reservoir excavation cost is based on USBR (1980) and assumes a soil excavation rate $\left(2 \$ / \mathrm{yd}^{3}\right)$ and rock excavation rate $\left(10 \$ / \mathrm{yd}^{3}\right)$, provided in $1978 \$$. These excavation cost are escalated to $2015 \$$ using an escalation factor of 3.41 based on the USBR CCT Powerplant Structure Index.

The cost information on riprap and geomembrane was collected from an online report published in public website ${ }^{18}$ and assumed minimum riprap rate $\left(30 \$ / \mathrm{yd}^{3}\right)$ and geomembrane rate as equivalent to turf reinforcement mats $\left(6 \$ / \mathrm{yd}^{3}\right)$. The document did not provide information on cost estimation year. For the modeling purpose, both the riprap and geomembrane rate was assumed given in $2013 \$$. An escalation factor of 1.036 based on USBR CCT Power Plant CCT Structure Index was used to converts these cost from $2013 \$$ to $2015 \$$.

18

http://www.damsafety.org/media/Documents/DownloadableDocuments/ResourcesByTopic/EMI_TS20_2013/PRES ENTATION27.pdf 
Table 24. Storage reservoir cost estimates in m-PSH model.

\begin{tabular}{|c|c|c|c|c|c|}
\hline Items & Unit & Quantity & Rate & Cost $(2015 \$)^{\dagger}$ & $\begin{array}{c}\text { Source/Modified } \\
\text { from }\end{array}$ \\
\hline \multicolumn{6}{|l|}{ Reservoir } \\
\hline Soil Excavation & $\mathrm{yd}^{3}$ & $\mathrm{~V}_{\mathrm{s}}$ & 7 & $6.3 \mathrm{~V}_{\mathrm{s}} \mathrm{F}_{\mathrm{c}}^{+}$ & USBR, 1980 \\
\hline Rock Excavation & $\mathrm{yd}^{3}$ & $\mathrm{~V}_{\mathrm{s}}$ & 34 & $3.4 \mathrm{~V}_{\mathrm{s}} \mathrm{F}_{\mathrm{c}}^{+}$ & USBR, 1980 \\
\hline Riprap & $\mathrm{yd}^{3}$ & $\mathrm{~V}_{\mathrm{r}}$ & 31 & $31 \mathrm{~V}_{\mathrm{r}} \mathrm{F}_{\mathrm{c}}^{+}$ & Web $1^{*}$ \\
\hline Geo-membrane & $\mathrm{yd}^{3}$ & $\mathrm{~V}_{\mathrm{s}}$ & 6.2 & $6.2 \mathrm{~V}_{\mathrm{s}} \mathrm{F}_{\mathrm{c}}^{+}$ & Web $1 *$ \\
\hline \multicolumn{6}{|c|}{$\begin{array}{l}* \text { All costs are escalated to } 2015 \$ \text { using USBR CCT Structure Index. } \\
\text { † Coefficients correspond to type of a construction New }=1 \text {, Refurbishment }=0.5 \text {, or Existing }=0.2 \text {, respectively. } \\
\text { Reservoir }{ }^{*} \text { m-PSH model assumes } 90 \% \text { soil and } 10 \% \text { rock excavation in reservoirs } \\
\text { construction. }+ \text { http://www.damsafety.org/media/Documents/DownloadableDocuments/ResourcesByTopic/EMI_TS }\end{array}$} \\
\hline
\end{tabular}

\section{Storage Tank}

Michigan State (2003) provides cost information for different type of tanks including welded steel, bolted steel, concrete water tanks (Table 25). The total tank cost includes average cost of completely erected surface reservoir and tank accessories. An empirical relationship was established between tank size and tanks in 2003\$. An escalation factor of 1.528 based on USBR CCT Power Plant CCT Structure Index was used to converts these cost from $2003 \$$ to $2015 \$$.

Table 25. Storage tank cost estimates in m-PSH model.

\begin{tabular}{|c|c|c|c|c|c|}
\hline Items & Unit & Quantity & Rate & $\operatorname{Cost}(2015 \$)^{\dagger}$ & $\begin{array}{c}\text { Source/Modified } \\
\text { from }\end{array}$ \\
\hline \multicolumn{6}{|l|}{ Storage Tank } \\
\hline & $\begin{array}{c}\text { million } \\
\text { gallon }\end{array}$ & $\mathrm{V}_{\mathrm{sg}}^{\mathrm{r}}$ & & $\begin{array}{c}\text { For Concrete Water Tank, } \\
832,870 \mathrm{~V}_{\mathrm{sg}} 0.684 \mathrm{~N}_{\mathrm{t}} \\
\text { For Weld Steel Tank, } \\
560,895 \mathrm{~V}_{\mathrm{sg}}^{\prime 0.714} \mathrm{~N}_{\mathrm{t}} \\
\text { For Bolted Steel Tank, } \\
412,945 \mathrm{~V}_{\mathrm{sg}} 0.849 \mathrm{~N}_{\mathrm{t}}\end{array}$ & $\begin{array}{c}\text { Michigan State, } \\
2003\end{array}$ \\
\hline
\end{tabular}

$\dagger$ All costs are escalated to $2015 \$$ using USBR CCT Structure Index.

$\mathrm{V}_{\mathrm{sg}}$ is gross volume of storage (in million gallons) $=\mathrm{V}_{\mathrm{sg}} / 1,000,000 . \mathrm{N}_{\mathrm{t}}$ is the number of storage tanks 


\section{A.2.1.3. WATER CONVEYANCE SYSTEM COST}

The water conveyance system cost includes the costs of the intake, intake gate, penstock, penstock supports, valves, and the tailrace (Table 26). Each cost component of water conveyances system is briefly describe below. An example of water conveyance cost scaling is provided in Figure 40.

Table 26. Water conveyance system cost estimates in m-PSH model.

\begin{tabular}{|c|c|c|c|c|c|}
\hline Items & Unit & Quantity & Rate & $\operatorname{Cost}(2015 \$)^{*}$ & $\begin{array}{l}\text { Source/ } \\
\text { Modified } \\
\text { from }\end{array}$ \\
\hline Intake & $\mathrm{cfs}$ & $\begin{array}{l}\mathrm{Q}_{\mathrm{iu}} \\
\mathrm{N}_{\mathrm{i}}\end{array}$ & & $\begin{array}{c}3.41 \mathrm{~N}_{\mathrm{i}}\left(\mathrm{C}_{1} \mathrm{Q}_{\mathrm{iu}}{ }^{3}+\mathrm{C}_{2} \mathrm{Q}_{\mathrm{iu}}{ }^{2}+\mathrm{C}_{3} \mathrm{Q}_{\mathrm{iu}}+\mathrm{C}_{4}\right) \mathrm{F}_{\mathrm{c}}^{\dagger} \\
\text { For } \mathrm{Q}_{\mathrm{iu}} \leq 1500 \mathrm{cfs}, \\
\mathrm{C}_{1}=\mathrm{C}_{2}=0, \mathrm{C}_{3}=150, \mathrm{C}_{4}=-94,019 \\
\text { For } \mathrm{Q}_{\mathrm{iu}}>1500 \mathrm{cfs}, \\
\mathrm{C}_{1}=-2 \mathrm{E}^{-6}, \mathrm{C}_{2}=4 \mathrm{E}^{-2}, \mathrm{C}_{3}=14.8, \mathrm{C}_{4}=19,844\end{array}$ & USBR, 1980 \\
\hline Intake Gate & $\mathrm{ft}^{2}$ & $\begin{array}{l}\mathrm{A}_{\text {ig }} \\
\mathrm{T}_{\mathrm{ig}}\end{array}$ & & $\begin{array}{c}3.41\left(\mathrm{C}_{1} \mathrm{~A}_{\mathrm{ig}}+\mathrm{C}_{2}\right) \mathrm{F}_{\mathrm{c}}^{\dagger} \\
\text { For Slide Gate: } \mathrm{C}_{1}=147, \mathrm{C}_{2}=384 \\
\text { For Radial Gate: } \mathrm{C}_{1}=249, \mathrm{C}_{2}=-6250\end{array}$ & USBR, 1980 \\
\hline Penstock & tonne & $\mathrm{W}_{\mathrm{tp}}$ & 6,000 & $6,000 \mathrm{~W}_{\mathrm{tp}} \mathrm{F}_{\mathrm{c}}^{\dagger}$ & $\mathrm{EC}^{\ddagger}, 2015$ \\
\hline $\begin{array}{c}\text { Penstock } \\
\text { Support }\end{array}$ & $\mathrm{yd}^{3}$ & $\mathrm{~V}_{\mathrm{tcs}}$ & 93 & $93 \mathrm{~V}_{\mathrm{tcs}} \mathrm{F}_{\mathrm{c}}^{\dagger}$ & $\mathrm{Web}^{\S}, 2015$ \\
\hline Valve $^{\dagger}$ & $\mathrm{ft}^{2}$ & $\mathrm{~A}_{\mathrm{vu}}$ & & $\begin{array}{c}3.41\left(\mathrm{C}_{1} \mathrm{~A}_{\mathrm{vu}}+\mathrm{C}_{2}\right) \mathrm{F}_{\mathrm{c}}^{\dagger} \\
\text { For Butterfly Valve: } \mathrm{C}_{1}=1,641, \mathrm{C}_{2}=6587,\end{array}$ & USBR, 1980 \\
\hline Tailrace $^{* * *}$ & $\mathrm{yd}^{3}$ & $\mathrm{~V}_{\mathrm{tt}}$ & & $\begin{array}{c}\left(0.625 \mathrm{C}_{1} \mathrm{~V}_{\mathrm{tt}}+0.625 \mathrm{C}_{2} \mathrm{~V}_{\mathrm{tt}}+51,150\right) \mathrm{F}_{\mathrm{c}}^{\dagger} \\
\text { Soil Excavation } \mathrm{C}_{1}=7 \$ / \mathrm{yd}^{3} \\
\text { Rock Excavation } \mathrm{C}_{2}=34 \$ / \mathrm{yd}^{3}\end{array}$ & USBR, 1980 \\
\hline
\end{tabular}

*All costs are escalated to $2015 \$$ using USBR CCT Structures Index.

**Assumes $50 \%$ soil and $50 \%$ rock excavation.

$\dagger$ Coefficients correspond to type of a construction $\mathrm{New}=1$, Refurbishment $=0.5$, or Existing $=0.2$, respectively. \$Steel penstock cost estimate obtained from an engineering consultant. This estimate includes penstock bifurcation, installation, and supports. The model assumes 50\% cost for HDPE pipe.

§Provides national average of concrete works cost http://www.concretenetwork.com/concrete-prices.html. USBR

(1980) valve cost equation is applicable to maximum design head of $66 \mathrm{ft}$.

- Intakes: Cost is determined based on design flow. USBR (1980) provides an empirical relationship between design flow and cost in $1978 \$$. An escalation factor of 3.415 based on USBR CCT Power Plant CCT Structure Index was used to converts these cost from $1978 \$$ to $2015 \$$.

- Intake Gates: Costs for both slide and radial gates are based on gate area. USBR (1980) provides an empirical relationship between gate area and cost in 1978\$. An escalation factor of 3.415 based on USBR CCT Power Plant CCT Structure Index was used to converts these cost from $1978 \$$ to $2015 \$$.

- Penstocks: Cost based on the total weight of penstock (calculated from design flow, velocity, pressure, and length of penstock). A unit price of $6000^{19} \$ /$ ton is used to calculate total cost of penstock in $2015 \$$.

19 The unit rate of penstock (6000\$/ton) was obtained through vendor. 
- Penstock Supports: Cost is based on concrete volume of saddle support. The unit cost of concrete volume was obtained through a website ${ }^{20}$ and assumes at $93 \$ / y^{3}$, provided in 2013 . An escalation factor of 3.036 based on USBR CCT Power Plant CCT Structure Index was used to converts these cost from $2013 \$$ to $2015 \$$.

- Valves: Cost for both butterfly and fixed cone valves are determined based on valve area which is in turn calculated from design flow. USBR (1980) provides an empirical relationship between valve area and cost in $1978 \$$. An escalation factor of 3.415 based on USBR CCT Power Plant CCT Structure Index was used to converts these cost from $1978 \$$ to $2015 \$$.

- Tailrace: Cost is based on tailrace excavation and lining and assumes a soil excavation rate $\left(2 \$ / y^{3}\right)$ and rock excavation rate $\left(10 \$ / y^{3}\right)$, provided in $1978 \$$. These excavation cost are escalated to $2015 \$$ using an escalation factor of 3.41 based on the USBR CCT Powerplant Structure Index. The tailrace excavation cost estimation approach is similar to powerhouse excavation. The tailrace lining cost is $25 \%$ of tailrace excavation cost.

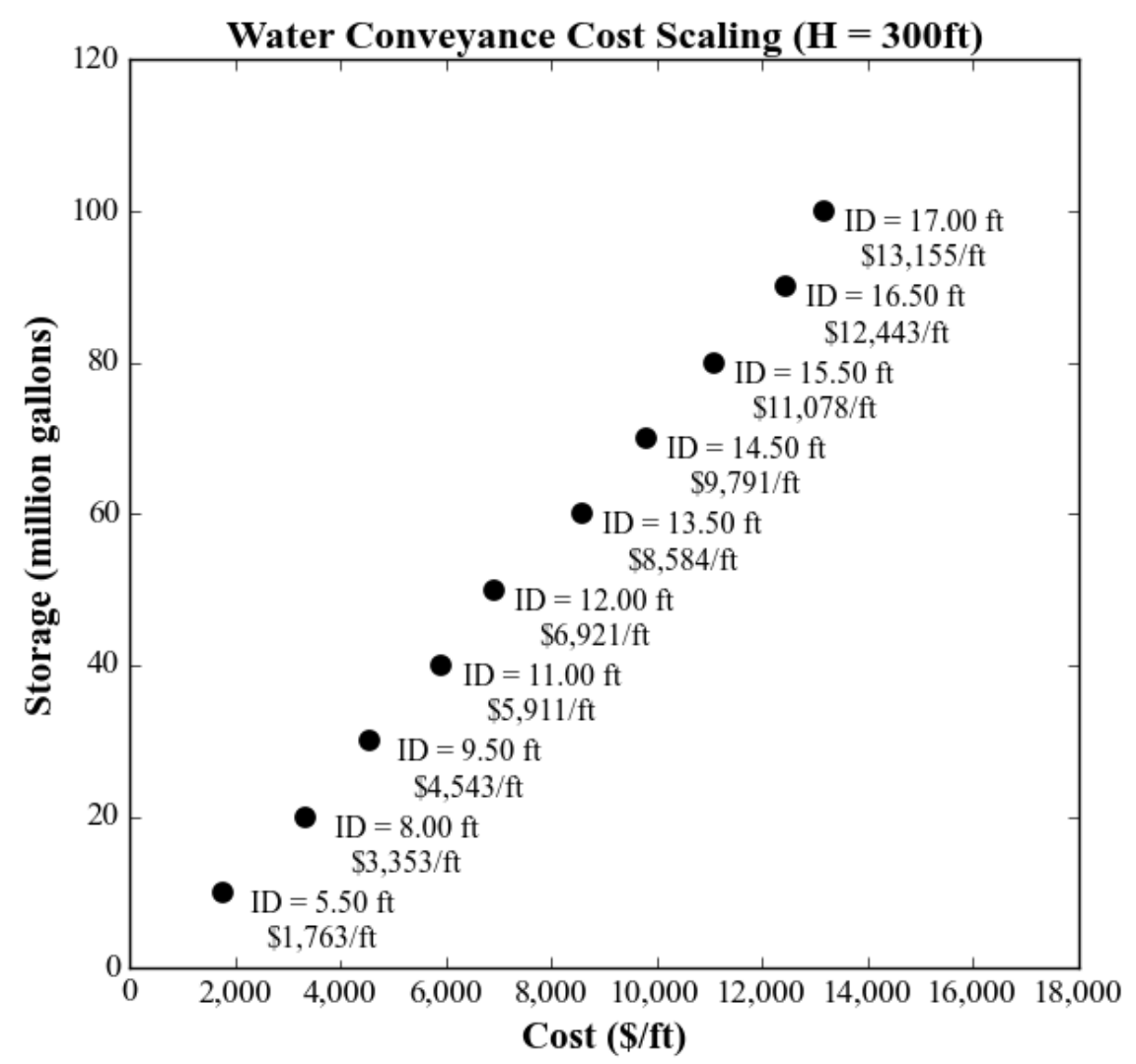

Figure 40. Example of water conveyance cost scaling. ID refers to inner diameter.

$20 \mathrm{http}: / /$ www.concretenetwork.com/concrete-prices.html 


\section{A.2.1.4. POWERHOUSE COST}

The powerhouse cost includes cost of powerhouse excavation and powerhouse structure (Table 27). Powerhouse structure cost is determined by establishing an empirical relationship between powerhouse area (calculated from runner diameter) and cost, provided in $1978 \$$. The powerhouse excavation cost is based on the excavation rate of soil $\left(2 \$ / \mathrm{yd}^{3}\right)$ and rock $\left(10 \$ / \mathrm{yd}^{3}\right)$ provided in $1978 \$$. An escalation factor of 3.415 based on USBR CCT Power Plant CCT Structure Index was used to converts these cost from $1978 \$$ to $2015 \$$. The m-PSH model provides flexibility to compute powerhouse cost based on powerhouse area $\left(\$ / \mathrm{ft}^{2}\right)$. An example of powerhouse cost scaling is provided in Figure 41 . As seen in the figure, an apparent positive correlation exists between design head and installed capacity, which demonstrates that the project capacity increases with increase in design head. In addition, the figure shows that unit powerhouse cost $(\$ / \mathrm{kW})$ generally decreases with project head or capacity, indicating that larger project can have economies of scale associated with larger hydropower development.

Table 27. Powerhouse cost estimates in m-PSH model.

\begin{tabular}{|c|c|c|c|c|c|}
\hline Items & Unit & Quantity & Rate & Cost $(2015 \$)^{*}$ & $\begin{array}{c}\text { Source/ } \\
\text { Modified from }\end{array}$ \\
\hline \multicolumn{6}{|l|}{ Powerhouse Excavation ${ }^{\dagger}$} \\
\hline Soil Excavation & $\mathrm{yd}^{3}$ & $0.5 \mathrm{~V}_{\mathrm{ph}}$ & 7 & $3.5 \mathrm{~V}_{\mathrm{ph}} \mathrm{F}_{\mathrm{c}}^{\ddagger}$ & USBR, 1980 \\
\hline Rock Excavation & $\mathrm{yd}^{3}$ & $0.5 \mathrm{~V}_{\mathrm{ph}}$ & 34 & $17 \mathrm{~V}_{\mathrm{ph}} \mathrm{F}_{\mathrm{c}}^{+}$ & USBR, 1980 \\
\hline Powerhouse Structure & $\mathrm{ft}^{2}$ & $\mathrm{~A}_{\mathrm{ph}}$ & & $\left(675 \mathrm{~A}_{\mathrm{ph}}+397,504\right) \mathrm{F}_{\mathrm{c}}^{\ddagger}$ & USBR, 1980 \\
\hline
\end{tabular}

* All costs are escalated to $2015 \$$ using USBR CCT Structures Index.

$\dagger$ Powerhouse Excavation assumes 50\% soil and 50\% rock.

$\$$ Coefficients correspond to type of a construction New $=1$, Refurbishment $=0.5$, or Existing $=0.2$, respectively

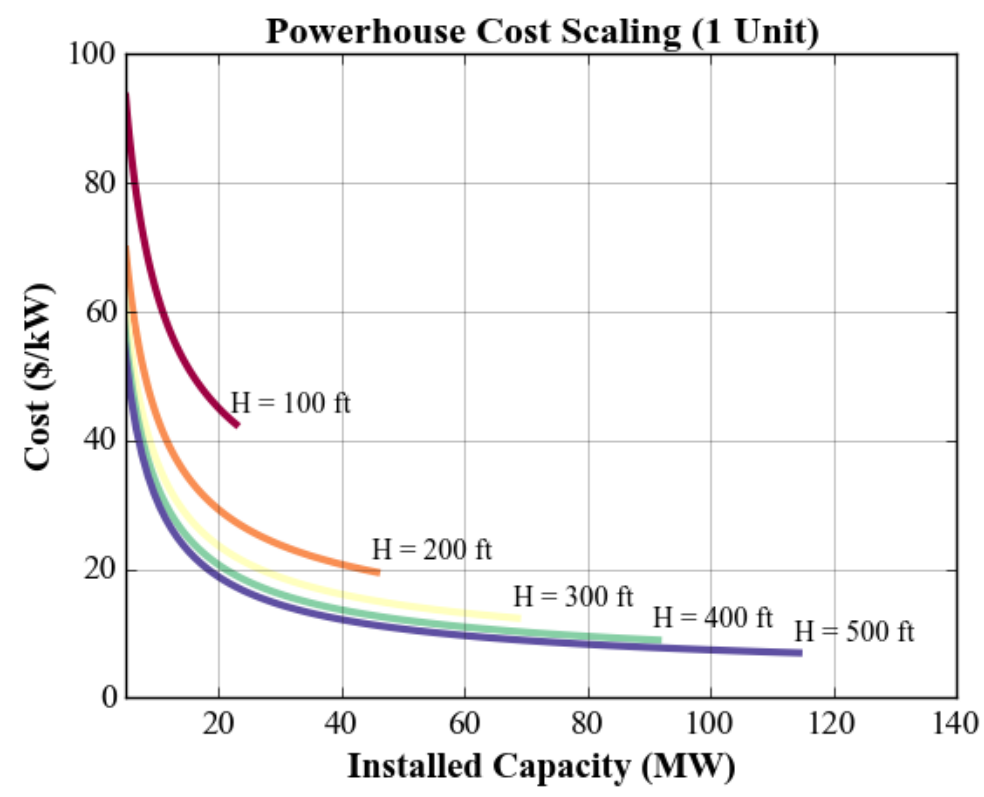

Figure 41. Example of powerhouse cost scaling. 


\section{A.2.2. ELECTRO-MECHANICAL EQUIPMENT COST}

The m-PSH electro-mechanical equipment cost includes cost of turbine-generator package, pump and ancillary electrical and mechanical system cost (Table 28). Each of these cost components is briefly describe below.

Table 28. Electro-mechanical equipment cost estimates in m-PSH model.

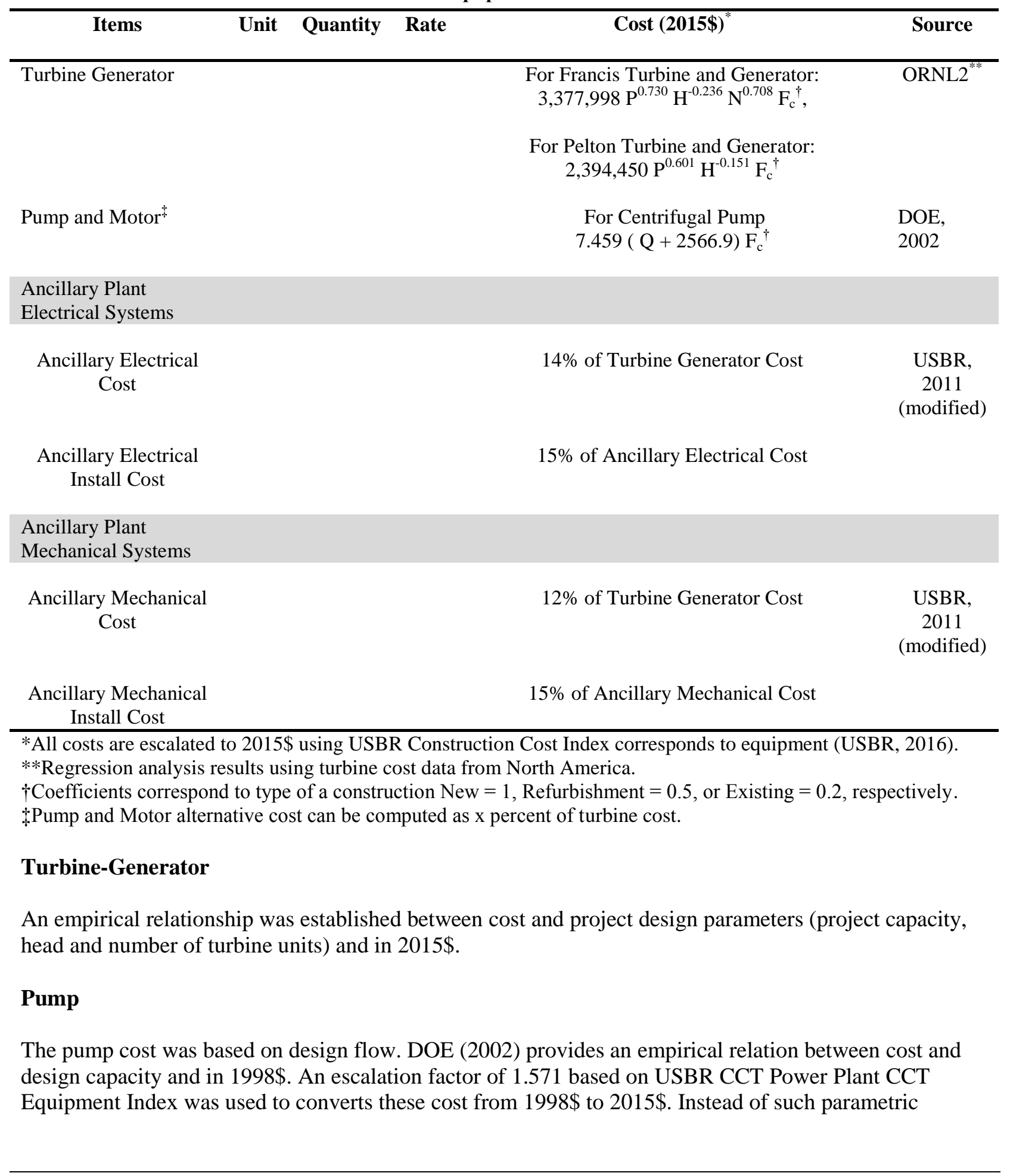


costing, the m-PSH model provides user flexibility to compute pump cost as a certain percent of total turbine generator cost.

\section{Ancillary Electrical and Mechanical System}

The m-PSH model's ancillary electrical system cost was computed as $14 \%$ of the turbine -generator cost. The ancillary mechanical system cost was computed as $12 \%$ of the turbine-generator cost.

An example of Francis turbine generator cost scaling is provided in Figure 42. As seen in the figure, an apparent positive correlation exists between design head and installed capacity, which demonstrates that the project capacity increases with increase in design head. In addition, the figure shows that unit electromechanical cost $(\$ / \mathrm{kW})$ generally decreases with project head or capacity, indicating that larger project can have economies of scale associated with larger hydropower development.

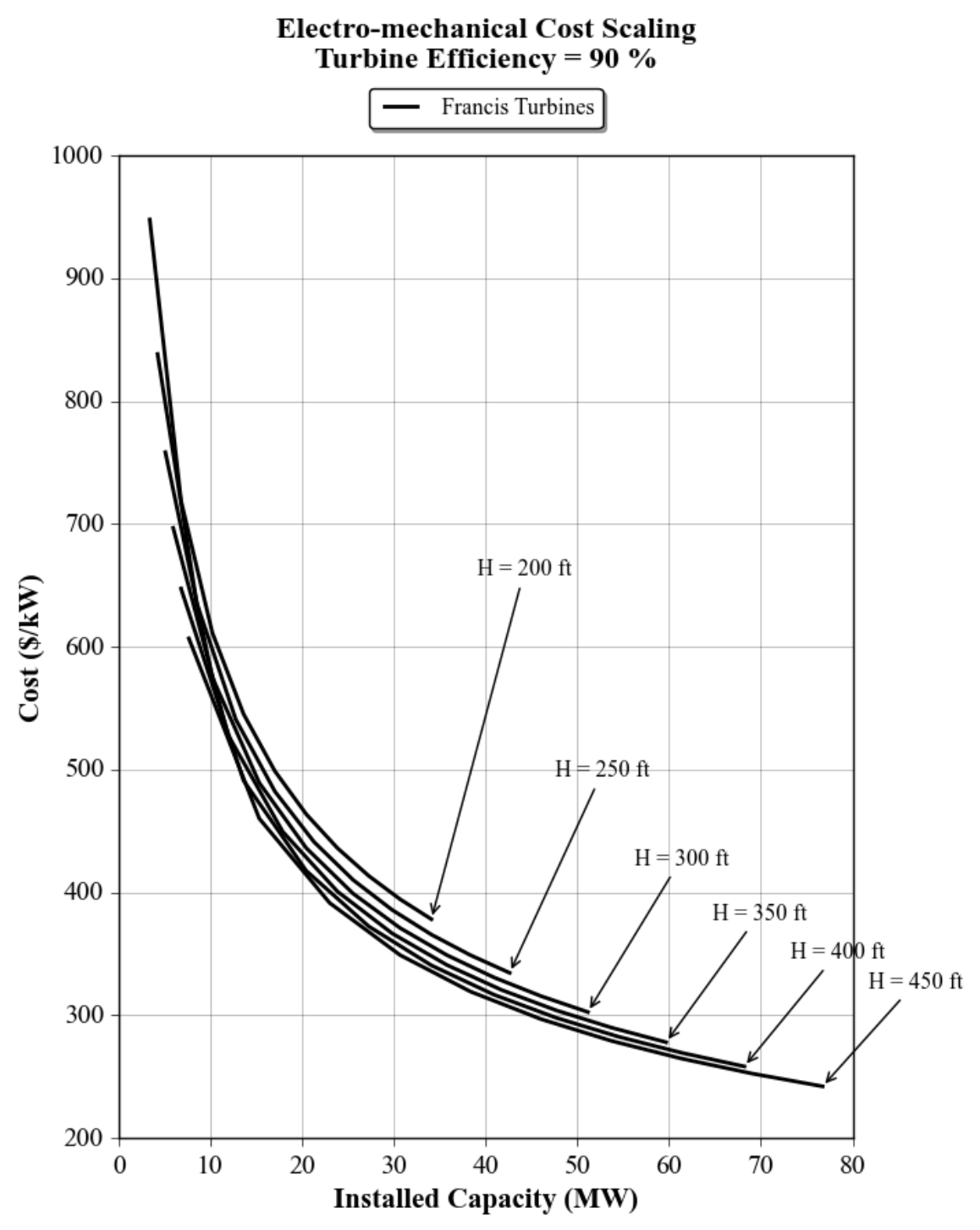

Figure 42. Example of Francis turbine and generator cost scaling. 


\section{A.2.3. ELECTRICAL INFRASTRUCTURE COST}

The electrical infrastructure cost includes the transmission line, transformers, switchyard, and substation costs (Table 29). USBR (2011) provides transmission line cost (in 2010\$) as a function of transmission length for three different ranges of transmission voltages. An escalation factor of 1.11 based on USBR CCT Power Plant CCT Equipment Index was used to converts these cost from $2010 \$$ to $2015 \$$. NRC (2004) provides transformer, switchyard, and substation cost (in 2001 CAD) as a function of project capacity, transmission line voltage, and the number of turbine units. Additional $15 \%$ cost is assumed for the installation of transformer, switchyard, and substation. An escalation factor of 1.05 was used to converts these cost from $2001 \mathrm{CAD}^{21}$ to $2015 \$$. The relationship between number of turbine units, installed capacity and transformer, switchyard and substation cost is shown in Figure 43.

Table 29. Electrical infrastructure cost estimates in m-PSH model.

\begin{tabular}{|c|c|c|c|c|c|}
\hline Items & Unit & Quantity & Rate & Cost $(2015 \$)^{\dagger}$ & Source \\
\hline $\begin{array}{l}\text { Transmission } \\
\text { Line }\end{array}$ & miles & & & $\begin{array}{l}\text { For } \mathrm{V}_{\mathrm{tl}}<69 \mathrm{kV}: 111,000 \mathrm{~L}_{\mathrm{tl}} \mathrm{F}_{\mathrm{c}}^{\dagger} \\
\text { For } \mathrm{V}_{\mathrm{tl}} \leq 115 \mathrm{kV}: 222,000 \mathrm{~L}_{\mathrm{tl}} \mathrm{F}_{\mathrm{c}}^{\dagger} \\
\text { For } \mathrm{V}_{\mathrm{tl}}>115 \mathrm{kV}: 255,300 \mathrm{~L}_{\mathrm{tl}} \mathrm{F}_{\mathrm{c}}^{\dagger}\end{array}$ & $\begin{array}{l}\text { USBR, } \\
2011\end{array}$ \\
\hline $\begin{array}{l}\text { Transformers, } \\
\text { Switchyard, } \\
\text { and } \\
\text { Substation* }\end{array}$ & $\begin{array}{l}\mathrm{P} \text { in } \mathrm{MW} \\
\mathrm{V}_{\mathrm{tl}} \text { in } \mathrm{kV}\end{array}$ & & & $\begin{array}{c}{\left[2,533 \mathrm{~N}^{0.95}+2,026(\mathrm{~N}+1)(\mathrm{P} / 0.95)^{0.9} \mathrm{~V}_{\mathrm{tl}}^{0.3}\right] \mathrm{F}_{\mathrm{c}}^{\dagger}} \\
\text { Where } \mathrm{N} \text { is no. of turbines }\end{array}$ & NRC, 2004 \\
\hline $\begin{array}{l}\text { Installation of } \\
\text { Transformers, } \\
\text { Switchyard, } \\
\text { and Substation }\end{array}$ & & & & $\begin{array}{l}15 \% \text { of Transformer Switchyard, and Substation } \\
\text { Cost }\end{array}$ & NRC, 2004 \\
\hline
\end{tabular}

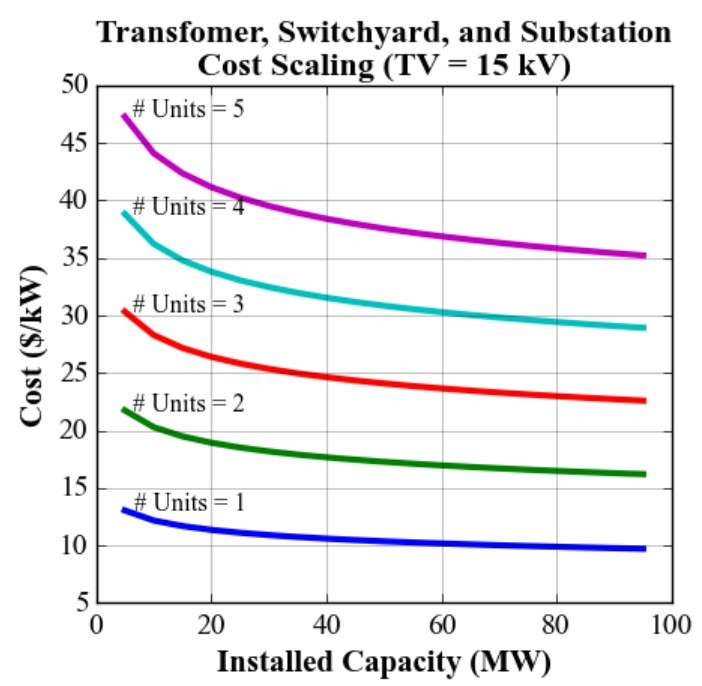

Figure 43. Example of transformer, switchyard, and substation cost scaling.

$21 \mathrm{CAD}$ is Canadian Dollars. The escalation factor includes a conversion factor of 0.68 to convert $2001 \mathrm{CAD}$ to 2001\$, which is escalated to $2015 \$$ using an escalation factor of 1.49 based on the USBR CCT Powerplant Equipment Index. 


\section{A.2.4. ENGINEERING AND CONSTRUCTION MANAGEMENT COST}

The engineering and construction management (ECM) cost includes engineering design, procurement, administration, and project commissioning costs. USBR (2011) documents ECM cost as a 15\% of the cumulative civil works, electro-mechanical equipment, and electrical infrastructure cost. The m-PSH model has no explicit design for the ECM works.

\section{A.2.5. ENVIRONMENTAL MITIGATION COST}

The environmental mitigation cost includes structure and installation of mitigation technologies. INL (2003) provides mitigation cost (in 2002\$) as a function of project capacity for five major mitigations namely 1) fish and wildlife mitigation, 2) recreation mitigation, 3) historical and archeological mitigation, 4) water quality monitoring, and 5) fish passage. The costs of these features are assumed to scale with project size. Table 30 provides mitigation cost for each of these mitigation types.

The fish passage, recreation facilities, and historical \& archeological mitigation costs uses an escalation factor of 1.58 to converts $2002 \$$ to $2015 \$$ based on the USBR CCT Powerplant Structure Index. The fish $\&$ wildlife mitigation and water quality monitoring mitigation costs uses an escalation factor of 1.32 to converts $2002 \$$ to $2015 \$$ based on the CPI Index. Care should be given to while using these INL (2003) cost equations. O'Connor et. al. (2015) has documented the uncertainty associated with these INL (2003) mitigation cost equations.

Table 30. Environmental mitigation cost estimates in m-PSH model.

\begin{tabular}{cccc}
\hline Items & Unit & Cost (2015\$) & $\begin{array}{c}\text { Source/ } \\
\text { Modified from }\end{array}$ \\
\hline Fish Passage & MW & $2,054,000 \mathrm{P}^{0.56} \mathrm{~F}_{\mathrm{c}}^{\dagger}$ & INL, 2003 \\
Fish and Wildlife Mitigation & MW & $419,635 \mathrm{P}^{0.96} \mathrm{~F}_{\mathrm{c}}^{\dagger}$ & INL, 2003 \\
Water Quality Monitoring and \\
$\begin{array}{c}\text { Mitigation } \\
\text { Recreation Facilities } \\
\text { MW }\end{array}$
\end{tabular}

*Fish Passage, Recreation Facilities and Historical and Archeological Mitigation costs are escalated using USBR CCT Structure Index. Fish \& Wildlife Mitigation and Water Quality \& Monitoring Costs are escalated using CPI index.

$\dagger$ Coefficients correspond to type of a construction New $=1$, Refurbishment $=0.5$, or Existing $=0.2$, respectively. $\mathrm{P}$ $=\mathrm{Q} \mathrm{H} \eta / 11800$ (Capacity in MW)

\section{A.2.6. DEVELOPMENT COST}

The project development cost includes licensing and initial engineering costs. As there is no explicit licensing cost methodology is available for pumped storage project, the m-PSH model's licensing cost is computed using INL (2003) non-powered dam licensing cost methodology (Table 31). INL (2003) 
provides licensing cost (in 2002\$) as a function of project capacity. An escalation factor of 1.317 based on CPI Index was used to converts these cost from $2002 \$$ to $2015 \$$. In addition, the initial engineering costs are estimated as $2.75 \%$ of the civil works $\operatorname{cost}^{22}$, based on USACE (1979).

Table 31. Development cost estimates in m-PSH model.

\begin{tabular}{cccc}
\hline Items & Unit & Cost (2015\$) & Source \\
\hline $\begin{array}{c}\text { Permitting, Licensing, and Site }_{\text {Acquisition }}{ }^{*} \\
\text { Initial Engineering }\end{array}$ & MW & $409,200 \mathrm{P}^{0.7}$ & $\begin{array}{c}\text { INL, 2003 } \\
\text { (modified) } \\
\text { USACE, 1979 }\end{array}$ \\
\hline
\end{tabular}

*Development Costs are escalated using CPI index. $\mathrm{P}=\mathrm{Q} \mathrm{H} \eta / 11800$ (Capacity in MW).

$\dagger$ Assumed equivalent to non-powered dam projects

\section{A.2.7. CONTINGENCIES}

Contingency is added to the original estimated cost to cover any unforeseen expenses as well as to cover specific expenses the model does not capture that may occur during project construction. The m-PSH model assumes a $20 \%$ contingency for civil works and $15 \%$ contingency for electro-mechanical equipment as a default values, based on USBR (2011). The model provides user flexibility to override these contingency percent.

\section{A.2.8. COST UNCERTAINTY IN EXCAVATION COST ESTIMATES}

Many m-PSH model components cost estimates are adapted from mid 1980s historical US Bureau of Reclamation cost curves and reports. Historical cost indices are further applied to escalate these costs to a common period to estimate project cost. During m-PSH model development, attempts are made by performing several spot checks to validate component level cost. This helps to identify model source of error and uncertainty in costing, which can be diagnosed in the future to improve the overall model performance.

For an example, the model's excavation cost is based on USBR (1980) and assumes a soil excavation rate $\left(2 \$ / \mathrm{yd}^{3}\right)$ and rock excavation rate $\left(10 \$ / \mathrm{yd}^{3}\right)$, provided in $1978 \$$. These excavation cost are escalated to $2015 \$$ using an escalation factor of 3.41 based on the USBR CCT Powerplant Structure Index. The model then uses soil excavation rate $\left(\sim 7 / \mathrm{yd}^{3}\right)$ and rock excavation rate $\left(34 \$ / \mathrm{yd}^{3}\right)$ to compute excavation cost. A spot check is performed by comparing against a soil and excavation priced data of 13 States, obtained from Department of Transportation (DOT) website (Table 32). As seen in the Table, DOT soil excavation rate varies from $\left(4 \$ / y^{3}\right.$ to $\left.27 \$ / y d^{3}\right)$ and its rock excavation rate varies from $\left(8 \$ / y^{3}\right.$ to $\left.68 \$ / y^{3}\right)$ among 13 States. The results show that m-PSH soil excavation rate $\left(\$ 7 / \mathrm{yd}^{3}\right)$ is slightly lower than the DOT average soil excavation rate and m-PSH rock excavation rate $\left(\$ 34 / \mathrm{yd}^{3}\right)$ is higher than the DOT average rock excavation rate. However, the model's soil and rock excavation rates fall within DOT excavation rate ranges. The results indicate that geography can influence the cost accuracy. For future modeling purpose, the user should use statewide excavation rate.

22 The total civil works cost includes site preparation, storage, water conveyance system, and powerhouse costs. 
Table 32. Soil and Rock Excavation rate across $\mathbf{U S}^{23}$.

\begin{tabular}{|c|c|c|c|c|c|}
\hline Region & State & $\begin{array}{c}\text { Original Soil } \\
\text { Excavation Price } \\
\$ / y^{3} \text { (Base Year) }\end{array}$ & $\begin{array}{c}\text { Original Rock } \\
\text { Excavation Price } \\
\$ / \mathbf{y d}^{3} \text { (Base Year) }\end{array}$ & $\begin{array}{c}\text { Escalated Soil } \\
\text { Excavation Price } \\
\$ / \mathbf{y d}^{3}(2015)\end{array}$ & $\begin{array}{c}\text { Escalated Rock } \\
\text { Excavation Price } \\
\$ / y^{3}(2015) \\
\end{array}$ \\
\hline \multicolumn{6}{|l|}{ Northeast } \\
\hline & Connecticut $^{24}$ & $\$ 20(2005)$ & $\$ 50(2005)$ & $\$ 27$ & $\$ 68$ \\
\hline & $\begin{array}{c}\text { New } \\
\text { Hampshire }^{25}\end{array}$ & $\$ 5(2015)$ & $\$ 11(2015)$ & $\$ 5$ & $\$ 11$ \\
\hline \multicolumn{6}{|l|}{ Southeast } \\
\hline & Florida $^{26}$ & $\$ 5$ (2015) & $\$ 10(2015)$ & $\$ 5$ & $\$ 10$ \\
\hline & Tennessee $^{27}$ & $\$ 7(2015)$ & $\$ 19(2015)$ & $\$ 7$ & $\$ 19$ \\
\hline & Texas $^{28}$ & $\$ 7$ (2016) & $\$ 11(2016)$ & $\$ 7$ & $\$ 11$ \\
\hline \multicolumn{6}{|l|}{ Midwest } \\
\hline & Colorado $^{29}$ & \$17 (2010) & $\$ 47$ (2010) & $\$ 19$ & $\$ 53$ \\
\hline & Wisconsin ${ }^{30}$ & $\$ 5(2014)$ & $\$ 8(2014)$ & $\$ 5$ & $\$ 8$ \\
\hline & Minnesota $^{31}$ & $\$ 6(2005)$ & $\$ 11(2005)$ & $\$ 8$ & $\$ 14$ \\
\hline & South Dakota ${ }^{32}$ & $\$ 4(2015)$ & $\$ 10(2015)$ & $\$ 4$ & $\$ 10$ \\
\hline \multicolumn{6}{|l|}{ Southwest } \\
\hline & California ${ }^{33}$ & $\$ 8$ (2013) & $\$ 15$ (2013) & $\$ 8$ & $\$ 15$ \\
\hline & New Mexico ${ }^{34}$ & $\$ 5(2007)$ & $\$ 8(2007)$ & $\$ 6$ & $\$ 9$ \\
\hline \multicolumn{6}{|l|}{ Northwest } \\
\hline & Oregon $^{35}$ & \$12 (2008) & $\$ 29(2008)$ & $\$ 14$ & $\$ 34$ \\
\hline & Washington $^{36}$ & $\$ 10(2015)$ & $\mathrm{n} / \mathrm{a}$ & $\$ 10$ & $\mathrm{n} / \mathrm{a}$ \\
\hline Average & & & & $\$ 9.47$ & $\$ 21.77$ \\
\hline
\end{tabular}

An additional spot check can be done by comparing unit prices found in FERC project accounts with the model's rates. In 1991, FERC lists common soil excavation for hydropower plant construction as $\$ 5 / \mathrm{yd}^{3}$ and rock excavation as $\$ 19 / \mathrm{yd}^{3}$ (FERC, 1991). Using an USBR CCT escalation factor of 2.13, these unit costs translate to $\$ 11 / \mathrm{yd}^{3}$ and $\$ 41 / \mathrm{yd}^{3}$, respectively, in $2015 \$$. These values are $16-34 \%$ higher than the model's which suggests the model's soil and rock excavation rates are reasonable.

23 USBR Composite Index is used to escalate DOT excavation cost to $2015 \$$.

24 http://www.ct.gov/dot/lib/dot/documents/dpolicy/WINS/Discussion-of-Conceptual-Costs-Estimates.pdf

$25 \mathrm{https} / / /$ www.nh.gov/dot/org/projectdevelopment/highwaydesign/documents/WeightedAveragesImperial.pdf

$26 \mathrm{ftp}: / / \mathrm{ftp}$.dot.state.fl.us/LTS/CO/Estimates/12MonthsMoving.pdf

27 https://www.tn.gov/assets/entities/tdot/attachments/Const-AUP2015.pdf

$28 \mathrm{http}: / /$ www.dot.state.tx.us/insdtdot/orgchart/cmd/cserve/bidprice/s_0102.htm

29 https://www.codot.gov/business/eema/.../2010/2010FINALCONST.txt

$30 \mathrm{http}: / /$ wisconsindot.gov/hcciDocs/contracting-info/average-unit-price.pdf

$31 \mathrm{http}: / /$ www.dot.state.mn.us/bidlet/avgPrice/2010.pdf

$32 \mathrm{http}: / / \mathrm{www}$. sddot.com/business/contractors/docs/averageunitprices.pdf

$33 \mathrm{http}: / /$ www.dot.ca.gov/hq/esc/oe/awards/2013CCDB/2013ccdb.pdf

34http://dot.state.nm.us/content/dam/nmdot/Plans_Specs_Estimates/AUB/2011\%20All\%20Items\%20.pdf

35 https://www.oregon.gov/aviation/docs/2009_Unit_Cost_Estimate.pdf

36 https://www.wsdot.wa.gov/NR/rdonlyres/A8EE6CB0-46F6-4EE8-95A3-62E9B793F31C/0/CostIndexData.pdf 


\section{APPENDIX B. FURTHER DISCUSSION OF STORAGE}

High and low elevation water storage is necessary for all closed-loop m-PSH projects. Two types of storage mechanisms are considered, broadly labeled tanks and reservoir. A tank is defined as a steel, fiberglass, or concrete structure with a floor and side walls, while a reservoir is defined as an excavated basin lined with a geomembrane to prevent leakage. Conventional PSH projects are constructed using reservoirs, and often the excavated material is used to create a berm around the basin to enhance storage capacity. With the smaller nature of m-PSH projects, the possibility of storage tanks may be considered. It is common to see municipal water storage or treatment facilities with storage tanks on the order of roughly 1 million $\mathrm{ft}^{3}$ or less, and the oil and gas industry maintains tanks capable of storing over 200,000 $\mathrm{m}^{3}\left(>7\right.$ million $\left.\mathrm{ft}^{3}\right)$ of liquefied natural gas. The ubiquity of large scale storage tanks and their current employ throughout the US appeals to both the modular and standardized goals of m-PSH development it can be assumed that a variety of storage tanks could be procured rather quickly, and that standard sizes are available. The pros and cons of tank and reservoir storage are presented further in Table 33.

Table 33. Comparison of tank and reservoir storage options for m-PSH facilities.

\begin{tabular}{ll|ll}
\hline \multicolumn{1}{c|}{ Tank } & \multicolumn{1}{c}{ Con } & \multicolumn{1}{c}{ Pro } & \multicolumn{1}{c}{ Peservoir } \\
\hline $\begin{array}{l}\text { Modular in nature, easily } \\
\text { expandable volume by } \\
\text { adding more tanks }\end{array}$ & $\begin{array}{l}\text { If multiple tanks are } \\
\text { needed they must be } \\
\text { linked with additional } \\
\text { water conveyance } \\
\text { infrastructure }\end{array}$ & $\begin{array}{l}\text { Well tested, understood, } \\
\text { and accepted energy } \\
\text { storage technique }\end{array}$ & $\begin{array}{l}\text { May require additional } \\
\text { time and expense to } \\
\text { dispose of excavated } \\
\text { material }\end{array}$ \\
\hline $\begin{array}{l}\text { Large tank systems are in } \\
\text { production by many tank } \\
\text { manufacturers }\end{array}$ & $\begin{array}{l}\text { Untested concept for } \\
\text { energy storage }\end{array}$ & $\begin{array}{l}\text { Relatively simple to } \\
\text { construct }\end{array}$ & $\begin{array}{l}\text { May require extensive } \\
\text { geotechnical exploration to } \\
\text { determine subsurface } \\
\text { characteristics }\end{array}$ \\
\hline $\begin{array}{l}\text { Long useful life on the } \\
\text { order of 50+ years }\end{array}$ & $\begin{array}{l}\text { Vortex suppression } \\
\text { required to minimize dead } \\
\text { pool storage requirement } \\
\text { above intake }\end{array}$ & $\begin{array}{l}\text { Long useful life on the } \\
\text { order of 50+ years }\end{array}$ & $\begin{array}{l}\text { Higher potential for } \\
\text { environmental disturbance } \\
\text { through runoff, migratory } \\
\text { birds, or s }\end{array}$ \\
\hline $\begin{array}{l}\text { Low maintenance } \\
\text { A venting system is } \\
\text { required for pressure } \\
\text { and/or vacuum relief } \\
\text { during filling and refilling } \\
\text { order of months }\end{array}$ & $\begin{array}{l}\text { Potential for large visual } \\
\text { and aesthetic impact }\end{array}$ & $\begin{array}{l}\text { Can maintain a low profile } \\
\text { and remain relatively } \\
\text { below the horizon }\end{array}$ & \\
\hline
\end{tabular}

The significant differentiator between the feasibility of reservoirs and tanks is cost and capacity. Material cost estimates for municipal water storage tanks (tank, foundation, and basic fittings from State of Michigan (2003)), m-PSH reservoir storage (site preparation, 90\% excavation in soil, 10\% excavation in rock, riprap, and geomembranes), and conventional PSH projects (MWH, 2009) are compared in Figure 44. Parametric tank cost equations generally exhibit economies of scale up to 1 million $\mathrm{ft}^{3}$, a common upper limit on tank size. If greater storage capacity is desired, several tanks must be considered, and additional expense in connecting them will be incurred. Cost estimates for an excavated reservoir do not show nearly the same economy of scale as capacity is increased, a modeling assumption that may require further clarity through discussions with construction firms. However, the cost of materials for excavation is nearly always lower than the cost of tanks, and deeper reservoirs are less expensive than shallow 
reservoirs given the same ratio of soil to rock excavation. If the geometry of the reservoir can be optimized, the total area of geomembrane, site preparation, and surface treatment required can be minimized. Large scale conventional PSH facilities exhibit the lowest cost overall, though these cost estimates are based on enormous projects that generally take advantage of existing landscape depressions, quarries, or existing natural reservoirs.

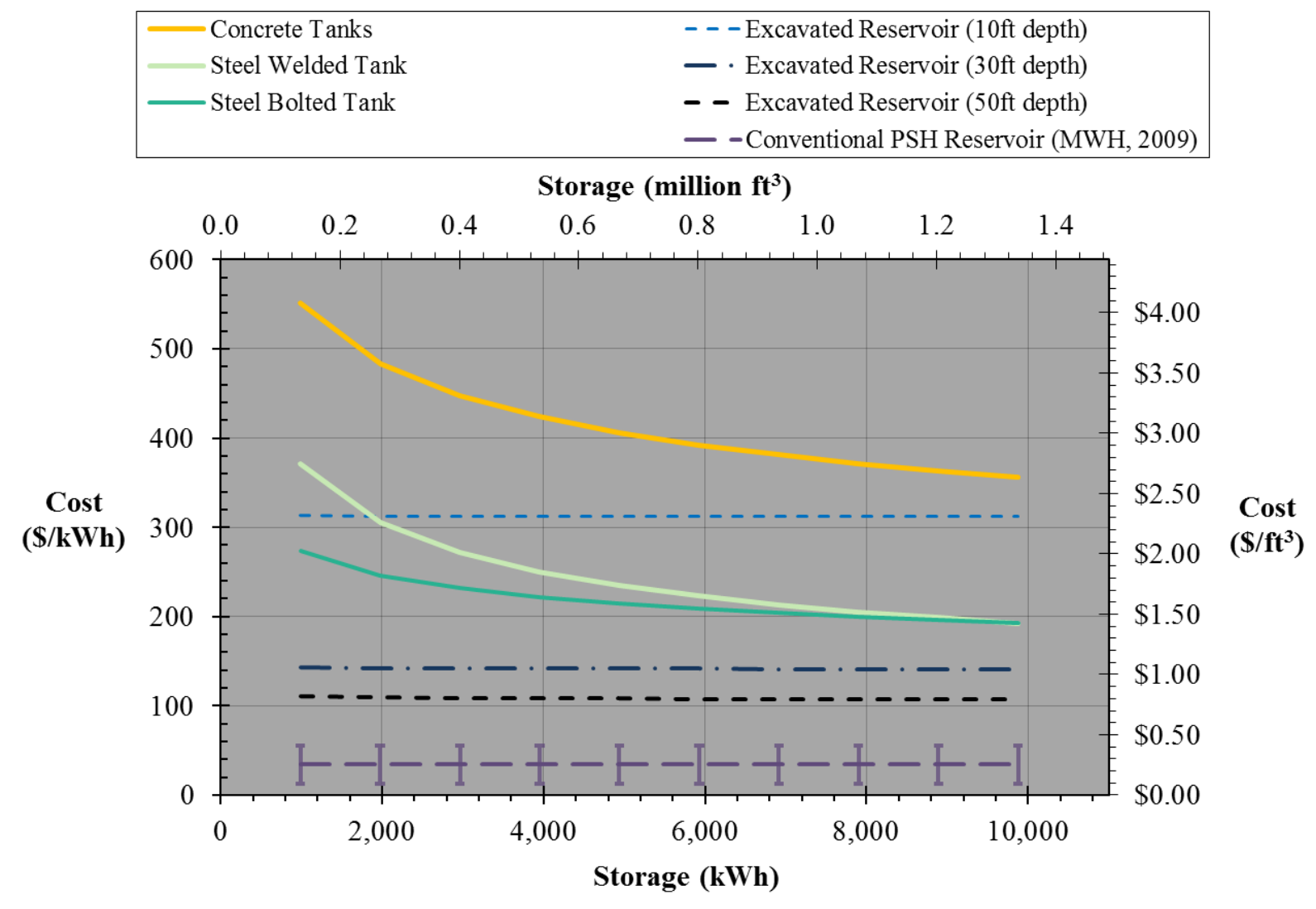

Figure 44. Material cost comparison of alternative water storage types. Net head of $350 \mathrm{ft}$, turbine efficiency of $90 \%$, and 10 hours of storage are assumed to provide an estimate of storage capacity in $\mathrm{kWh}$.

Storage cost dynamics tend to favor reservoirs at scales larger than a million $\mathrm{ft}^{3}$, where multiple tank options would need to be considered. Assuming 1 million $\mathrm{ft}$ of storage capacity at $350 \mathrm{ft}$ of head and $90 \%$ turbine efficiency, an m-PSH system could be capable of just over 7MWh of storage, suitable to meet the energy needs of small scale commercial or industrial consumer. The lowest cost tank option is roughly $\$ 200 / \mathrm{kWh}$, and two are needed for each reservoir, bringing the cost of water storage alone to over $\$ 400 / \mathrm{kWh}$, or $\$ 4,000 / \mathrm{kW}$, above the target for the entire m-PSH system. Using fewer, smaller tanks would only result in increased costs due to the economies of scale inherent to large tank production. Water storage tanks may be more attractive for shorter term energy storage deployment, such as emergency backup, frequency regulation, or black start, however, these services generally represent fairly low revenue prospects for storage technologies, and the economic tradeoff is not considered attractive in this report. 


\section{APPENDIX C. REFERENCES}

AACE. (2013). Cost Estimate Classification System - As Applied in Engineering, Procurement, and Construction for the Hydropower Industry. AACE International Recommended Practice No. 69R12. January, 2013.

BLS (Bureau of Labor Statistics). (2016). Consumer Price Indexes. Available online at http://www.bls.gov/cpi/, accessed online March 2016.

Chalise D.R, O’Connor P., Deneale S., Waldoch C. (2016). Hydropower Integrated Design and Economic Assessment Tool for Use in Preliminary Feasibility Assessments - Modeling Frameworks. Proc., HydroVision International Conference, Minneapolis, MN. July 2016.

DOE (Department of Energy). (2002). Process Equipment Cost Estimation Final Report. DOE/NETL2002/1169.

ENR (Engineering News Record). (2016). Construction Cost Indices, Engineering News Record. Available online at http://enr.construction.com/economics/, accessed online March 2016.

ESHA (European Small Hydropower Association). (2004). Guide on How to Develop a Small Hydropower Plant. Accessed at http://www.esha.be/fileadmin/esha_files/documents/publications/GUIDES/GUIDE_SHP/GUIDE_SH $\underline{\text { P EN.pdf }}$

FERC (Federal Energy Regulatory Commission). (1991). Environmental Impact Statement Glines Canyon (FERC No. 588) and Elwha (FERC No. 2683) Hydroelectric Projects. FERC Uniform System of Accounts.

Gordon, J. L. (2001). Hydraulic Turbine Efficiency. Canadian Journal of Civil Engineering. Vol. 28, No. 2, April, pp. 238-253.

INL (Idaho National Lab). (2003). Estimation of Economic Parameters of U.S. Hydropower Resources. INEEL/EXT-03-00662.

Michigan State (2003). Tanks. https://www.michigan.gov/documents/Vol235UIP11Tanks_121080_7.pdf accessed online June 2016.

NRC (Natural Resources Canada). (2004). RETScreen International: Small Hydro Project Analysis. Minister of Natural Resources Canada 2001-2004.

O'Connor, P.W., Zhang, Q.F., DeNeale, S.T., Chalise, D.R., Centurion, E. (2015a). Hydropower Baseline Cost Modeling. Oak Ridge, TN: ORNL/TM 2014/15.

O'Connor, P.W., Zhang, Q.F., DeNeale, S.T., Chalise, D.R., Centurion, E, and Maloof, A. (2015b). Hydropower Baseline Cost Modeling version 2. Oak Ridge, TN: ORNL/TM 2015/471.

O'Connor, P.W., Chalise, D.R., DeNeale, S.T., Waldoch C. (2016). The Hydropower Integrated Design and Economic Assessment Model: Documentation and Selected Applications. Oak Ridge, TN: ORNL/TM 2016/587. Publication is Under Development 
U.S. Army Corps of Engineers (USACE). (1979). Feasibility Analysis in Small Hydropower Planning. TP 65, August 1979

U.S. Army Corps of Engineers (USACE). (2013a). Civil Works Construction Cost Index System, Army Corps of Engineers. Available online at http://www.publications.usace.army.mil/Portals/76/Publications/EngineerManuals/EM_1110-21304.pdf, accessed online September 2016.

U.S. Bureau of Reclamation (USBR). (1980). Reconnaissance Evaluation of Small, Low-Head Hydroelectric Installation. Bureau of Reclamation, Water and Power Resources Service, Denver, 1980

U.S. Bureau of Reclamation (USBR). (2011). Hydropower Resource Assessment at Existing Reclamation Facilities. Bureau of Reclamation, Power Resources Office, Denver, 2011.

United States Bureau of Reclamation (USBR). (2014) Embankment Dams, Chapter 20: Geomembranes Phase 4 (Final). DS-13(20)-16, March 2014

United States Bureau of Reclamation (USBR). (2016). Hydropower Construction Costs Trends, Bureau of Reclamation. Available online at http://www.usbr.gov/pmts/estimate/cost_trend.html, accessed online February 2016.

Vortex Hydra (2015). Hydraulic Works. Available online at http://www.vortexhydradams.com/ accessed online December 2015. 